\title{
WestVirginiaUniversity
}

THE RESEARCH REPOSITORY @ WVU

Graduate Theses, Dissertations, and Problem Reports

1998

\section{Engine instrumentation and data analysis for ignition system testing}

William Joseph Chambers

West Virginia University

Follow this and additional works at: https://researchrepository.wvu.edu/etd

\section{Recommended Citation}

Chambers, William Joseph, "Engine instrumentation and data analysis for ignition system testing" (1998). Graduate Theses, Dissertations, and Problem Reports. 909.

https://researchrepository.wvu.edu/etd/909

This Thesis is protected by copyright and/or related rights. It has been brought to you by the The Research Repository @ WVU with permission from the rights-holder(s). You are free to use this Thesis in any way that is permitted by the copyright and related rights legislation that applies to your use. For other uses you must obtain permission from the rights-holder(s) directly, unless additional rights are indicated by a Creative Commons license in the record and/ or on the work itself. This Thesis has been accepted for inclusion in WVU Graduate Theses, Dissertations, and Problem Reports collection by an authorized administrator of The Research Repository @ WVU. For more information, please contact researchrepository@mail.wvu.edu. 


\title{
Engine Instrumentation and Data Analysis for Ignition System Testing
}

\author{
William Joseph Chambers
}

Thesis submitted to the faculty of the College of Engineering and Mineral Resources at West Virginia University in partial fulfillment of the requirements for the degree of

\author{
Master of Science \\ in \\ Mechanical Engineering
}
Gregory J. Thompson, Ph.D. Chair
Nigel N. Clark, Ph.D.
James E. Smith, Ph.D.

December 3, 1998

Morgantown, West Virginia

Keywords: Instrumentation, Internal Combustion Engine, Ignition, Data Acquisition 


\title{
Engine Instrumentation and Data Analysis for Ignition System Testing
}

\author{
William Joseph Chambers
}

\begin{abstract}
The charge ignition system is used to ignite the fuel-air mixture in the combustion chamber of a spark ignited internal combustion engine and is the subject of many ongoing research projects. As a means to quantify the performance of an ignition system, a 16 horsepower Briggs and Stratton V-twin engine has been instrumented and the necessary data analysis software developed. This test engine was used to monitor the performance of three different ignition sources. When the performance of these ignition sources was analyzed using the test engine, the differences in performance of the systems was evident in the calculated values for the engine's exhaust temperature, specific fuel consumption, indicated mean effective pressure, and fuel conversion efficiency. The test engine also provided pressure versus volume traces, which provide a visual representation of the poor combustion caused by inadequate ignition sources.
\end{abstract}




\section{Acknowledgments}

I would like to thank my advisors, Dr. Greg Thompson and Dr. James Smith, for their guidance, technical advice, and support during my research. I would also like to thank Dr. Nigel Clark both for sharing his technical expertise and for taking time from his schedule to join my committee. Additional thanks are extended to Joanna Davis-Swing, Robert Craven, Andy Pertl, Tim Bryan, Josh Hak, John Halterman, John Ruth, and the rest of the CIRA staff, who provided crucial support to my research efforts.

I would also like to thank Andrew Traxel and Briggs \& Stratton Corporation for the donation of the Vanguard engine, which was the foundation for my test engine. 


\section{Table of Contents}

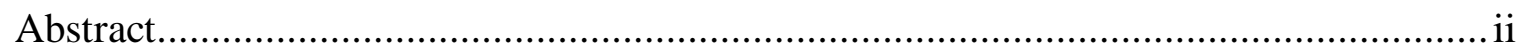

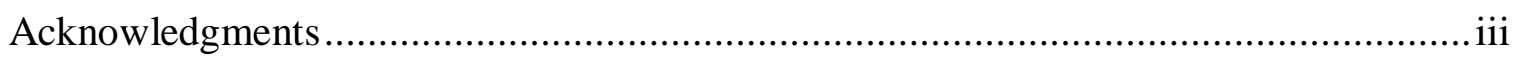

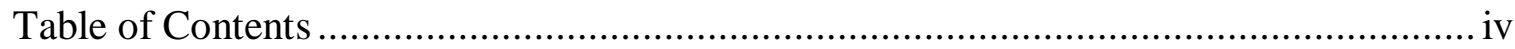

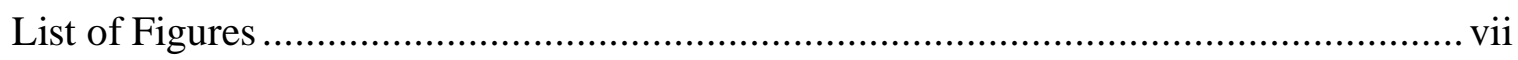

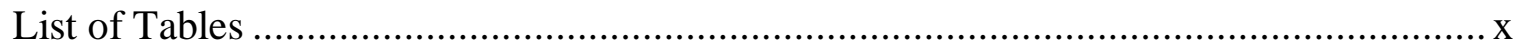

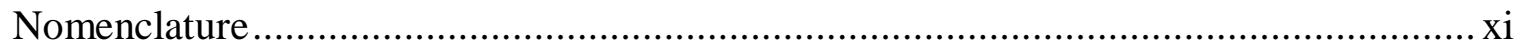

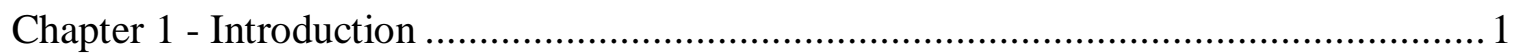

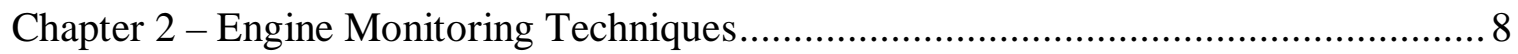

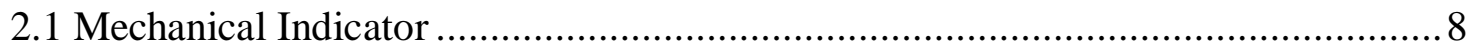

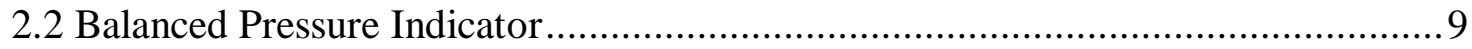

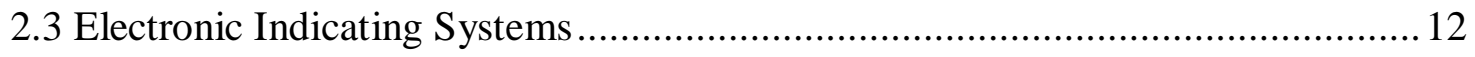

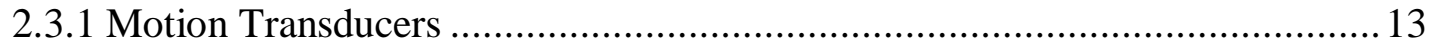

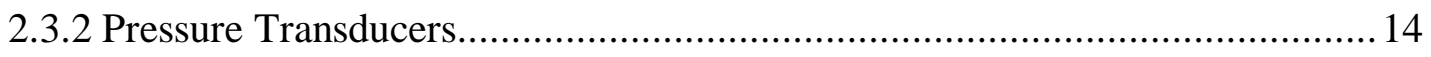

2.3.3 Readout and Recording Devices................................................................... 15

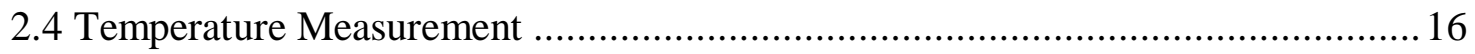

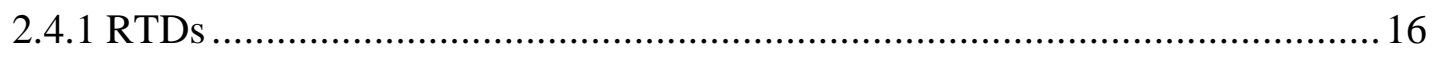

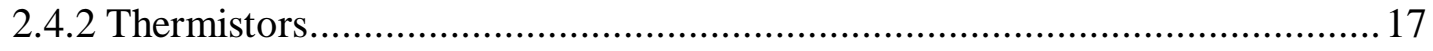

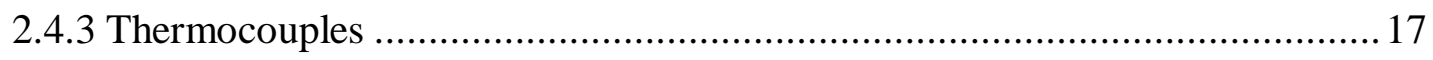

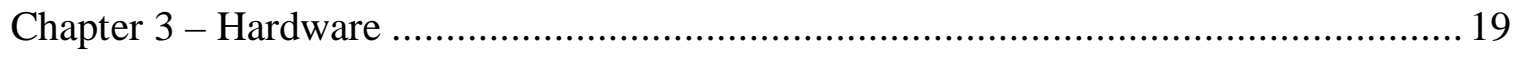




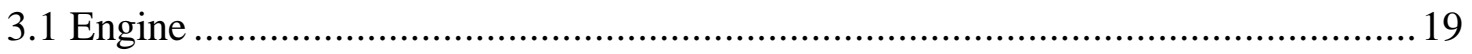

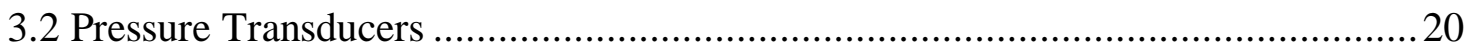

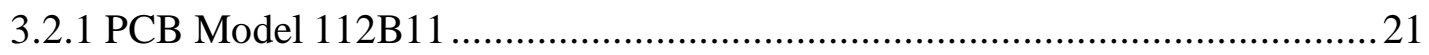

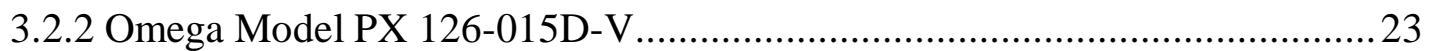

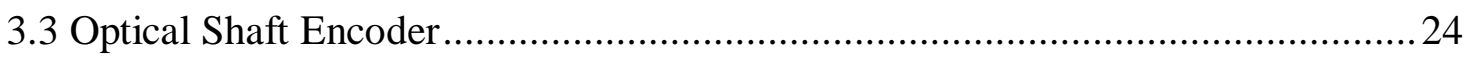

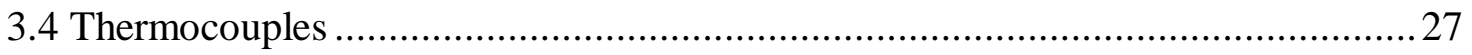

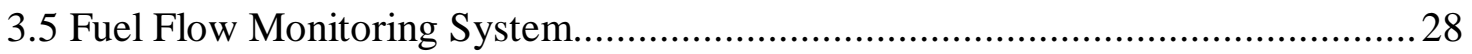

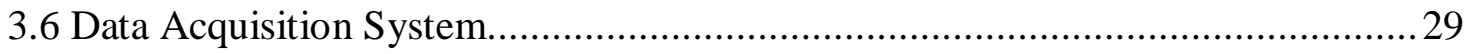

Chapter 4 - Software

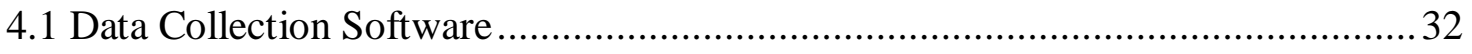

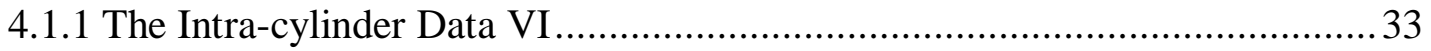

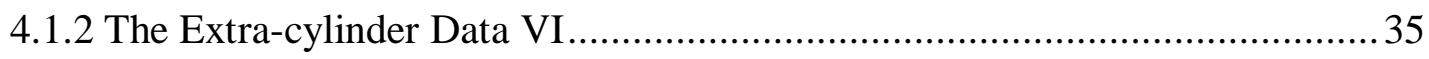

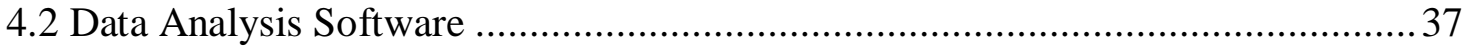

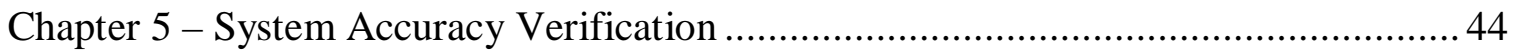

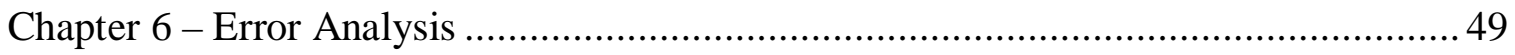

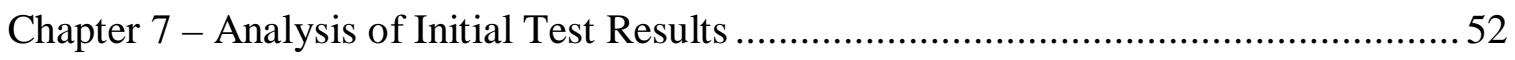

7.1 Test Results for Champion Model RC12YC with a 0.03 " Gap .............................53

7.2 Test Results for Champion Model RC12YC with a 0 .008” Gap ...........................56

7.3 Test Results for Champion Model J19LM with a 0 .03" Gap ...............................59

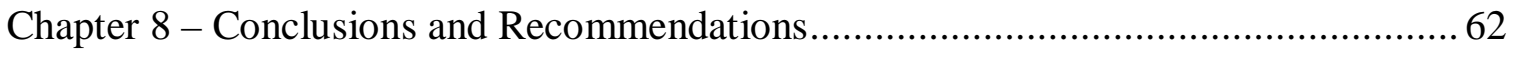

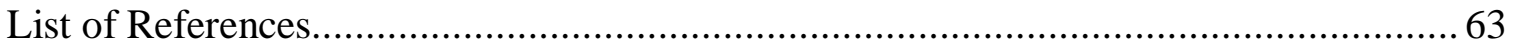


Appendix A - Intra-Cylinder Engine Data Excel Macro.

Appendix B - Extra-Cylinder Engine Data Excel Macro

Appendix C - Engine.m

Appendix D - Output of Engine.m for the Champion Model RC12YC Sparkplug with the Recommended Gap of .03".

Appendix E - Output of Engine.m for the Champion Model RC12YC Sparkplug with a Gap of .008"

Appendix F - Output of Engine.m for the Champion Model J19LM Sparkplug with a .03 " Gap. 103

Approval of Examining Committee 110 


\section{List of Figures}

Figure 1 - The plasma igniter (left) and a conventional spark plug (right). ..................3

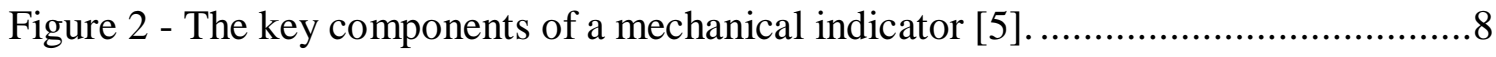

Figure 3 - The cylinder head pick-up unit of a balanced pressure indicator [7]...........11

Figure 4 - Layout of a balanced pressure indicator system [7] .............................. 12

Figure 5 - Cross-section of a piezoelectric pressure transducer [10]. ......................... 15

Figure 6 - The complete test engine hardware system. .....................................19

Figure 7 - The Briggs \& Stratton Vanguard Engine [15] ........................................20

Figure 8 - Housing Design of a PCB Model 112B11 Pressure Transducer [17]...........21

Figure 9 - Cylinder head transducer placement............................................. 22

Figure 10 - The complete PCB pressure transducer system. .................................23

Figure 11 - The Omega model PX 126-015-V pressure transducer............................24

Figure 12 - The Accu-Coder model 755A incremental shaft encoder [20]..................25

Figure 13 - The rigid pointer used to determine top dead center of the engine..............26

Figure 14 - The Omega model KQSS-18E-12 thermocouple and Omega model MCJ-K ice point device. ................................................................ 27

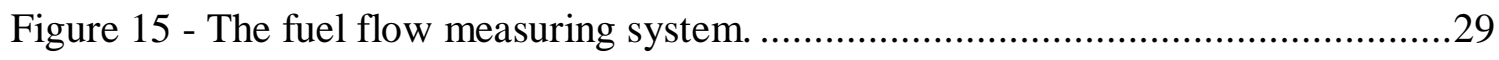

Figure 16 - The National Instruments model DAQcard-A1-16E-4 data acquisition

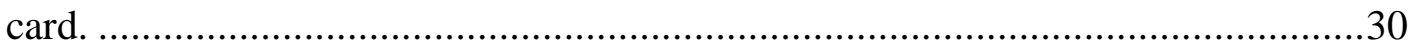

Figure 17 - Wiring diagram for the data acquisition system. ................................. 31

Figure 18 - The instrument diagram for the intra-cylinder data VI. ...........................33

Figure 19 - The control panel for the intra-cylinder data VI.................................34

Figure 20 - The instrument diagram for the extra-cylinder data VI...........................36

Figure 21 - The control panel for the extra-cylinder data VI. ................................37

Figure 22 - A pressure versus volume plot produced by Engine.m...........................43 
Figure 23 - The test engine coupled to the General Electric DC Cradled Dynamometer.

Figure 24 - A log-log plot of pressure versus volume for the motored engine cycle.

Figure 25 - Piezoelectric pressure transducer signal and its five point moving average.

Figure 26 - The Champion model RC12YC (top) and model J19LM (bottom) that were used for initial testing.

Figure 27 - A P-V diagram for the cylinder using the Champion model RC12YC with a gap of 0.03 " displaying proper combustion...

Figure 28 - A P-V diagram for the cylinder using the Champion model RC12YC with a gap of 0.008 " displaying delayed combustion.

Figure 29 - A P-V diagram for the cylinder using the Champion model RC12YC with a gap of $0.008 "$ displaying a misfire. .58

Figure 30 - A P-V diagram for the cylinder using the Champion model J19LM with a gap of $0.03 "$ displaying delayed and incomplete combustion.

Figure D 1 - Pressure versus volume diagram for cycle one using the Champion model RC12YC sparkplug with the recommended gap of 0.03 "....

Figure D 2 - Pressure versus volume diagram for cycle two using the Champion model RC12YC sparkplug with the recommended gap of 0.03 ”....

Figure D 3 - Pressure versus volume diagram for cycle three using the Champion model RC12YC sparkplug with the recommended gap of 0.03 ".

Figure D 4 - Pressure versus volume diagram for cycle four using the Champion model RC12YC sparkplug with the recommended gap of 0.03 "....

Figure D 5 - Pressure versus volume diagram for cycle five using the Champion model RC12YC sparkplug with the recommended gap of 0.03 ". .95

Figure E 1 - Pressure versus volume diagram for cycle one using the Champion model RC12YC sparkplug with a gap of 0.008 ".

Figure E 2 - Pressure versus volume diagram for cycle two using the Champion model RC12YC sparkplug with a gap of 0.008 " 100

Figure E 3 - Pressure versus volume diagram for cycle three using the Champion model RC12YC sparkplug with a gap of 0.008 ". 
Figure E 4 - Pressure versus volume diagram for cycle four using the Champion model RC12YC sparkplug with a gap of 0.008 "......................................... 101

Figure E 5 - Pressure versus volume diagram for cycle five using the Champion model RC12YC sparkplug with a gap of 0.008 "........................................... 102

Figure F 1 - Pressure versus volume diagram for cycle one using the Champion model J19LM sparkplug with a 0.03" gap.................................................... 107

Figure F 2 - Pressure versus volume diagram for cycle two using the Champion model J19LM sparkplug with a 0.03 " gap................................................ 107

Figure F 3 - Pressure versus volume diagram for cycle three using the Champion model J19LM sparkplug with a 0.03 " gap............................................... 108

Figure F 4 - Pressure versus volume diagram for cycle four using the Champion model J19LM sparkplug with a 0.03 " gap................................................ 108

Figure F 5 - Pressure versus volume diagram for cycle five using the Champion

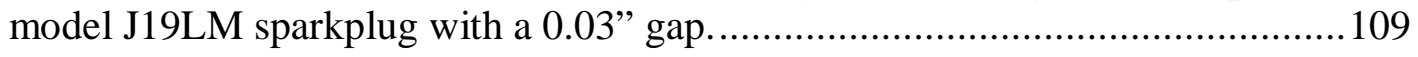




\section{List of Tables}

Table 1 - Engine performance parameters for the Champion Model RC12YC with

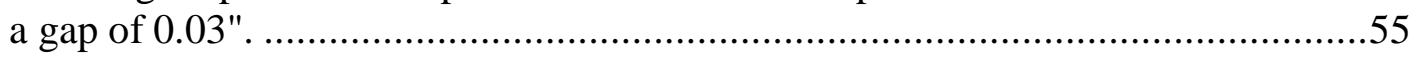

Table 2 - Engine performance parameters for the Champion Model RC12YC with a gap of $0.008 "$.

Table 3 - Engine performance parameters for the Champion Model J19LM with a

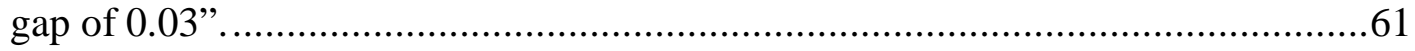




\section{Nomenclature}

$\begin{array}{ll}\text { Abbreviations and Symbols } \\ \text { AC } & \text { Alternating Current } \\ \mathrm{b} & \text { Bore } \\ \mathrm{BDC} & \text { Bottom Dead Center } \\ \mathrm{DC} & \text { Direct Current } \\ \mathrm{E}_{\mathrm{a}} & \text { Absolute Error } \\ \text { imep } & \text { Indicated Mean Effective Pressure } \\ \text { isfc } & \text { Indicated Specific Fuel Consumption } \\ \mathrm{l} & \text { Connecting Rod Length } \\ \text { LED } & \text { Light Emitting Diode } \\ \mathrm{M}_{\mathrm{f}} & \text { Fuel Mass Flow Rate } \\ \mathrm{N} & \text { Angular Speed } \\ \mathrm{n}_{\mathrm{f}} & \text { Fuel Conversion Efficiency } \\ \mathrm{NPT} & \text { National Pipe Thread } \\ \mathrm{n}_{\mathrm{R}} & \text { Crank Revolutions per Power Stroke } \\ \mathrm{p} & \text { Power } \\ \mathrm{P} & \text { Pressure } \\ \mathrm{P}_{\mathrm{c}} & \text { Cylinder Pressure } \\ \mathrm{psi} & \text { Pounds Per Square Inch } \\ \mathrm{P}-\mathrm{V} & \text { Pressure versus Volume } \\ \mathrm{Q}_{\mathrm{LHV}} & \text { Lower Heating Value } \\ \mathrm{r} & \text { Crank Length } \\ \mathrm{RPM} & \text { Revolutions Per Minute } \\ \mathrm{T} & \text { Temperature } \\ \mathrm{TDC} & \text { Top Dead Center } \\ \mathrm{V} & \text { Voltage } \\ \mathrm{V} & \text { Volume } \\ \mathrm{V}_{\mathrm{cv}} & \text { Clearance Volume } \\ \mathrm{V}_{\mathrm{d}} & \text { Volume Displaced } \\ \mathrm{VI} & \text { Virtual Instrument } \\ \mathrm{V}_{\mathrm{z}} & \text { Zeroing Voltage } \\ \mathrm{W} & \text { Work } \\ \mathrm{x} & \text { Cylinder Travel } \\ & \end{array}$




Greek Symbols
$\partial$
$\begin{array}{ll}\partial & \text { Differential } \\ \theta & \text { Pi } \\ \Delta & \text { Crank Angle } \\ \end{array}$

\section{Subscripts}

$\begin{array}{ll}\mathrm{b} & \text { Brake } \\ \mathrm{f} & \text { Friction } \\ \mathrm{i} & \text { Indicated } \\ \mathrm{im} & \text { Intake Manifold }\end{array}$

\section{Notation}

$\begin{cases}\text { Integral } \\ \mid & \text { Absolute Value }\end{cases}$




\section{Chapter 1 - Introduction}

Since the development of the first commercially successful steam engine in 1769 by James Watt, engineers and scientists have studied the intra-cylinder phenomena of reciprocating engines to better understand their principles of operation in order to develop new methods of optimizing the performance of these versatile power sources [1]. This research has led to great improvements in the field of internal combustion engines.

For instance, the quality of fuel used to power internal combustion engines has improved tremendously. Once, it was difficult to predict how a certain batch of fuel would perform in an engine due to inconsistencies caused by the imprecise production techniques used to manufacture the fuel. By monitoring the intra-cylinder phenomena that occurred when different fuels were used, knowledge was gained and discoveries were made in areas such as the importance of octane rating in fuels. Today, fuels are produced following strict guidelines so that their performance is predictable and reliable.

Another area that has seen great improvement is the charge induction system. The most basic system used to mix air and fuel into a combustible mixture and deliver that mixture to the cylinder is the carburetor. Most carburetors rely on the venturi effect caused by air being drawn through a restricted passage to draw a measured amount of fuel into the flow. Analysis of the effects of different carburetor settings and designs on intra-cylinder phenomena resulted in the carburetor evolving into a complex electronic device, which is still in use on modern engines. In addition, the development and perfection of modern electronic fuel injection systems was brought about when the study of combustion fueled the desire to more precisely control the charge mixture. 
The charge ignition system ignites the fuel-air mixture in the combustion chamber of spark ignition engines and is the subject of many ongoing internal combustion engine research projects. The goal of this system is to ignite the mixture so that it undergoes complete combustion, which maximizes the energy released by the fuel and minimizes the production of harmful pollutants. This ignition is normally accomplished by means of a direct current (DC) system consisting of an ignition coil, which stores a charge that is then directed to the proper engine cylinder by means of either a rotating distributor or an electronic ignition system. At the cylinder head, the charge is applied to a spark plug; as the charge arcs across the gap between the sparkplug electrodes, the mixture is ignited.

This system works well, as long as the mixture surrounding the spark plug gap contains the proper ratio of air to fuel necessary for successful combustion. One way of achieving greater efficiency in an engine while decreasing harmful emissions is to burn a leaner mixture, that is, to use less fuel with the same amount of air for combustion. However, when this is attempted with a conventional ignition system the result is often misfires and incomplete combustion. The point where misfires or incomplete combustion occurs is termed the lean limit, which is approximately equivalent to an air to fuel ratio of 18 for conventional spark ignition engines operating on gasoline [2]. This incomplete combustion is partially due to the construction of the spark plug. As the flame front propagates from the point of ignition, the combustible mixture directly behind the arm of the spark plug electrode is often shielded and therefore may not burn completely.

As a solution to these problems, the Center for Industrial Research Applications at West Virginia University has proposed a high-energy plasma system to ignite the mixture. The system consists of a quarter-wave coaxial cavity resonator operating at 
radio frequencies [3]; an example prototype is shown in Figure 1. This device is capable of producing a flame volume that is much larger than a conventional DC spark and has unobstructed contact with the combustible mixture in the cylinder. It is theorized that this plasma igniter will allow the use of an air-to-fuel mixture that is much leaner than what is necessary for the use of conventional sparkplugs, therefore allowing the engine to operate much more efficiently [4].

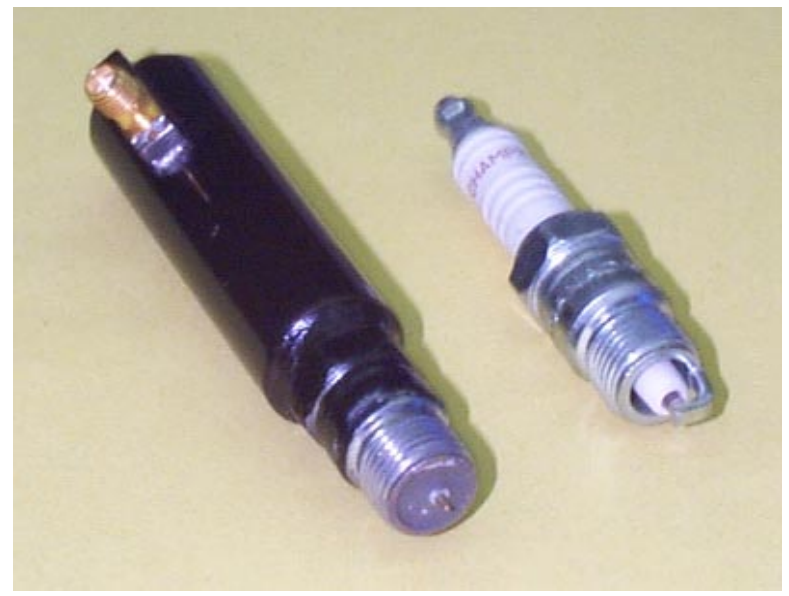

Figure 1 - The plasma igniter (left) and a conventional spark plug (right).

The plasma ignition system is still in the preliminary design phase, and to determine if these theories are accurate it is necessary to have a means of quantifying the performance of an engine into which an ignition system such as the plasma ignition system can be installed. One method of quantifying the performance of a reciprocating engine is to calculate the fuel conversion efficiency. This value is a measure of how effectively an engine converts the chemical energy stored in the supplied fuel to mechanical energy. To calculate the fuel conversion efficiency, it is necessary to know the work done by the working fluid in the cylinder. To determine this work value, a plot of pressure with respect to volume for an individual engine cycle must be produced. This procedure has been accomplished by using a variety of devices known as indicators. The 
information provided by these indicators is useful because the engine extracts work from the working fluid by using the increasing pressure in the cylinder to force the piston down the bore in an attempt to maintain equilibrium with the crank case pressure.

This relates to the thermodynamic definition of work, which is

$$
w_{i}=\int P \cdot d V
$$

where $\mathrm{P}$ is the pressure of the working fluid and $\mathrm{V}$ is the volume that is occupied by this fluid. Thus, it can be inferred that the work transferred from the working fluid to the piston for one engine cycle is equal to the area enclosed by the trace of pressure verses volume, supplied by the indicator [2]. This value is known as indicated work and can be used to quantify an engine's performance.

It should be noted that unless otherwise stated when discussing indicated quantities in this text, the work is assumed to be the gross work. This definition of work represents only the work done during the compression and expansion strokes and ignores any pumping work. This choice was made due to the fact that the research at hand is primarily concerned with the performance of the engine during the compression and expansion strokes. In addition, it is possible to perform tests using a dynamometer to determine values for the brake and frictional work which when summed should approximate the gross indicated work, thereby allowing the validation of the techniques used to determine indicated work [2].

Knowing the work, it is possible to determine the indicated power for the given cylinder. This power is given by 


$$
p_{i}=\frac{w_{i} \cdot N}{n_{R}}
$$

where $\mathrm{N}$ is the angular speed of the engine and $\mathrm{n}_{\mathrm{R}}$ is the number of crank revolutions for each power stroke per cylinder [2].

Once the indicated power has been determined, it is possible to calculate the indicated specific fuel consumption given by

$$
i s f c=\frac{M_{f}}{p_{i}}
$$

where $\mathrm{M}_{\mathrm{f}}$ is the mass of fuel supplied to the engine per unit time and $\mathrm{p}_{\mathrm{i}}$ is the indicated power produced by the engine [2]. The determination of indicated power is discussed above, and the fuel mass consumed per unit time can be determined by using a scale to measure the amount of time required to use a given mass of fuel under the current engine operating conditions.

The fuel conversion efficiency, defined as

$$
n_{f}=\frac{3600}{i s f c(g / k W \cdot H) \cdot Q_{L H V}(M J / k g)} \text {, }
$$

can now be calculated. The $\mathrm{Q}_{\mathrm{LHV}}$ is the lower heating value of the fuel used in the engine. For gasoline, the value is approximately $44 \mathrm{MJ} / \mathrm{kg}$ [2].

Another value that can be used to quantify the performance of an internal combustion engine is the indicated mean effective pressure, defined as 


$$
\text { imep }=\frac{p_{i} \cdot n_{R}}{V_{d} \cdot N},
$$

where $\mathrm{V}_{\mathrm{d}}$ is the volume displaced by the cylinder. The imep is equal to the constant pressure that, if applied to the cylinder for the entire power stroke, would yield work equal to the work of the actual cycle [2].

In addition to the many useful calculations that can result from a plot of the cylinder pressure history with respect to volume, a great deal can be inferred by simple inspection of these plots. Intra-cylinder phenomena that can be diagnosed in this manner include knock and poor or nonexistent combustion.

It can be seen that quantifying the performance of an internal combustion engine relies on the ability to accurately acquire data for the pressure verses volume trace. This task became increasingly difficult with the development of the first commercially successful internal combustion engine by Lenoir in 1860 and the modern multi-cylinder engines into which it evolved [1]. Modern engines typically operate at speeds that are one hundred times the operating speed of the early internal combustion engines. In addition, the energy crisis and pollution control laws made necessary the development of increasingly more efficient engines. Therefore, the technology used to measure and monitor the engines operating conditions was forced to evolve with the engines.

It is the goal of this work to develop an inexpensive test engine that can be used in the preliminary testing phases of ignition systems. This system should allow the analysis of the combustion process, as well as support the determination of values that can be used to quantify engine performance under the given operating conditions. The work presented here includes the selection of the engine to be used, the determination and 
implementation of the instrumentation techniques necessary to meet the goals of this research, and the analysis of data collected when using different ignition systems in the test engine. 


\section{Chapter 2 - Engine Monitoring Techniques}

One of the most effective means of quantifying the performance of a given engine is to develop a plot of cylinder pressure verses volume. By integrating this curve, indicated power can be determined. Over the years various means have been devised to produce this plot. A few of the more popular methods are discussed in this chapter.

\subsection{Mechanical Indicator}

The earliest attempts to monitor the working fluids in the cylinder resulted in the development of a mechanical indicator in 1796 by John Southern, an assistant to Watt [1]. The mechanical indicator was attached directly to the head of the engine and could accurately produce $\mathrm{P}-\mathrm{V}$ diagrams of the engine cycles for large-displacement, low-speed engines. Figure 2 depicts the key components of a mechanical indicator [5].

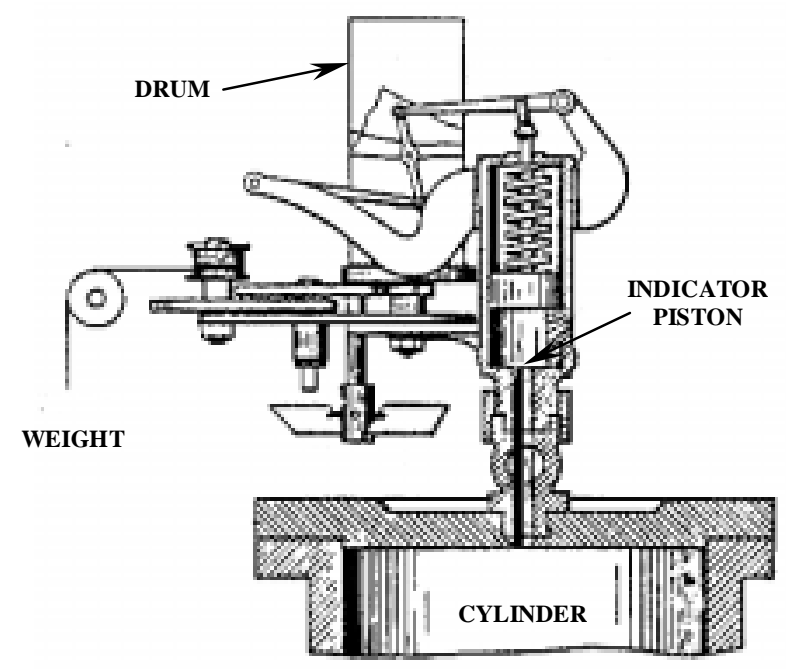

Figure 2 - The key components of a mechanical indicator [5].

The mechanical indicator functioned by measuring the cylinder pressure with an indicator piston that was loaded by a spring at one end and exposed to the cylinder pressure at the other via a small passage leading to the combustion chamber. Thus, the 
indicator cylinder displacement was directly proportional to the cylinder pressure. The cylinder movement was transferred to a pen via a kinematic system. The pen recorded the pressure data on a drum that rotated at a rate equal to the rate of the volume change in the cylinder [6]. This task was accomplished by driving the drum with a kinematic linkage powered by a cyclic engine component, usually the piston or crankshaft [7].

Although the mechanical indicator was considered to be a highly accurate method of producing pressure verses volume diagrams when properly calibrated for a given low speed engine, its shortcomings became evident as the operating speeds of internal combustion engines increased. The increased engine speed inhibited the ability of mechanical indicators to accurately follow the rapid changes in cylinder pressure and volume due to inertia and friction of the indicator piston, linkage, and drum. In addition, the volume of the passage between the clearance volume and the indicator piston was found to affect the performance of the engine by altering its compression ratio. The same passage could also be the source of inaccurate data caused by pressure waves resonating in the passage. Many of the inertia and friction problems were solved by replacing certain rigid components of the mechanical indicator with an optical system and recording the data on light sensitive paper, but there was still concern in the engineering community about the accuracy of mechanical indicators. Therefore, the National Bureau of Standards developed the balanced pressure indicator [6].

\subsection{Balanced Pressure Indicator}

The balanced pressure indicator consists of a diaphragm connected to a set of electrical contacts and a piston-operated recording electrode centered on a rotating drum. The diaphragm is exposed to engine cylinder pressure on one side and to a set reference 
pressure on the other. The reference pressure source is normally either a mechanical pump or some form of compressed gas, usually nitrogen. On the reference pressure side of the diaphragm, the electrical contacts are mounted in such a way that when the engine cylinder pressure reaches the reference pressure, the diaphragm moves, and the circuit is closed. Then when the cylinder pressure drops back below the reference pressure, the circuit is opened. Closing the electrical circuit results in the generation of a spark that arcs from the marker point, which is positioned by the action of the reference pressure on a spring-loaded piston through a piece of paper to a conductive drum. This drum is driven by the crankshaft so that it is known at exactly what crank angle the pressure reaches the reference pressure. By slowly varying the reference pressure over the entire span of engine cylinder pressure, it is possible to produce a complete pressure verses crank angle diagram [7]. Then if the geometric characteristics of the engine are known, a pressure verses volume diagram can be produced. The cylinder head unit of a typical balanced pressure indicator is shown in Figure 3 [7].

Due to the nature of operation of this device, the diagram produced by the balanced pressure indicator contains an average of data points from many engine cycles. The cycle-to-cycle variation inherent to spark ignition internal combustion engines appears as a widening of the pressure data curve produced by a balanced pressure indicator [7]. 


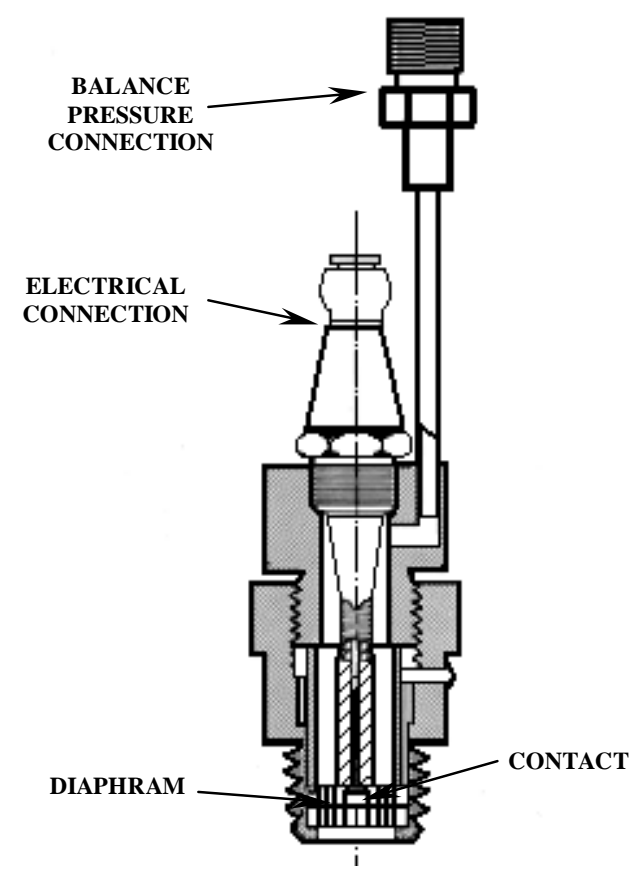

Figure 3 - The cylinder head pick-up unit of a balanced pressure indicator [7].

This type of indicator is thought to be very accurate and was used to develop much of the current information concerning intra-cylinder combustion phenomena. A typical balanced pressure indicator is constructed as depicted in Figure 4 [7].

In addition to its high level of accuracy, the balanced pressure indicator has several other advantages. It is not susceptible to electrical interference and temperature effects, and by design it allows the averaging of data from machines with short-term cycle-to-cycle variations [7].

However, the balanced pressure transducer is not without its disadvantages. It records pressure with respect to crank angle, therefore necessitating a conversion to pressure with respect to volume for work calculations. In addition, the amount of time required to vary the reference pressure across the range of cylinder pressures to obtain a complete set of data and then compile it is many times greater than the time required to obtain similar results with other available methods. Probably the greatest single 
drawback of the balanced pressure transducer is its inability to measure and record the intra-cylinder data for a single engine cycle [7]. This data is very important to the study of phenomena such as engine knock. Therefore, many researchers began experimenting with new technology brought about by the availability of economical microprocessors, and the result was the development of high-speed electronic indicating systems.

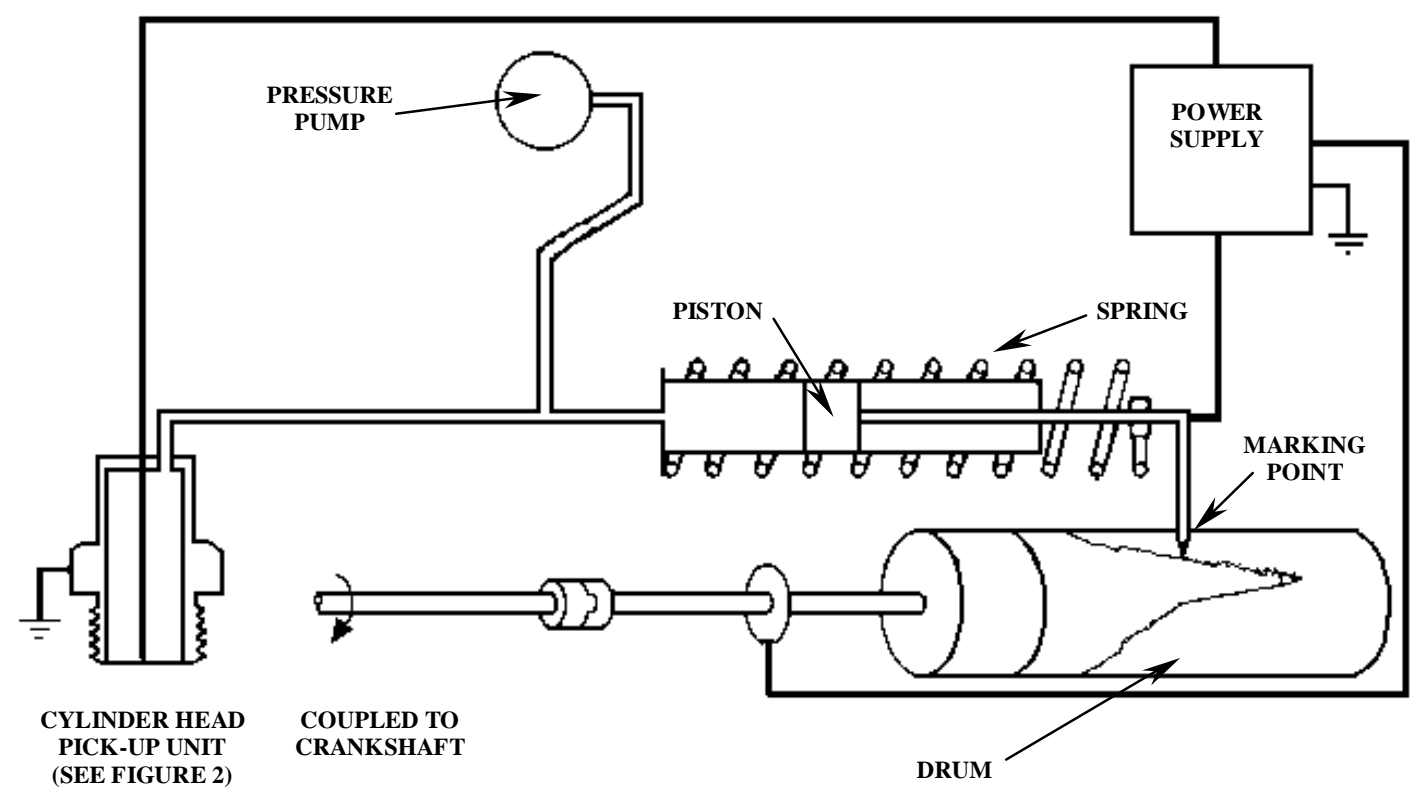

\section{Figure 4 - Layout of a balanced pressure indicator system [7].}

\subsection{Electronic Indicating Systems}

Electronic indicating systems have been developed to instantaneously acquire and record cylinder pressure data at multiple points during a single engine cycle, thus allowing researchers the ability to accurately map the cycle and study the combustion phenomena based on this single cycle. Electronic indicators have been designed using a wide variety of hardware, but they all share the same general components, namely a 
power supply, a motion transducer, a pressure transducer, and a readout or recording device.

\subsubsection{Motion Transducers}

One of the greatest obstacles that had to be overcome during the development of electronic indicator systems was the problem of acquiring accurate data concerning the piston position and synchronizing that data with the cylinder pressure data. Several schemes for accomplishing this task have been devised. One early method involved the mounting of a number of AC generators to the crankshaft and using their output to generate engine position data [8]. Another technique, which was employed by Caterpillar Tractor Company researchers, involved using a photocell to measure the intensity of light shining through a slot that was partially blocked by a cam driven by the crankshaft [9]. These methods were functional but lacked the precision necessary for accurate combustion analysis. The development of the optical shaft encoder provided researchers the required accuracy.

Optical shaft encoders consist of an LED source, a photocell, and a slotted disk. The disk separates the light source from the photocell and is driven by the crankshaft. The unit produces a square wave every time a slot passes by the photocell. Therefore, the number of slots in the disk determines the resolution of the encoder. Encoders are currently commercially available in resolutions up to 60,000 counts per revolution. In addition, most commercial optical encoders are available with a reference signal that occurs once per revolution. The system can be set up so that the reference signal occurs precisely when the engine is at top dead center (TDC). By monitoring the number of 
counts occurring since TDC, the crank angle and corresponding piston position can be determined.

\subsubsection{Pressure Transducers}

An electronic pressure transducer produces an electrical signal proportional to the pressure the sensor is exposed to. Many different types of electronic pressure transducers have been developed, each operating on a different scientific principle. The most popular of these designs have been the strain gage type and the piezoelectric type.

The strain gage type is constructed by mounting a thin metal diaphragm across a hollow tube. Strain gages are then mounted to measure the deformation as the pressure differential across the diaphragm changes. These transducers can be very accurate; however, the frequency response of this type of transducer is generally too slow for many internal combustion engine applications.

Since it is small, lightweight, and has a high frequency response, the piezoelectric charge mode pressure transducer, as shown in Figure 5 [10], is the sensor of choice for most researchers. It is made up of a housing containing a quartz element surrounding an electrode. As the pressure applied to the unit changes, the piezoelectric properties of the quartz produce a static charge that is linearly proportional to the change in pressure. This charge can then be amplified and recorded to obtain an accurate record of the changes in the pressure applied to the unit.

The main shortcoming of the piezoelectric charge mode pressure transducer is that it measures the changes in pressure rather than measuring the absolute pressure. Consequently, an accurate baseline for the pressure data must be determined. The simplest method to accomplish this is to assume that the pressure at the completion of the 
intake stroke is equal to the average intake manifold pressure, which can be measured with a transducer or manometer [11]. Care must also be taken when mounting this type of transducer since it can be adversely affected by rapid changes in temperature, which could be caused by hot combustion gasses coming into contact with the sensor. In addition, these transducers are susceptible to temperature response errors caused by small changes in the transducer temperature. Care must be taken to minimize these errors in experimental work.

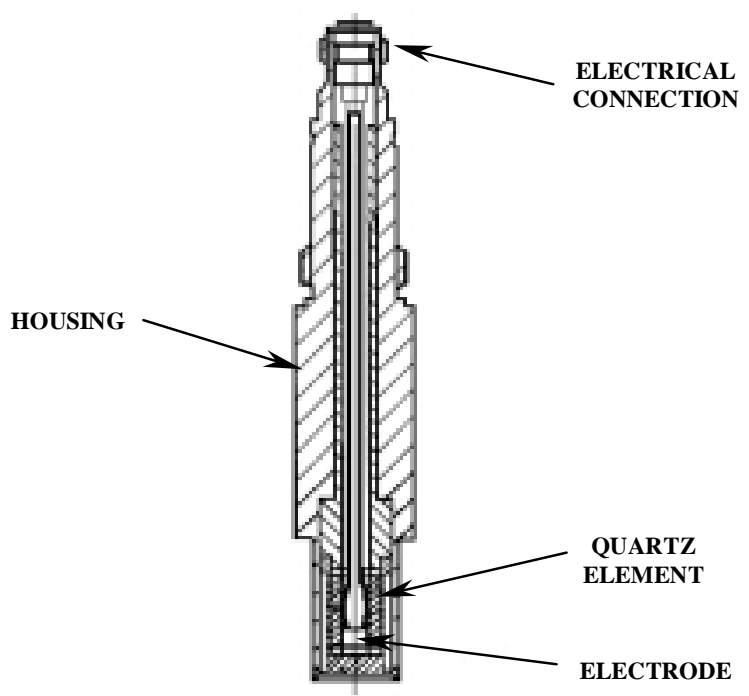

Figure 5 - Cross-section of a piezoelectric pressure transducer [10].

\subsubsection{Readout and Recording Devices}

Early researchers utilized oscilloscopes and oscillographs as readout and recording devices. However, due to the availability of economical high-speed microcomputers these methods are virtually obsolete. A variety of manufacturers produce data acquisition boards that interface with personal computers, allowing the researcher to monitor a number of analog signals at millions of samples per second. 
Various computer software packages can then be used to compile and analyze the stored experimental data.

\subsection{Temperature Measurement}

Often, it is necessary to monitor certain operating temperatures of an engine. The most important of these are the intake air and the exhaust gas temperatures. The measurement of the intake air temperature is important because it allows any performance quantifying values that are determined for the engine to be corrected for standard ambient conditions. The temperature of the exhaust gas can be used as a tool to determine engine combustion efficiency. For instance, if engine combustion efficiency increases, then there should be more energy released in the cylinder, which will cause the exhaust temperature to rise due to more energy being lost in the form of heat. There are a number of devices available that can accurately measure such temperatures, the most common of which are the resistance temperature detector, thermistor, and thermocouple.

\subsubsection{RTDs}

Resistance temperature detectors, or RTDs, were first developed in 1821 by Humphrey Davy [12]. They operate on the principle that certain metals display a highly predictable change in resistivity as their temperature changes. Therefore, by properly monitoring the resistance of a thin wire, it is possible to determine accurately the temperature of that wire. The most common materials for this application are platinum and nickel, with platinum being the more accurate as well as the more expensive.

While RTDs are capable of measuring temperatures with a great deal of precision, and have response times of less than one tenth of a second, they are limited to maximum 
temperatures of around $593{ }^{\circ} \mathrm{C}$. For this reason, they are not the devices of choice for many internal combustion engine applications [12].

\subsubsection{Thermistors}

A thermistor is another temperature measuring device that operates on the principle of temperature dependant resistance. However, unlike the wire elements used in RTDs, the element used in a thermistor is made of a semi-conductor material. They are by far the most accurate of the temperature measuring devices; however, they are extremely fragile and are limited by response times of several seconds and maximum temperatures of around $100{ }^{\circ} \mathrm{C}$. It is for these reasons that thermistors have limited usefulness in the field of internal combustion engine monitoring [12].

\subsubsection{Thermocouples}

The thermocouple is by far the most versatile of the temperature measuring devices. It operates on the thermoelectric principle discovered by Thomas Seebeck in 1821 [12]. Seebeck observed that when two wires made of dissimilar metals are joined at both ends and one end is heated, there is a continuous current that flows in the thermoelectric circuit. If the circuit is broken at the center, the voltage difference between the wires is a function of the junction temperature and the composition of the two metals. Therefore, by measuring this voltage the temperature at the junction can be determined.

However, this voltage cannot simply be measured with a voltmeter because doing so creates a second thermoelectric circuit, thus corrupting the data. To correct for this phenomenon, is necessary to control the temperature of the junction between the voltmeter and the thermocouple. This can be done by placing the junction in an ice bath, 
thereby holding its temperature at $0{ }^{\circ} \mathrm{C}$, or more practically by utilizing an electronic ice point compensator. This device uses a battery to create a voltage that mimics placing the reference junction in an ice bath, and therefore greatly simplifies the use of thermocouples.

The relationship between thermocouple voltage output and junction temperature is nonlinear, but it can be accurately modeled by a higher order polynomial function. This somewhat complicates the use of thermocouples as temperature monitoring devices, but these polynomial equations are readily available for the thermocouples and are easily programmed into personal computers for data acquisition applications. Depending on the type of metals used, thermocouples are available that can measure temperatures up to $1815^{\circ} \mathrm{C}$ with an error of less than $2{ }^{\circ} \mathrm{C}$. This, along with the fact that they are extremely rugged and inexpensive, makes thermocouples the logical choice for most internal combustion engine temperature measurement applications [12]. 


\section{Chapter 3 - Hardware}

The requirements for the test system are that it be rugged, reliable, accurate, and user friendly. To meet these requirements the key components were carefully selected and assembled with precision. These key components include an engine, pressure transducers, an optical shaft encoder, thermocouples, a fuel flow monitoring system, and a data acquisition system. The complete hardware system can be seen in Figure 6 .

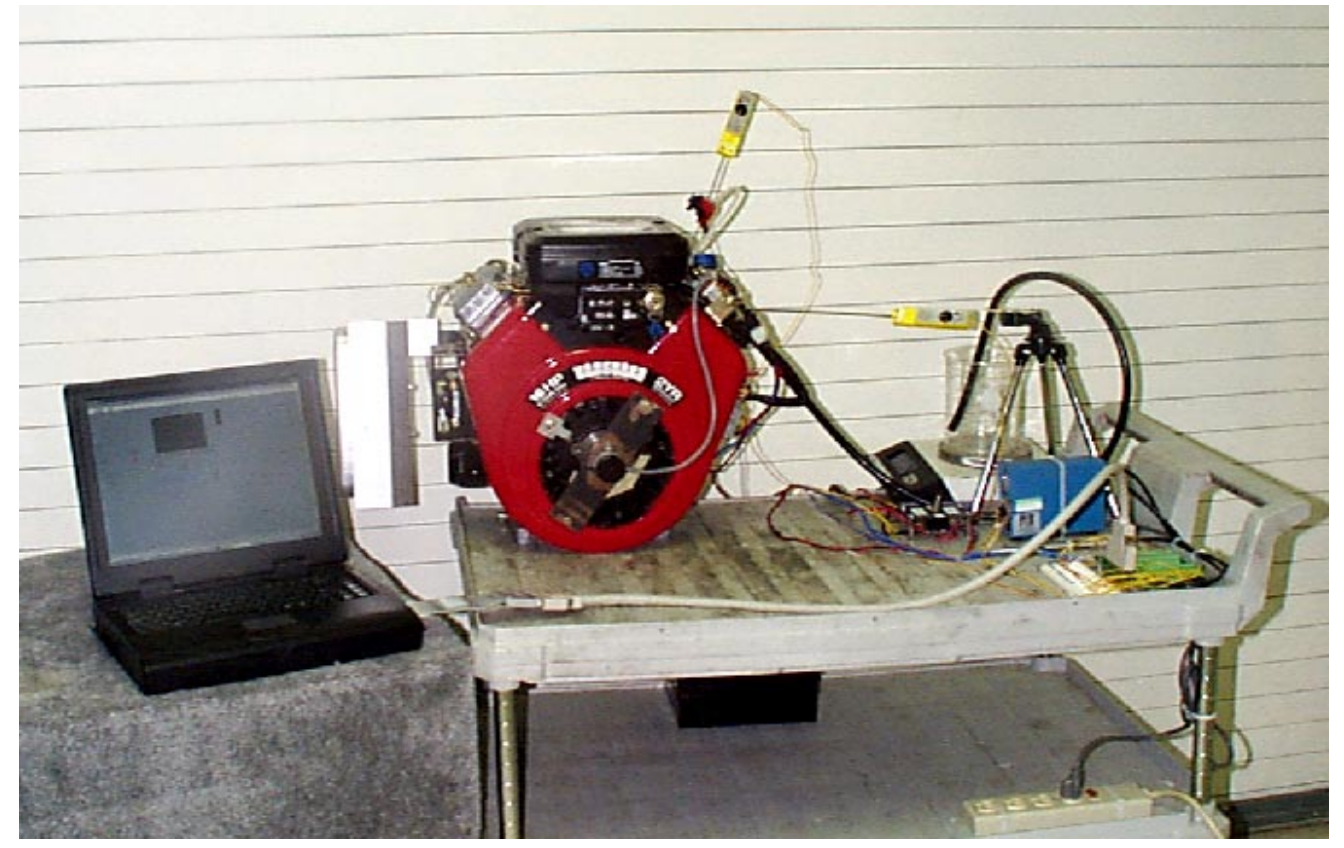

Figure 6 - The complete test engine hardware system.

\subsection{Engine}

The engine chosen as a test engine for the new ignition system is a sixteen horsepower Briggs \& Stratton Vanguard model number 303447 as shown in Figure 7 [15]. It is a four-stroke, twin cylinder, carbureted engine powered by gasoline. It has an overhead valve design and is air-cooled. This particular engine was chosen as the test engine largely due to its twin cylinder design, which allows the engine to run on only one 
cylinder. This feature is useful for the initial testing phases of ignition system. The engine was donated to the Center for Industrial Research Applications by Briggs \& Stratton Corporation.

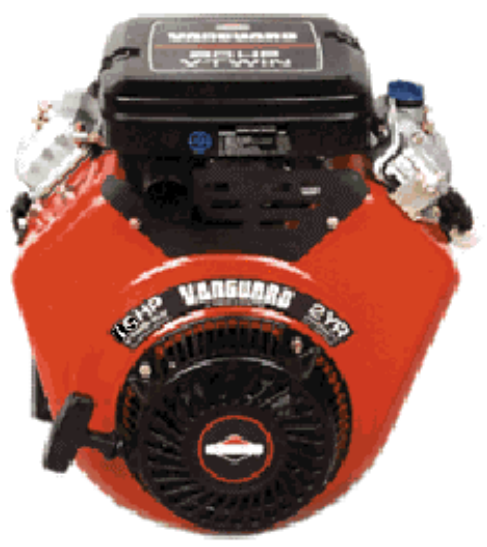

Figure 7 - The Briggs \& Stratton Vanguard Engine [15].

The engine specifications state that it has a total displacement of $29.3 \mathrm{in}^{3}$ and is capable of producing a maximum torque of $24.3 \mathrm{ft}-\mathrm{lbs}$ at an engine speed of 2400-RPM [16]. The major modifications to the engine include the removal of the manual start mechanism to facilitate the mounting an optical encoder to the crankshaft and the tapping of the cylinder head to accept a pressure transducer. In addition, the exhaust manifold is tapped to mount a thermocouple and both a thermocouple and pressure transducer are mounted in the intake manifold.

\subsection{Pressure Transducers}

Two pressure transducers are utilized in the completed test engine. The first transducer is a PCB model 112B11. It is mounted directly into the cylinder head and is used to monitor the cylinder pressure throughout the engine cycle. The second is an Omega model PX 126-015-V. It is mounted in the intake manifold and is used to acquire 
the baseline necessary to establish the absolute values for the pressure curve produced by the cylinder head transducer.

\subsubsection{PCB Model 112B11}

The Model 112B11 pressure transducer is manufactured by PCB Piezotronics. It is a piezoelectric charge mode transducer; it contains a quartz crystal that produces a static charge when the pressure applied to its surface changes. This particular transducer was chosen for its small size, as can be seen in Figure 8, as well as for its accuracy and quick response time [17].
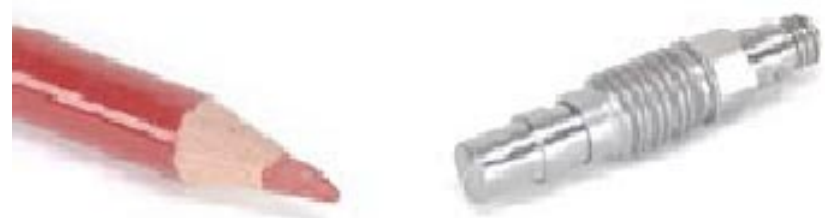

Figure 8 - Housing Design of a PCB Model 112B11 Pressure Transducer [17].

The manufacturer's specifications state that this transducer weighs only .2 ounces, has a resolution of $.01 \mathrm{psi}$, and has a rise time of 3 microseconds [18]. These accuracy and response time values are more than adequate for monitoring the high cylinder pressures in this relatively low speed engine.

To mount the transducer in the test engine, a mounting hole and orifice were drilled and tapped in accordance with the suggested mounting procedure as described in the Operator's Manual supplied by the manufacturer [18]. The orifice enters the combustion chamber through the outboard surface of the cylinder head in the position indicated in Figure 9. This position was chosen because it allowed easy access for 
transducer maintenance and allowed for the modifications to be made in the area of the head with the most material, thus preserving the structural integrity of the cylinder head.

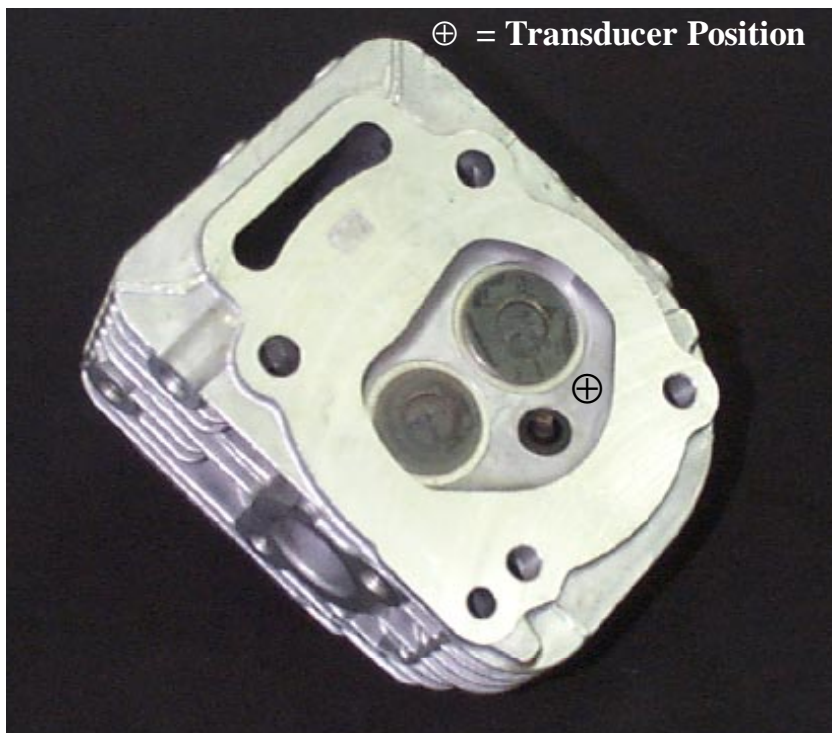

\section{Figure 9 - Cylinder head transducer placement.}

For the initial development of the test engine, only one cylinder was instrumented. However, the instrumentation of the other cylinder could easily be accomplished using the same techniques discussed in this work.

Since this type of transducer produces a high impedance charge, several additional pieces of equipment are necessary to transform the signal into a low impedance voltage that can be monitored by a data acquisition system. Those pieces of equipment are an in-line charge amplifier and a line power supply/signal conditioner. The complete PCB system is shown in Figure 10. 


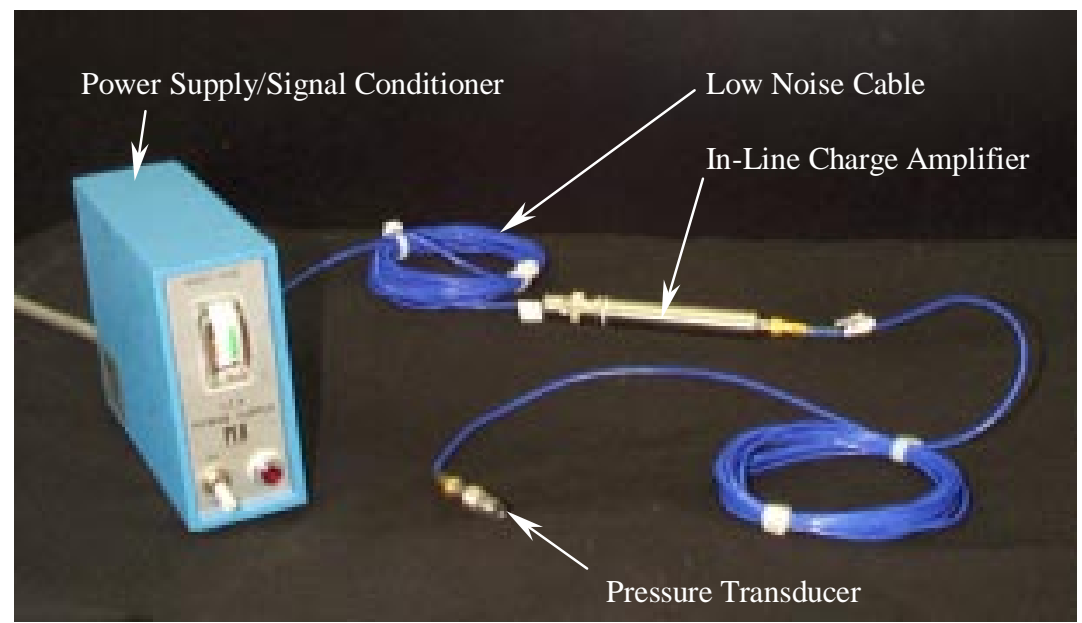

Figure 10 - The complete PCB pressure transducer system.

\subsubsection{Omega Model PX 126-015D-V}

As stated previously, when using a piezoelectric charge mode transducer it is necessary to determine an accurate baseline to establish the absolute values for the points on the pressure trace. It has been suggested that one accurate method of doing this is to set the pressure at $\mathrm{BDC}$ on the intake stroke equal to the average intake manifold pressure [11]. Therefore, in order to determine the average manifold pressure in the test engine, an Omega model PX 126-015-V pressure transducer, such as the one shown in Figure 11, is connected to the intake manifold by means of a length of PVC tubing and a 1/4 inch NPT barbed tubing fitting.

This transducer operates on the principle of piezoresistivity, which means that the resistivity of the sensing element changes proportionally with the changes in the pressure that is applied to it. The heart of the transducer is a 0.1 inch square silicon chip. Embedded in this chip is a sensing diaphragm and piezoresistors. As the pressure changes, the diaphragm flexes causing the resistance values to change. The piezoresistors are connected to a four-active-member Wheatstone bridge allowing the 
transducer to measure differential pressures between 0 and 15 psi with a maximum error of 0.5 psi and a response time of one millisecond [19].

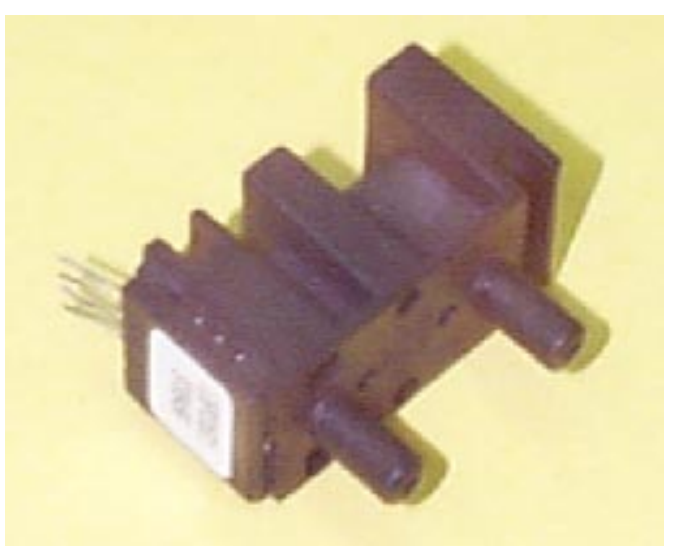

Figure 11 - The Omega model PX 126-015-V pressure transducer.

\subsection{Optical Shaft Encoder}

As mentioned previously, one of the major problems in the development of an electrical indicator system is developing a method of acquiring accurate data concerning the piston position and synchronizing that data with the cylinder pressure data. To accomplish this, the manual start mechanism was removed from the engine, and a custom flywheel retainer bolt was used to replace the original factory bolt. This custom bolt incorporated a 1/2" extension shaft, which allowed an Accu-Coder size 15 model 755A hollow shaft flexible mount incremental encoder, such as the one shown in Figure 12, to be directly coupled to the crankshaft [20]. 


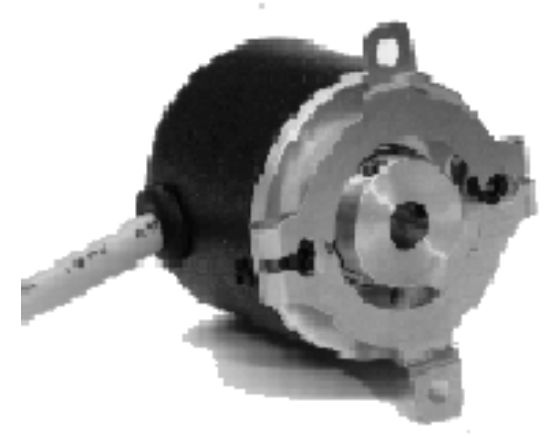

Figure 12 - The Accu-Coder model 755A incremental shaft encoder [20].

The Accu-Coder model 755A operates by means of a slotted disk that rotates between a photocell and an LED. This particular encoder has 1000 slots in the disk. When one of these slots passes in front of the photocell, light from the LED is allowed to pass through to the photocell, thus triggering a pulse output. The pulse activates an NPN pull up resistor circuit that is connected to an external 5-volt source. The result is a square wave that displays 1000 pulses per revolution, allowing the shaft angle to be determined to within 0.36 degrees. In addition, there is a second channel and a reference channel that operate on the same principle as the first. The output of the second channel lags the output of the first signal by a phase difference of ninety degrees and can be used to determine the direction of rotation for certain applications; it was not used for this work. The reference channel displays only one pulse per revolution [20].

The encoder was installed so that the occurrence of the reference signal corresponds to the piston being at top dead center in the cylinder. This was accomplished by first positioning the engine crank so that the piston was at exactly top dead center. This position was determined by mounting a dial indicator in such a way that its shaft went through the spark plug mounting hole and made contact with the piston. The engine was then turned until it was roughly estimated to be at top dead center; this position is 
approximate due to the small amount of piston travel that corresponds to considerable crank shaft rotation when the piston nears top dead center. The position was marked on the flywheel using a custom built rigid pointer that was installed on the engine as shown in Figure 13.

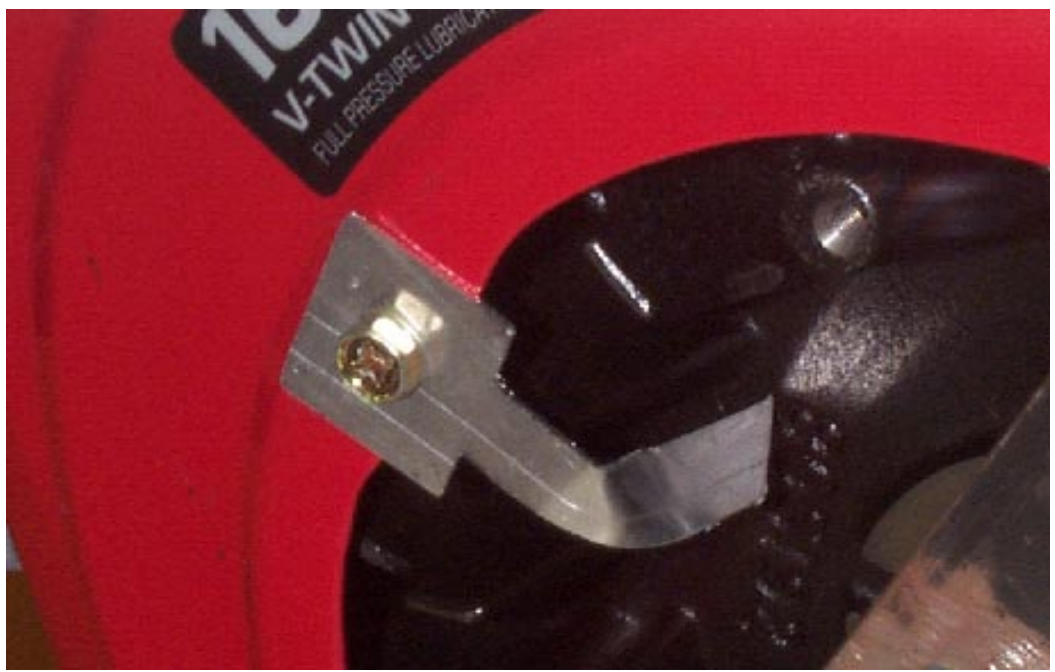

Figure 13 - The rigid pointer used to determine top dead center of the engine.

The exact top dead center of the engine was then determined using the procedure described in the ASME test codes for the measurement of indicated power [7]. First, the engine was turned clockwise to a position that was approximately twenty degrees before top dead center. Using the pointer, this position was marked on the flywheel and the dial indicator was zeroed. Next, the engine was turned clockwise until the dial indicator passed top dead center and passed the zero reading. The engine was then turned counter clockwise until the dial indicator returned to the zero reading. This position was also marked using the pointer. Bisecting the angle between these two marks allowed an accurate mark indicating top dead center to be produced. This mark was lined up with the pointer, and the encoder was rotated until the reference signal point was reached. The 
encoder was then firmly coupled to the crankshaft by tightening the two set-screws on the encoder collar.

With the encoder synchronized with top dead center, it is possible to use the reference pulse to trigger the data acquisition system to begin taking data at top dead center. In addition, the 1000 counts per revolution square wave produced by the encoder can be used as an external clock to time the data acquisition, which allows the engine pressure data to be precisely synchronized with the cylinder volume data.

\subsection{Thermocouples}

Two thermocouples are utilized in the instrumentation of the test engine. They are both Omega model KQSS-18E-12 quick disconnect thermocouples. These thermocouples are type $\mathrm{K}$, which means that they are capable of measuring temperatures from $-200{ }^{\circ} \mathrm{C}$ to $1250{ }^{\circ} \mathrm{C}$ with a maximum error of $0.75 \%$ of the measured temperature value [12]. This type of thermocouple was chosen because the temperatures to be measured were predicted to fall into this range. Coupled to each thermocouple is an Omega model MCJ-K miniature electronic ice point device. As discussed earlier, this device provides a voltage that is equivalent to placing the reference junction of the thermocouple into an ice bath. The entire temperature measurement system can be seen in Figure 14.

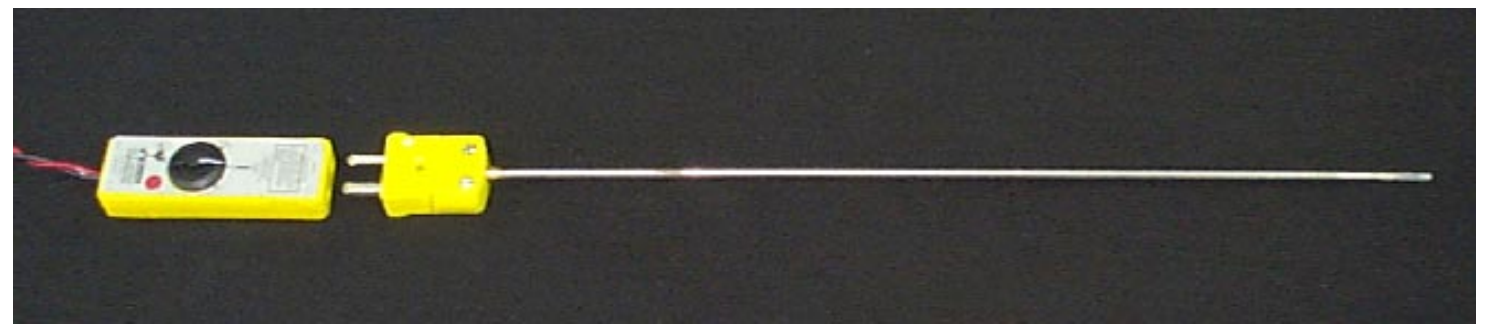

Figure 14 - The Omega model KQSS-18E-12 thermocouple and Omega model MCJ$K$ ice point device. 
The first thermocouple is mounted in the intake manifold, thereby allowing it to monitor the intake air temperature. It was mounted by drilling and tapping the manifold to accept a $1 / 4$ " NPT x $1 / 8$ " compression fitting. In order to allow the thermocouple to pass completely through the fitting to reach the center of the manifold, it was necessary to enlarge the center of the fitting using a $1 / 8$ " drill bit. The second thermocouple is mounted in the exhaust manifold, allowing it to monitor the exhaust gas temperature. It was mounted by welding a similar $1 / 4$ " NPT $\mathrm{x} 1 / 8$ " compression fitting to the exhaust manifold. Once again, it was necessary to enlarge the center of the fitting to accept the $1 / 8$ " thermocouple.

\subsection{Fuel Flow Monitoring System}

In order to calculate the indicated specific fuel consumption, it is necessary to determine accurately the mass of fuel that is consumed by the engine per unit time under the given operating conditions. To accomplish this, the engine is supplied with fuel from a 1000-ml beaker. The beaker rests on an Ainsworth model 400 digital scale that is calibrated in grams. This allows the mass of fuel used by the engine over a given length of time to be measured, so the mass fuel consumption per unit time can be calculated. One of the most important features of the fuel monitoring system is the fuel line support stand. This stand is a tripod structure that straddles the scale supporting the fuel line so that it does not rest on the beaker, which would cause an error in the fuel mass measurements. The entire fuel flow monitoring system can be seen in Figure 15. 


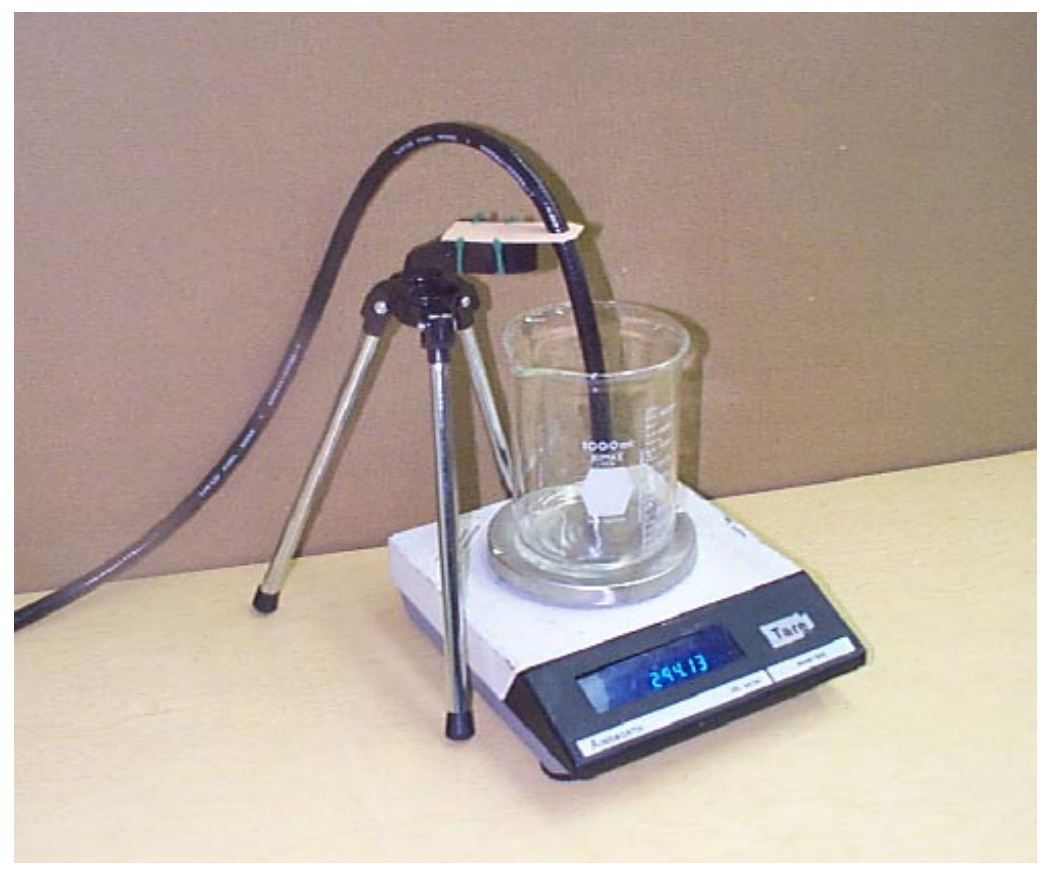

Figure 15 - The fuel flow measuring system.

\subsection{Data Acquisition System}

In order to collect data from the array of transducers used to monitor the operation of the test engine, it was necessary to utilize an electronic data acquisition system. This system is capable of monitoring the output of every transducer simultaneously at an acquisition rate that is great enough to allow the collection of data at maximum engine speed. The heart of this system is a National Instruments model DAQCard-A1-16E data acquisition card such as the one shown in Figure 16. 


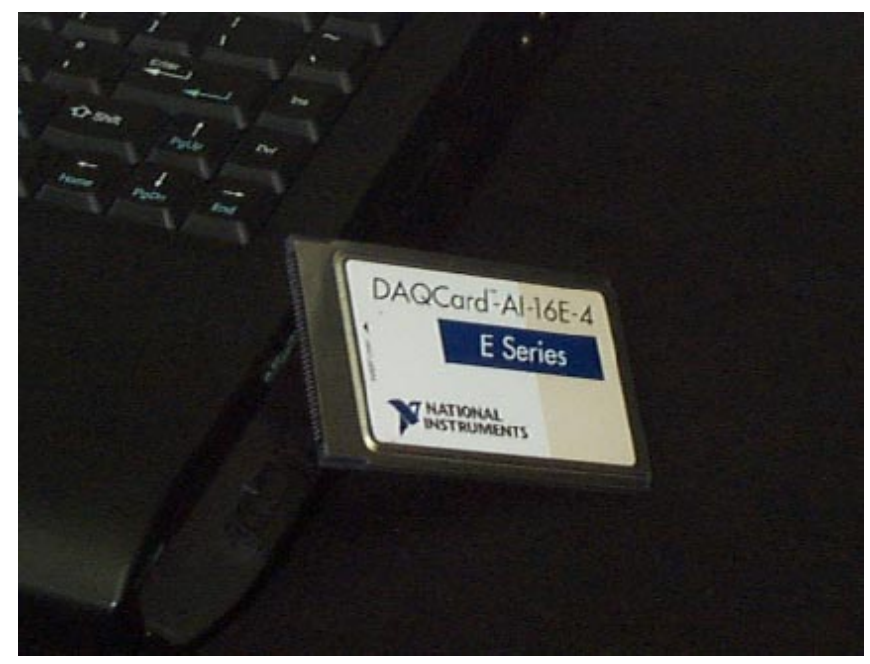

Figure 16 - The National Instruments model DAQcard-A1-16E-4 data acquisition card.

This card is placed into the PCMCIA drive of the $200 \mathrm{MHz}$ Kapok Computer Company model 7200 notebook computer that is used to acquire and compile the engine data. It is then connected by a shielded cable to a terminal block. The various transducers are then connected to this terminal block, allowing the transducers to interface and communicate with the computer. A wiring diagram that displays the necessary terminal block connections is shown in Figure 17. The DAQcard-A1-16E-4 is capable of monitoring 16 single ended or 8 differential analog input channels with 12-bit resolution. Gains are available from .5 to 100 and are channel independent. It is capable of sampling at rates up to 500,000 samples per second for single channel sampling and 250,000 samples per second for multi-channel scanning. It also allows both analog and digital triggering of the data acquisition, which is necessary for the test engine application [21]. 


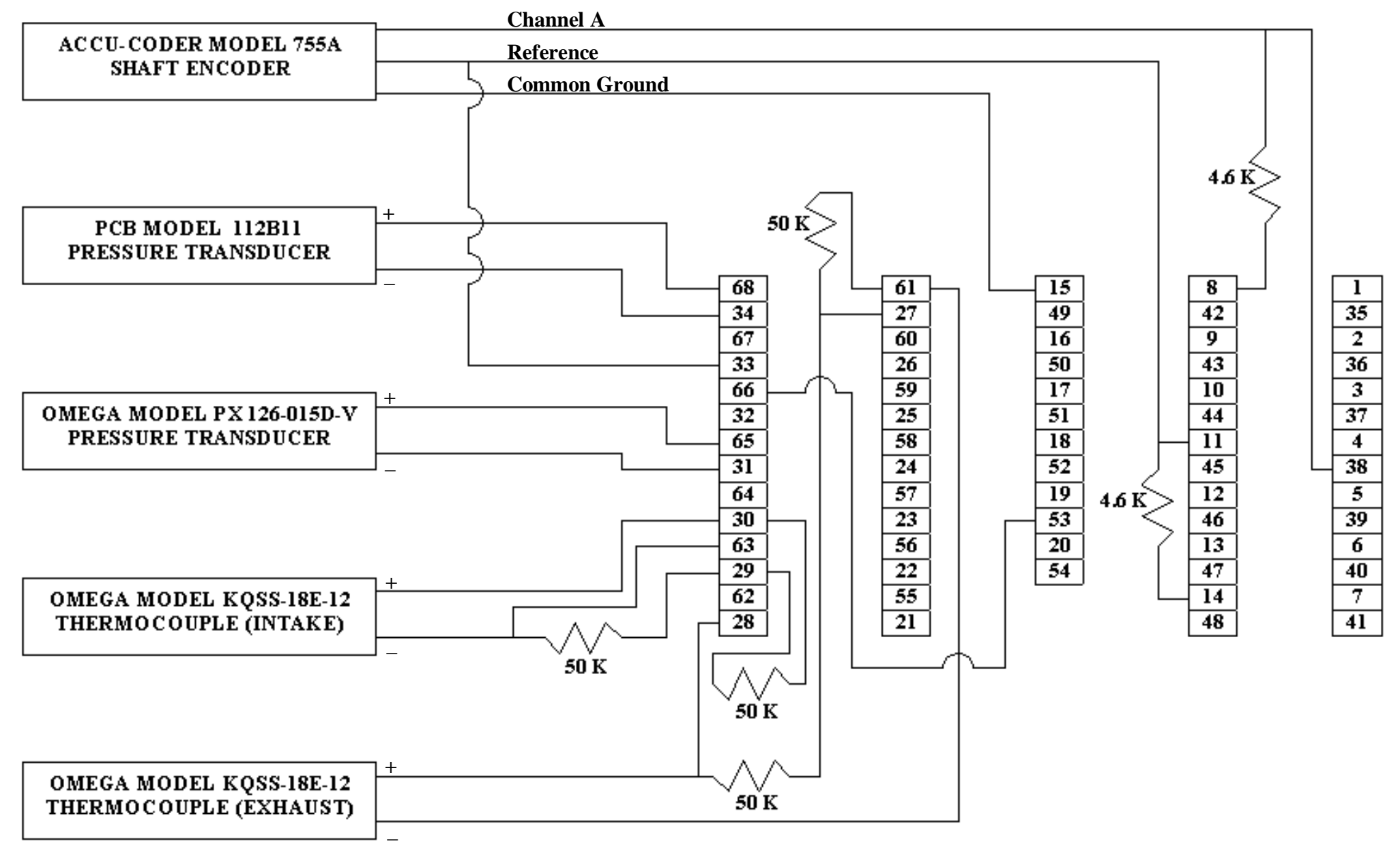

Figure 17 - Wiring diagram for the data acquisition system. 


\section{Chapter 4-Software}

The numerous transducers and engine monitoring systems that are used to quantify the engine's performance supply a tremendous amount of information to the DAQ-A1-16E-4 card in the form of analog signals. In order to collect and compile this information, a number of software packages are utilized. The collection and storage of raw data is controlled by Labview [22] while the data is compiled into a more user friendly format and analyzed using Microsoft Excel [23] and Matlab [24].

\subsection{Data Collection Software}

Labview, the program that controls the data acquisition card, is a software package that automates laboratory instrumentation and data acquisition. With Labview and the proper data acquisition card, a researcher controls on the PC what was once a laboratory full of electronic equipment. With Labview, it is possible to create customized virtual instruments or VIs. For the test engine development it was necessary to develop two separate virtual instruments. The first virtual instrument is used for acquiring and storing the intra-cylinder data such as the cylinder pressure and shaft position (volume), while the second monitors the parameters external to the cylinder, those being intake temperature, intake pressure, and exhaust temperature.

Labview virtual instruments consist of two windows. The first is the instrument diagram, which is a schematic representation of the instrument showing the individual components, how they are virtually connected, and how they interact with one another. The second screen is the instrument control panel. Through this screen, variables are input to the instrument, the instrument is operated, and the resulting output is displayed. 


\subsubsection{The Intra-cylinder Data VI}

The intra-cylinder data virtual instrument for this test engine application was created to allow digital triggering of the data acquisition. Digital triggering was necessary to allow the optical shaft encoder reference signal to trigger the start of data acquisition, thus beginning data acquisition at top dead center. In addition, the VI employs an external counter clock. This feature allows the signal from the optical encoder to be used to trigger the acquisition of each data point. Therefore, the exact piston position at the time of data acquisition is known.

This virtual instrument also allows the acquired data to be saved to a user specified file in a comma delimited format, allowing the data to be transferred to a spreadsheet program for analysis. The instrument diagram for this VI can be seen in Figure 18.

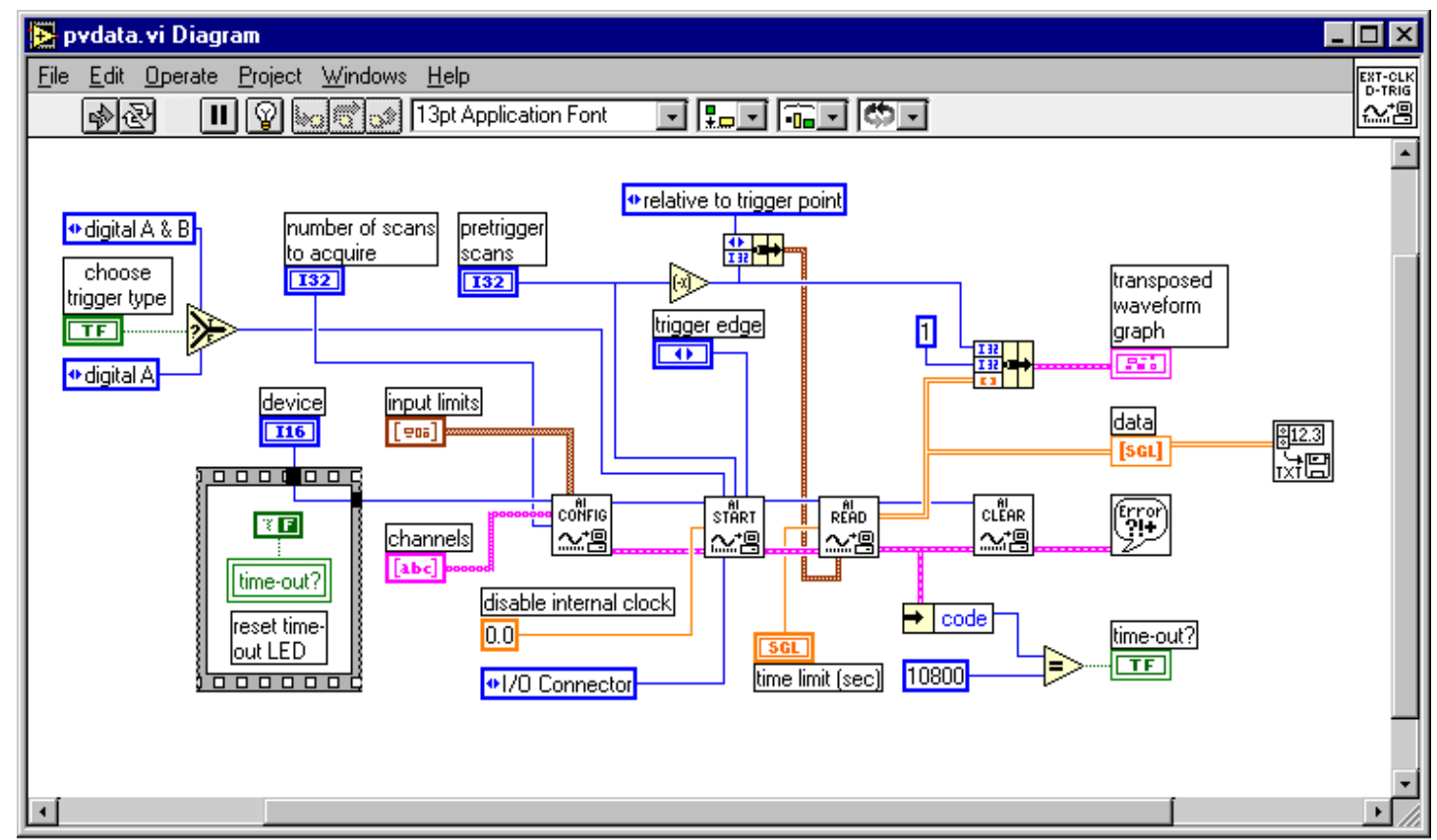

Figure 18 - The instrument diagram for the intra-cylinder data VI. 
The control panel for the VI is shown in Figure 19. It displays windows for entering the trigger type, device number, channels, number of scans to acquire, pretrigger scans, input limits, trigger edge, and time limit.

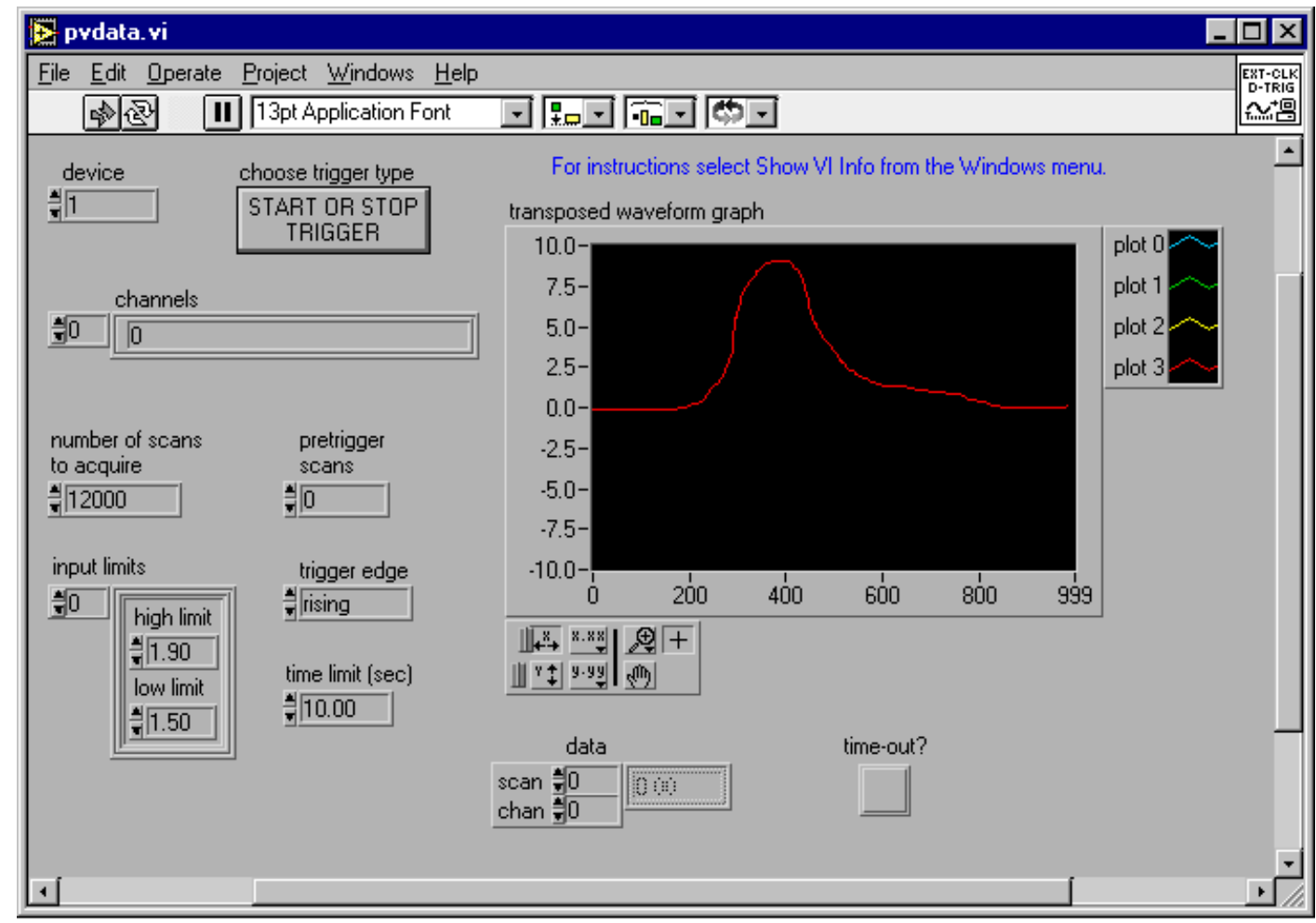

Figure 19 - The control panel for the intra-cylinder data VI.

The trigger type window allows two choices, the first is Start or Stop Trigger and the second is Start and Stop Trigger. The Start or Stop Trigger choice allows the digital trigger signal to either stop or start the data acquisition depending on the value entered into the pretrigger scans window. If the pretrigger scans value is zero, then the external signal will trigger the start of data acquisition, and acquisition will terminate when the desired amount of data is collected. If the pretrigger scans value is greater than zero, then the software starts the data acquisition and waits for the stop trigger. The program then stores the amount of data that corresponds to the pretrigger scans value and records the 
remainder of the data after the trigger. This setting is useful if the researcher is interested in acquiring data both before and after the trigger signal. If the trigger type window is set to Start and Stop Trigger, then the pretrigger scans value must be greater than zero. The data acquisition is started by the first trigger signal, and then when the second trigger signal occurs, the program stores the amount of data that corresponds to the pretrigger scans value and records the remainder of the data after the trigger.

The device number determines which data acquisition card is to be activated by the instrument to take the data, while the channels window informs the instrument of which channels on that card are to be monitored. The number of scans to acquire determines the amount of data to be collected before data acquisition is terminated. The input limits window allows the user to set values for the extreme limits of the input signals for each channel. These values are then used by the software to automatically set gain values for maximum accuracy. The trigger edge window can be set to trigger on either the rising edge of the input signal, the falling edge of the input signal, or when there is no change in the input signal. The time limit window allows the user to set a limit as to how long the instrument will wait for a trigger signal. This feature provides a means to terminate the instrument run if a hardware problem should occur. In addition to these input windows, a graphical display is provided to exhibit the acquired data traces.

\subsubsection{The Extra-cylinder Data VI}

The extra-cylinder data virtual instrument for the test engine was created to allow a number of input signals to be monitored using the PC clock as a timing signal. This gives the user a real-time reference with which to determine engine speed. In addition, signals that do not need to be synchronized with piston position, such as intake and 
exhaust parameters, are monitored using this VI to allow for maximum acquisition speed when monitoring the engine with the intra-cylinder data VI. The instrument diagram for this VI can be seen in Figure 20.

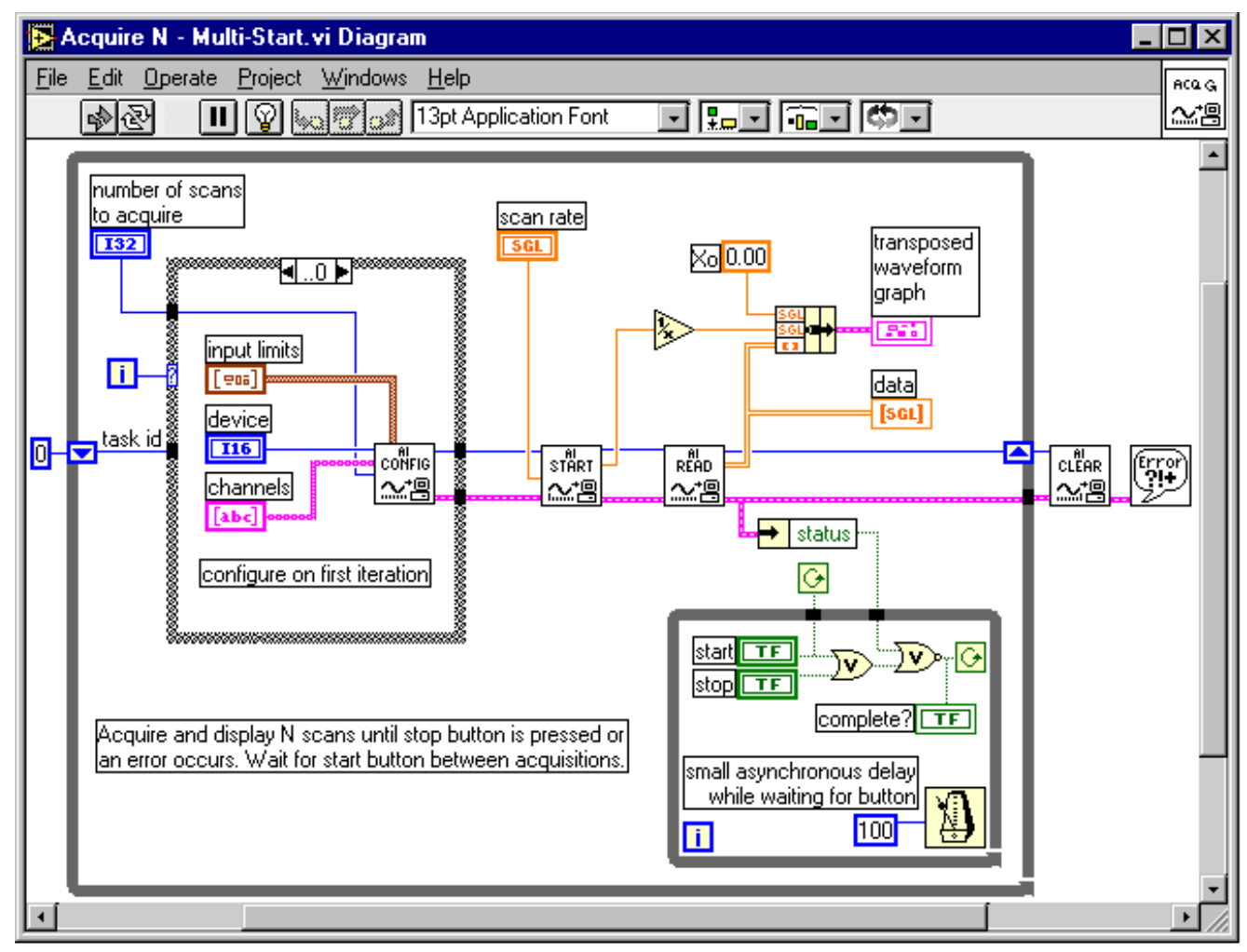

Figure 20 - The instrument diagram for the extra-cylinder data VI.

The control panel for the extra-cylinder data VI is shown in Figure 21. It displays windows for entering device number, channels, number of scans to acquire, scan rate, and input limits. Just as with the intra-cylinder VI, the device number determines which data acquisition card is to be activated by the instrument to take the data, while the channels window informs the instrument of which channels on that card are to be monitored. The number of scans to acquire determines the amount of data to be collected before data acquisition is terminated. The scan rate window allows the user to set the speed at which data will be acquired in scans per second. This value is restricted by the capability of the 
card. Its value cannot be greater than the maximum speed of the card divided by the number of channels to be monitored. In the case of this system, the maximum value is 62,500 scans per second. The input limits window allows the user to set values for the extreme limits of the input signals for each channel. These values are then used by the software to set gain values for maximum accuracy. Again, in addition to these input windows, a graphical display is provided to exhibit the acquired data traces.

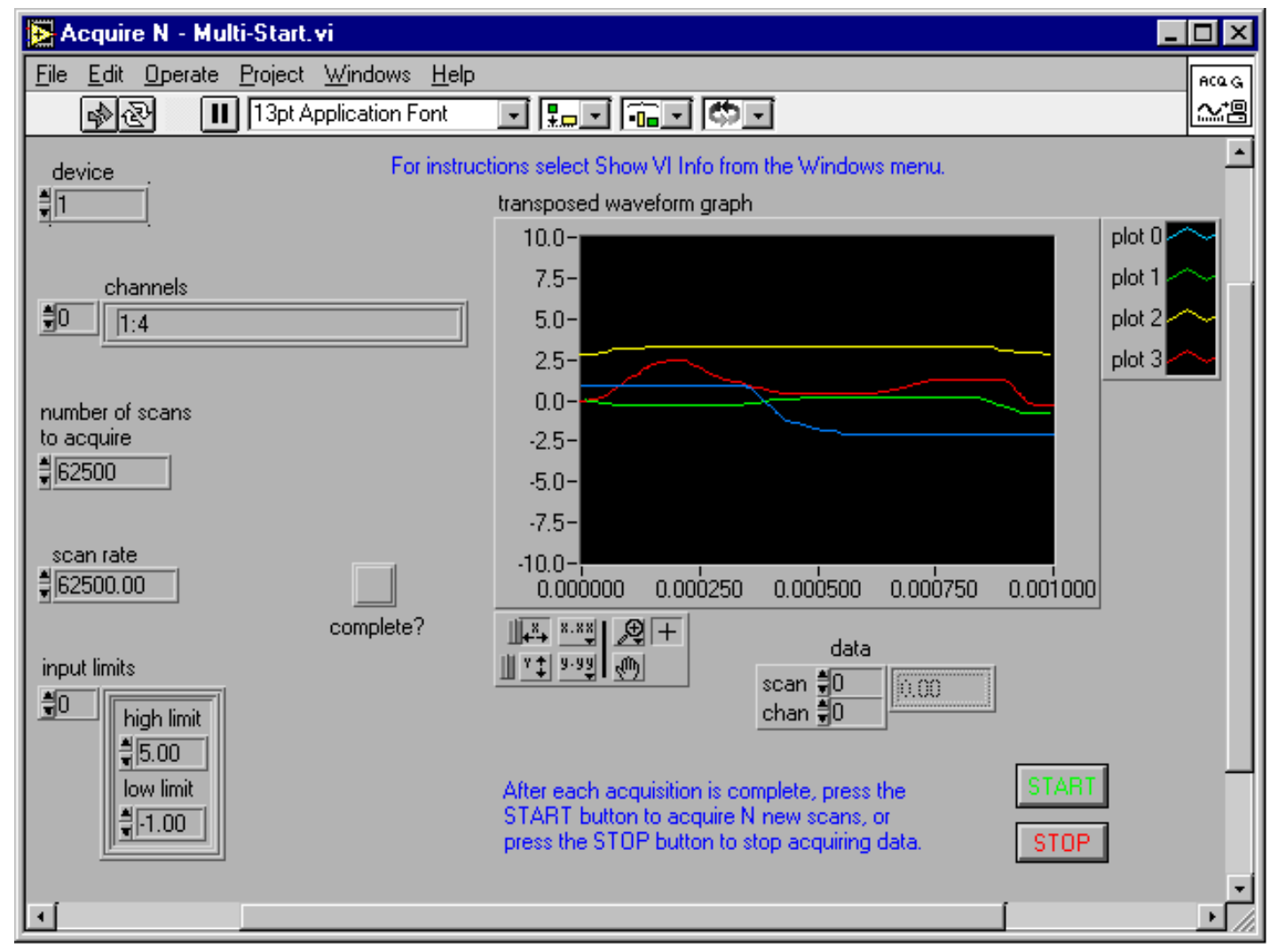

\section{Figure 21 - The control panel for the extra-cylinder data VI.}

\subsection{Data Analysis Software}

After data has been secured from the engine transducers by Labview, it is transferred to an Excel spreadsheet. While Labview does have the capability of performing the data analysis, the decision was made to perform these tasks in Excel and 
Matlab for the ease of data manipulation that they provide. Once the data is transferred, a set of custom macros that were created using Excel's macro recording feature are applied to the data files.

The first macro can be found in Appendix A and is used to compile the engine pressure and position data. It first applies a five point moving average to the data set. This reduces the amount of noise that is found in the data signal. Next, the macro repositions the information into the first 8000 rows of the spreadsheet. This is necessary to allow the next step of the macro, which is saving the file to the Matlab directory in a "filename.wk1" format. This format allows the file to be opened by Matlab.

The second macro can be found in Appendix B and is used to compile the engine speed, exhaust, and intake data. It first determines average values for the intake temperature, intake pressure, and exhaust temperature. Next, it places this data along with the engine speed data into the first 8000 rows of the spreadsheet and saves the file in "filename.wk1" format in the Matlab directory so that it can be opened by Matlab.

Once the engine data has been processed through the spreadsheet macros, the Matlab program Engine.m as shown in Appendix $\mathrm{C}$ is executed. This program first asks the user to input the fuel consumption of the engine in grams per minute under the current operating conditions. This information is obtained by using the digital scale to monitor fuel flow during testing. Next, the program opens both of the data files and arranges the data points into the proper arrays. The speed of the engine is then calculated using the reference signal from the Accu-Coder model 755A optical encoder that is recorded by the extra-cylinder data VI. This calculation is carried out by first using a counter routine to step through the data file and mark the sample numbers where the reference signal 
occurs. These values should correspond to top dead center of the engine. Then, since it is known that the data was recorded at 62,500 samples per second, the revolutions per minute can be calculated by using:

$$
R P M=\frac{62500 \cdot 60}{T D C 2-T D C 1},
$$

where TDC1 is the data point number where the first reference signal occurred, and TDC2 is the data point number where the second reference number occurred. This procedure is carried out for the entire data set, and an average value for the speed of the engine is calculated.

Next, the program uses the other data recorded by the extra-cylinder data VI to determine the intake manifold air pressure, the intake manifold air temperature, and the exhaust manifold air temperature.

To calculate intake manifold air pressure, the absolute value of the signal from the Omega model PX 126-015-V pressure transducer is determined. This is necessary because the transducer is measuring vacuum pressure; therefore, its output signal is negative. The Omega model PX $126-015-\mathrm{V}$ is designed to have linear output over a range of 0 to 15 psi differential pressure, and it is designed to have a full scale output that is equal to 10 milli-volts for every volt of supply power [19]. Since the transducer is powered by an automotive battery measuring $12.3 \mathrm{VDC}$, the intake manifold pressure in pounds per square inch can be calculated by substituting the value of the transducer output into the equation:

$$
p_{\text {im }}=14.7-\frac{v_{1} \cdot 15}{.123}
$$


where $\mathrm{v}_{1}$ is the absolute value of the signal from the transducer in volts.

To determine the intake and exhaust manifold temperatures, the program first retrieves the output of the respective Omega model KQSS-18E-12 thermocouple and Omega model MCJ-K ice point device systems. Then, since the output of the thermocouple system does not vary linearly with temperature, the polynomial equation:

$$
\begin{aligned}
T= & 0.226584602+24152.109 \cdot v_{2}+67233.4248 \cdot v_{2}{ }^{2}+2210340.682 \cdot v_{2}{ }^{3} \\
& -860963914.9 \cdot v_{2}{ }^{4}+(4.83506 E+10) \cdot v_{2}{ }^{5}-(1.18452 E+12) \cdot v_{2}{ }^{6} \\
& +(1.3869 E+13) \cdot v_{2}{ }^{7}-(6.33708 E+13) \cdot v_{2}{ }^{8}
\end{aligned}
$$

where $\mathrm{T}$ is the temperature in degrees Celsius and $\mathrm{v}_{2}$ is the output of the thermocouple system in volts, must be used to calculate the temperatures [12].

The next stage of the program is concerned with beginning the analysis at top dead center (TDC) on the intake stroke. To determine this point, the program looks at the pressure data for the first two TDC points. It then picks the one with the lowest pressure and marks it as TDC1. The remaining TDC points are then located and labeled by adding 1000 to the previous TDC value. This technique works because the encoder pulses that trigger the acquisition of each data point have a resolution of 1000 pulses per revolution.

Once the TDC values have been labeled, the program proceeds to convert the pressure data into units of pressure and shift these pressure curves so that the pressure at the completion of the intake stroke is equal to the average manifold air pressure [11]. To accomplish this, first five data points are at the end of the intake stroke by adding 496...500 to the respective intake TDC values. The output of the PCB Model 112B11 pressure transducer for these data points is then averaged to obtain a "zeroing" value. That is a value that when subtracted from the entire pressure curve will shift that curve so 
that the end of the intake stroke lies on the x-axis. Using the average of five data points for this "zeroing" value protects the true pressure trace from being corrupted by noise in the signal. Once the pressure trace is "zeroed," then the intake manifold air pressure can be added to the curve, causing it to shift an amount that creates an accurate trace of absolute cylinder pressure when the appropriate conversion factors are applied to the data. These conversion factors are specific to the individual transducer calibration. The final equation for cylinder pressure in pounds per square inch that is applied to the entire pressure data array for the individual engine cycles appears as:

$$
P_{c}=\frac{\left(v_{3}-v_{z}\right) \cdot 1000}{1.08216}+P_{i m}
$$

where $v_{3}$ is the output of the pressure transducer in volts, $v_{z}$ is the zeroing value in volts, and $\mathrm{P}_{\mathrm{im}}$ is the intake manifold pressure in pounds per square inch [18].

The next stage of the program creates an array of crank angles from 0 to $4 \pi$ radians in increments of $2 \pi / 1000$ for each engine cycle. Each crank angle value then corresponds to a pressure data point since the pressure data acquisition was triggered by the optical encoder every $2 \pi / 1000$ radians. Once the crank angle arrays have been created, then if the physical parameters of the engine are known they can be transformed into cylinder volume arrays. This is done by applying the equations:

$$
x=r \cdot \cos \theta+\sqrt{l^{2}-\left(r^{2} \cdot \sin ^{2} \theta\right)}
$$

and 


$$
V=V_{c v}+\pi \cdot \frac{b^{2}}{4} \cdot(l+r-x)
$$

where $\mathrm{x}$ is the distance of the piston from TDC in inches, $\mathrm{r}$ is the distance from the center of the crank pin to the center of the main pin in inches, $\theta$ is the crank angle in radians, 1 is the length of the connecting rod in inches, $\mathrm{V}$ is the cylinder volume in cubic inches, $\mathrm{V}_{\mathrm{cv}}$ is the clearance volume in cubic inches, and $b$ is the bore of the cylinder in inches [2]. The physical dimensions of the engine components, with the exception of clearance volume, were obtained by contacting Briggs \& Stratton Corporation customer service. From Heywood [2] it was determined that a typical compression ratio for an engine of this type and size is 7 , so the clearance volume was assumed to be 2.45 cubic inches, which provides this compression ratio. This assumption will be proved valid later in this work.

The pressure and volume arrays for each cycle are then divided into separate arrays for the intake, compression, expansion, and exhaust strokes. From Equation 1, it is known that the integral, or area under the plot of pressure versus volume, can be used to determine indicated horsepower. This area is calculated by using the TRAPZ function in Matlab. This function utilizes trapezoidal numerical integration to determine the area under each curve. The program then calculates the gross indicated work for the cylinder by subtracting the area under the compression stroke from the area under the expansion stroke. This results in the total area enclosed by the power loop, which is equal to the gross indicated power. The program also calculates the net indicated power, which is the area enclosed by the pumping loop subtracted from the gross indicated power. Since this work is primarily concerned with gross engine parameters, this quantity is not currently 
utilized by the program; however, its availability allows the program to be easily modified to analyze net engine parameters.

With the gross indicated work for each cycle calculated, the program then calculates the gross indicated power for each cycle using Equation 2. This allows the program to apply Equations 3, 4, and 5 to calculate the indicated specific fuel consumption, fuel conversion efficiency, and indicated mean effective pressure for each cycle. The program then displays the calculated values to the user, and through a graphical user interface, allows the user to request a pressure verses volume plot, such as the one shown in Figure 22, for any of the cycles.

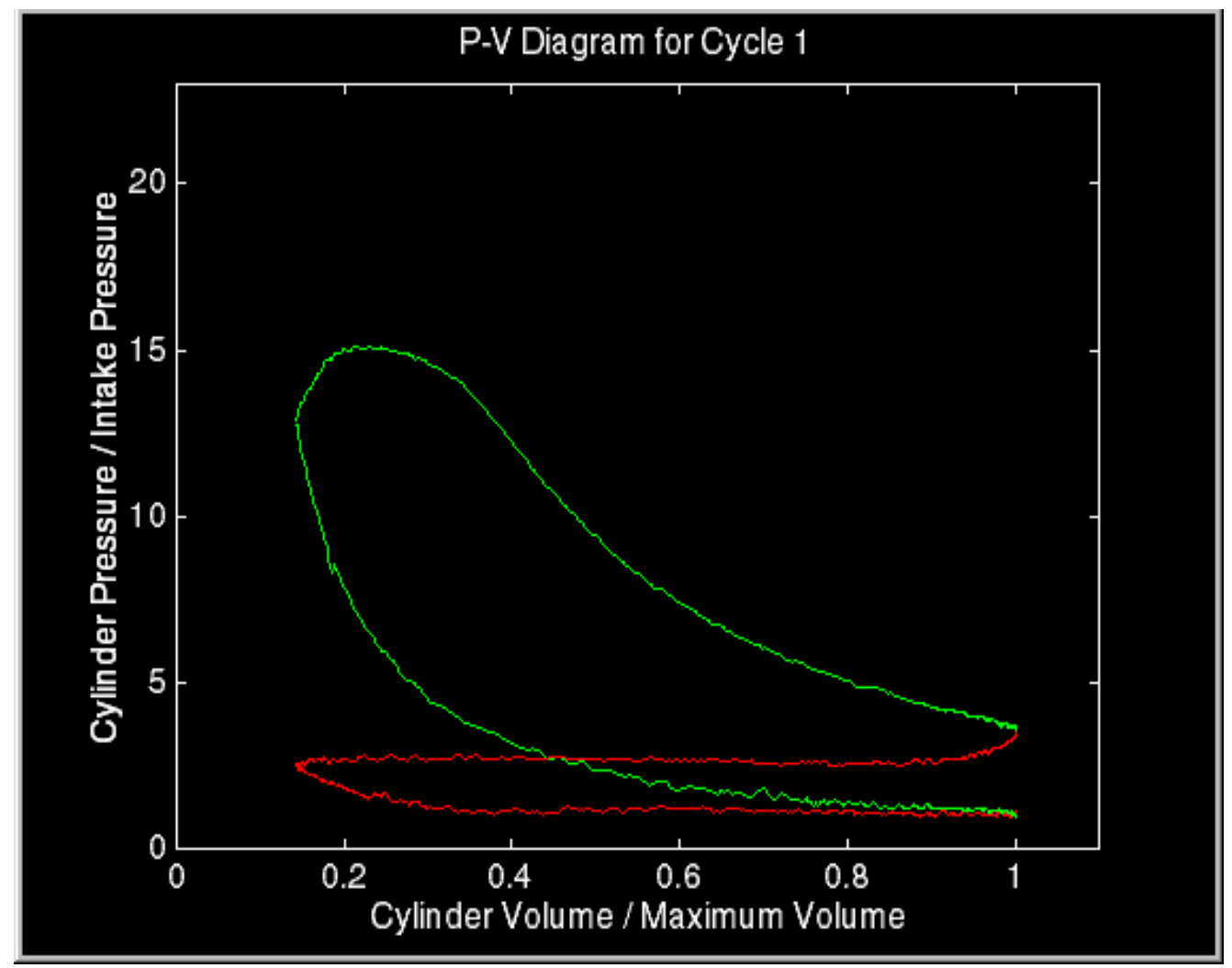

Figure 22 - A pressure versus volume plot produced by Engine.m. 


\section{Chapter 5 - System Accuracy Verification}

To provide a degree of confidence in the results obtained from this research, it is necessary to determine and quantify possible sources of inaccuracy in the acquired data. Two such sources of inaccuracy are the phasing of volume data with the pressure data and the assumed value for the clearance volume. A test to determine the accuracy of these parameters has been defined by Randolph [11]. It involves plotting the pressure versus volume history that is created as the engine is motored on a log-log scale. If the resulting graph shows the lines corresponding to the compression and expansion stroke crossing, then the pressure and volume data is not phased properly. If this graph shows curvature of the compression and expansion lines, it can be concluded that the value for the clearance volume of the cylinder is incorrect. A plot with a correct value for the clearance volume displays linear compression and expansion curves.

To acquire the necessary data, the engine was coupled to a General Electric model 5T20GA5 DC cradled dynamometer as seen in Figure 23. This dynamometer allowed the engine to be motored at its normal operating speed.

Unfortunately, due to the condition of the available dynamometer, it was only possible to motor the engine, and little else. Had it been possible to load the engine and measure the corresponding torque, an additional test for accuracy would be to first arrive at an estimate for the power necessary to perform the pumping work as well as overcome the internal friction of the engine. This value is called the friction power, which could be determined by measuring the power input from the dynamometer to the engine during motoring. Next, the engine could be loaded, data taken, and the corresponding brake 
power measured by the dynamometer. The resulting values should correspond with the equation:

$$
p_{i}=p_{b}+p_{f}
$$

where $\mathrm{p}_{\mathrm{i}}$ is the indicated power given by running Engine.m, $\mathrm{p}_{\mathrm{b}}$ is the brake power measured by the dynamometer, and $\mathrm{p}_{\mathrm{f}}$ is the friction power measured while motoring the engine, which will include the power necessary to overcome mechanical friction as well as the pumping power [2]. The fact that the test engine was designed to be completely mobile will allow this test to be performed should a suitable dynamometer become available.

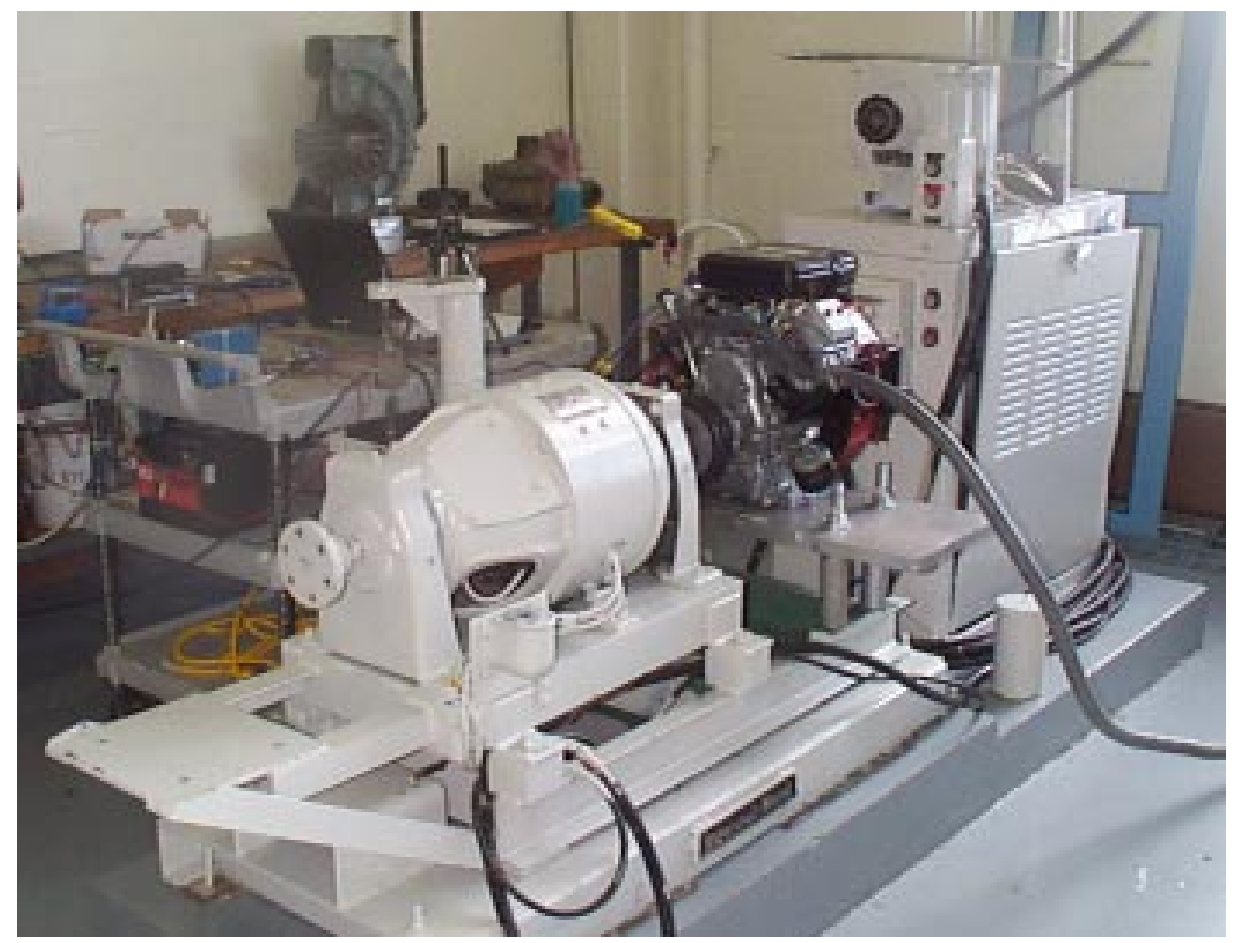

Figure 23 - The test engine coupled to the General Electric DC Cradled Dynamometer. 
The pressure and volume data sets resulting from the motoring test were plotted, and it was noticed that the compression and expansion curves did indeed cross near the center of the strokes. An attempt was made to correct this error by shifting the volume data one point. This improved the situation but did not alleviate it. When the volume data was shifted one additional point, the curves no longer crossed as can be seen in Figure 24. The data analysis program was then modified to perform the shift to correct for this error. Thus it can be concluded that the phasing of the pressure and volume data is accurate to within one volume unit. Since a sample is triggered 1000 time per revolution, the resulting phase shift is equal to 360/1000 degrees. This error is of great concern when computing mean effective pressures. However, previous research has shown that this is accurate enough for this type of research [25]. In addition, it can be seen that the curves corresponding to compression and expansion in Figure 24 are indeed linear, which validates the assumption of a 2.45 cubic inch clearance volume. 


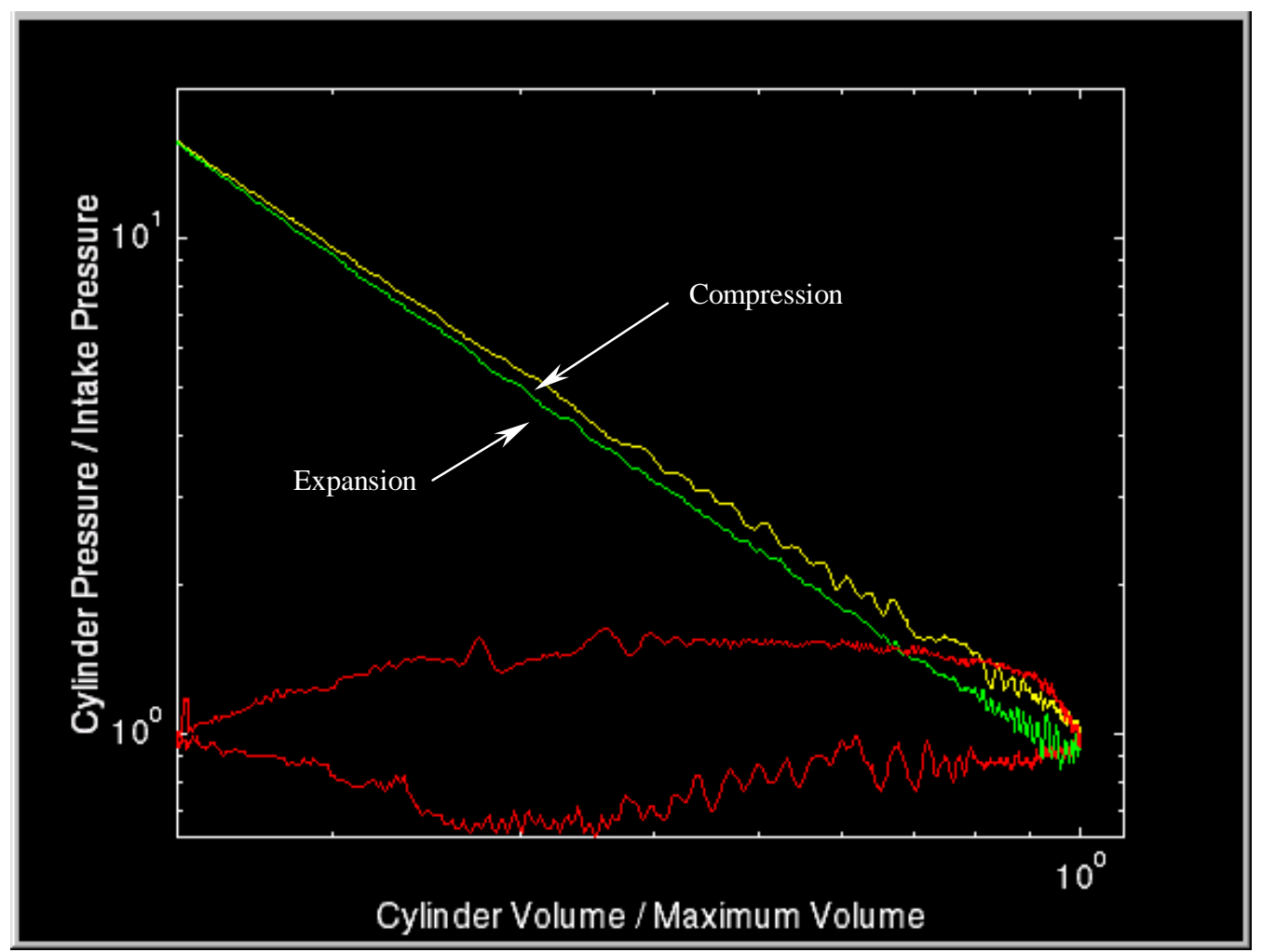

Figure 24 - A log-log plot of pressure versus volume for the motored engine cycle.

Another possible source of inaccuracy is the five point moving average that is applied by the intra-cylinder data macro to the output data from the piezoelectric pressure transducer. This routine is meant to smooth the noise in the data. This noise in inherent to piezoelectric pressure transducers, especially at low cylinder pressures. It is believed that this phenomenon may be due to the turbulent flow of working fluid near the sensor [25]. Figure 25 shows a small section of the piezoelectric pressure transducer output signal along with the results of the five point moving average. From this plot, it is clear that the moving average curve shows a significant improvement over the original curve. It was found that the maximum difference between the actual output and the moving average at peak pressure was on the order of $1 \%$. This possible error was found to be 
acceptable when the overall improvement caused by the smoothing effect on the data was considered.

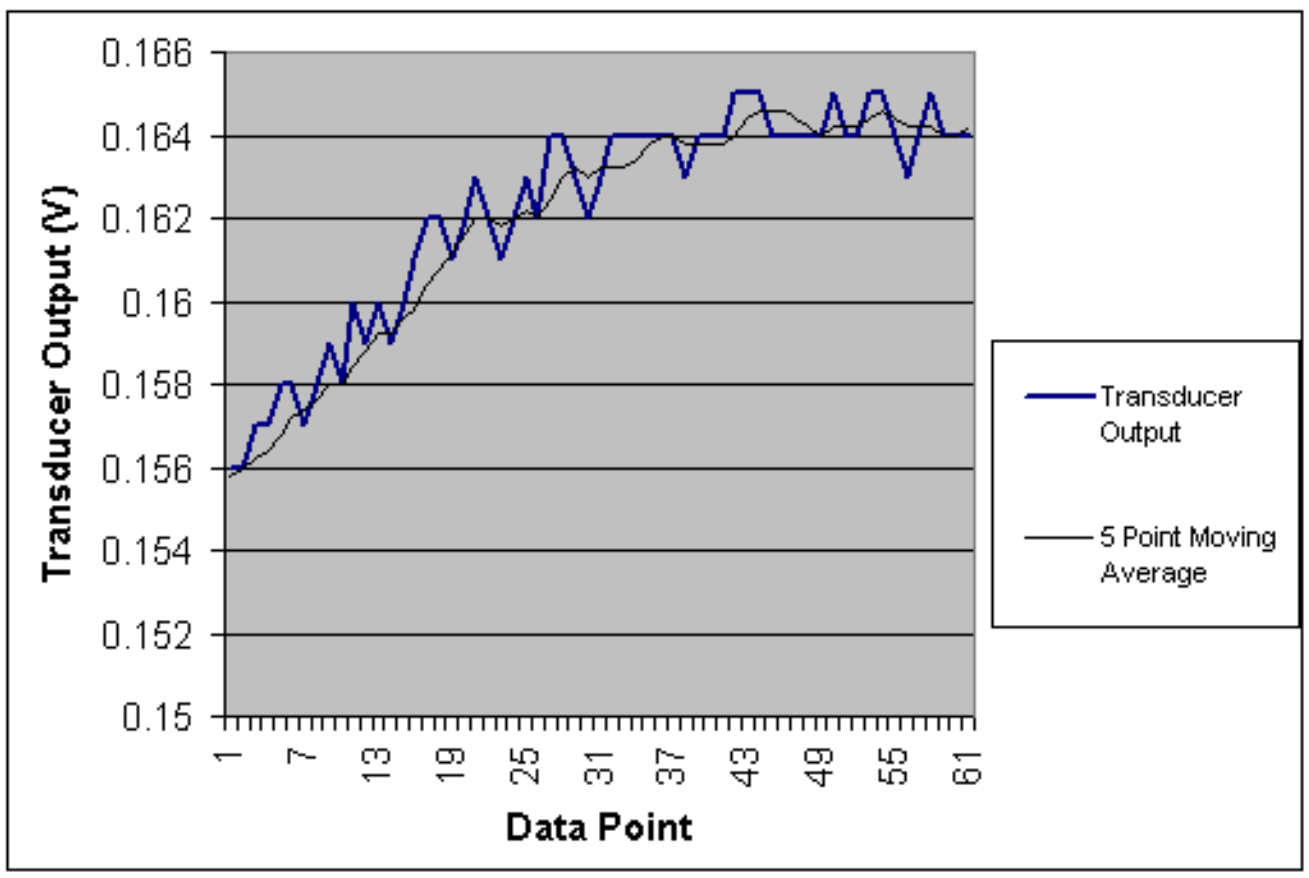

\section{Figure 25 - Piezoelectric pressure transducer signal and its five point moving average.}

These tests have shown that the three most likely sources of error - phasing of the pressure and volume data, the assumption of a clearance volume value, and the 5 point moving average routine are creating some error. However, the magnitude of the error is minimal. The objective of this research is to provide an inexpensive means of monitoring the performance of an ignition system and not to provide highly accurate data that can be used to optimize the ignition system. Such data would require moving the ignition system to a more predictable and therefore more costly test engine. For this reason the error is considered to be acceptable for the work at hand. 


\section{Chapter 6 - Error Analysis}

The test engine system is made up of several different transducers and acquisition systems. The information supplied by these systems is used to determine the engine performance quantifying parameters. Since it is desirable to know the accuracy of these parameters, an error analysis was conducted for the system. Each component in the system has an inherent inaccuracy associated with it. If these inaccuracies are known, one can calculate the error in any value that is calculated using data supplied by these components by using the equation:

$$
E_{a}=\left|\Delta u_{1} \cdot \frac{\partial f}{\partial u_{1}}\right|+\left|\Delta u_{2} \cdot \frac{\partial f}{\partial u_{2}}\right|+\cdots+\left|\Delta u_{n} \cdot \frac{\partial f}{\partial u_{n}}\right|,
$$

where $E_{a}$ is the absolute error, $\Delta u_{n}$ is the error in the measured quantity $u_{n}$, and $f$ is the function of the measured values, $\mathrm{u}_{1}, \mathrm{u}_{2}, \ldots \mathrm{u}_{\mathrm{n}}$, to be calculated [26].

Equation 13 was first applied to Equations 10 and 11. These equations govern the calculation of cylinder volume. For the error calculations, all length measurements are considered to be accurate to within 0.01 ", and the bore is considered to be accurate to within 0.005 ". These estimations were derived from information found in the operator's manual for the engine [16]. The other parameter used in Equations 10 and 11 is crank angle. This measurement is made by the Accu-Coder Model 755A. As discussed earlier, this instrument is accurate to within 0.36 degrees [20]. It should be noted that all data collected by the data acquisition system is subject to a small error due to the $12 \mathrm{bit}$ system. This error is on the order of $0.02 \%$ and is considered negligible when compared to the other sources of error. When the calculations were carried out for Equations 10 
and 11, it was determined that the absolute errors in cylinder displacement and volume are approximately $0.8 \%$ and $2.3 \%$, respectively.

Knowing this, the error in indicated work was calculated by applying Equation 13 to Equation 1. Equation 1 involves the measured values of cylinder pressure and change in volume. The cylinder pressure measurements were made by the PCB Model 112B11 pressure transducer. The manufacturer's specifications for this device state that it has a maximum error of $\pm 0.07 \mathrm{kPa}$ [18]. However, the readings from the piezoelectric transducer were baselined by using data collected from the Omega Model PX 126-015D$\mathrm{V}$, which has an error of $\pm 3.5 \mathrm{kPa}$ [19]. The error in cylinder volume has been determined to be approximately 2.3\%. By applying Equation 13, it was determined that the absolute error in indicated work is approximately $3.1 \%$.

The remainder of the performance quantifying parameters are derived from the work; therefore, it can be concluded that any errors in their values are of similar magnitude to the work error.

Another measured parameter that has the potential to be a substantial source of error is the mass flow rate of the fuel. The error contained in this reading is largely due to human error and is therefore difficult to quantify. These values are determined by reading from a digital scale the fuel consumed in three minutes as shown on a stopwatch. If care is taken when making these readings, it is felt that the error can be kept below a value of \pm 2 grams, or approximately $5 \%$.

As stated in Chapter 5, the objective of this research is to provide an inexpensive means of monitoring the performance of an ignition system and not to provide highly accurate data that can be used to optimize the ignition system. Such data would require 
moving the ignition system to a more predictable and therefore more costly test engine.

For this reason these errors are considered to be acceptable for the work at hand. 


\section{Chapter 7 - Analysis of Initial Test Results}

To prove the reliability of the test engine, three different ignition sources were tested. These ignition sources were three conventional sparkplugs. The first two plugs were Champion model RC12YC as seen in Figure 26, which is the sparkplug recommended by Briggs \& Stratton Corp. for use in the Vanguard engine. The gap on the first sparkplug was set to the manufacturer's specification of 0.03 ". For the second model RC12YC sparkplug, the gap was set to 0.008 ". The third sparkplug tested was a Champion model J19LM as seen in Figure 26 with the gap set to 0.03". This sparkplug has the same thread size as the model RC12YC, but it is only long enough to extend half way through the head, thereby not allowing it to protrude into the combustion chamber.

In addition, the heat range of this plug differs from that of the manufacturer's recommended plug. The model J19LM is a "colder" plug than the model RC12YC. This means that the operating temperature of the electrode will be less than the temperature of the "hotter" model RC12YC plug. The result of this cooler temperature will be that the fuel in contact with the electrode may not be completely vaporized, resulting in a fouled plug and poor combustion. 


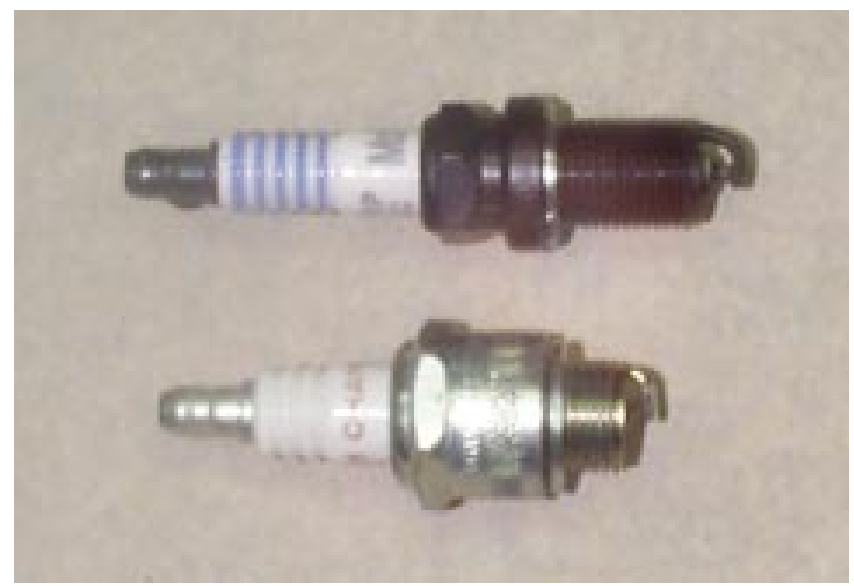

Figure 26 - The Champion model RC12YC (top) and model J19LM (bottom) that were used for initial testing.

With the engine coupled to the dynamometer, which provided an estimated one horsepower load, data was taken with the engine running on each of the three different sparkplugs at approximately 2700 RPM, which is in the center of the engine's normal operating range. The data was then processed through the Excel macros and Engine.m.

\subsection{Test Results for Champion Model RC12YC with a 0.03 ” Gap}

The first sparkplug tested was the manufacturer recommended Champion model RC12YC with the gap set to the recommended 0.03 ”. The complete results from this test can be found in Appendix D. From the results of this test, an estimate of the expected performance of the test engine was developed. The plot of pressure versus volume for the cylinder when this plug was used, as shown in Figure 27, displays characteristics typical to a properly operating internal combustion engine. 


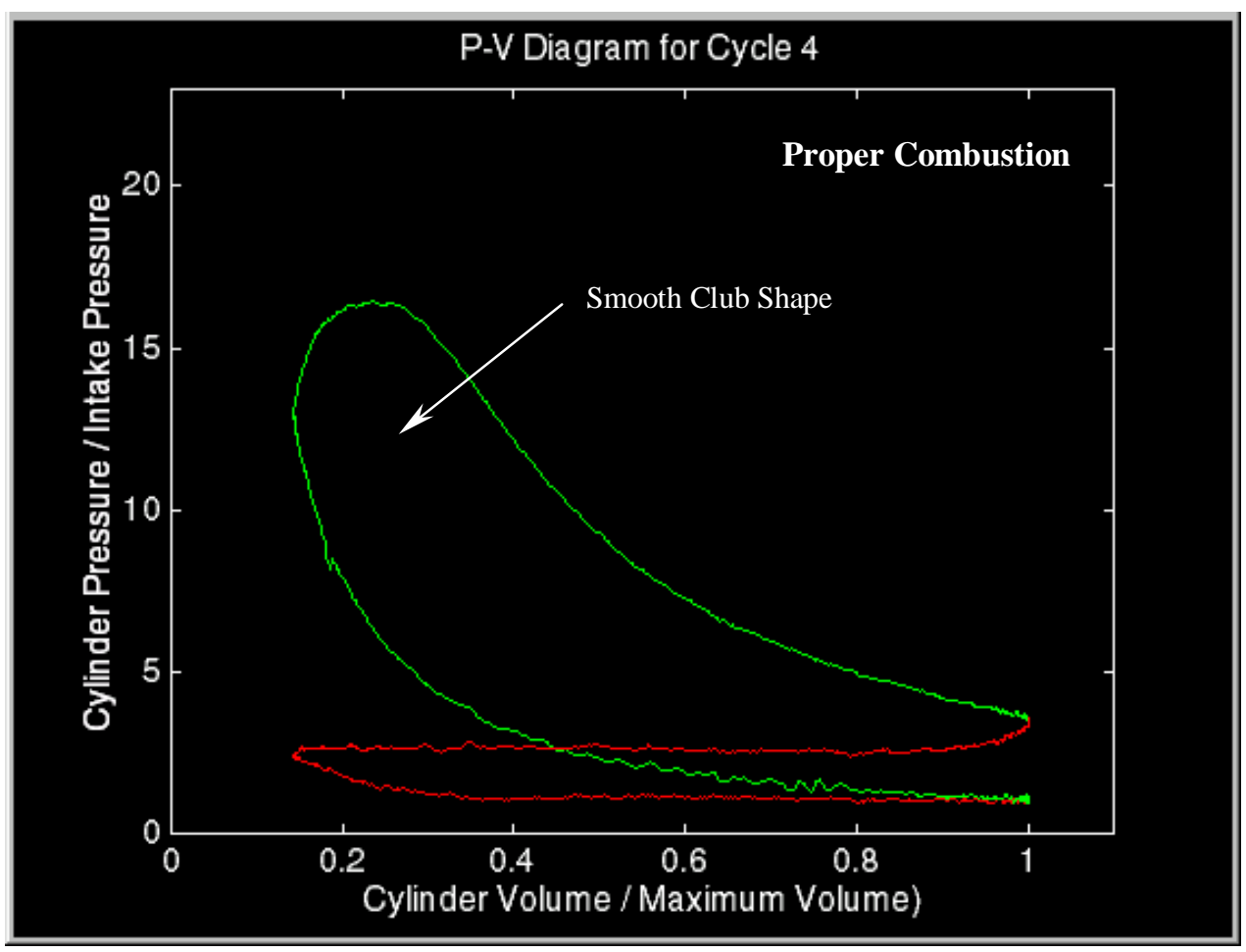

Figure 27 - A P-V diagram for the cylinder using the Champion model RC12YC with a gap of 0.03 " displaying proper combustion.

This shape is characterized by the smooth club shaped curve that is formed by the compression and expansion strokes, shown in green. In addition to the pressure versus volume diagram, the performance parameters for the engine were also calculated and are displayed in Table 1. 
Table 1 - Engine performance parameters for the Champion Model RC12YC with a gap of $0.03 "$.

\begin{tabular}{|l|l|l|}
\hline PARAMETER & VALUE & UNIT \\
\hline Average Engine Speed & 2790 & $\mathrm{RPM}$ \\
\hline Fuel Consumption & 15.05 & $\mathrm{~g} / \mathrm{min}$ \\
\hline Average Exhaust Temperature & 806.7 & Celsius \\
\hline Average Gross Indicated Power & 0.79 & $\mathrm{~kW}$ \\
\hline $\begin{array}{l}\text { Average Gross Indicated Specific Fuel } \\
\text { Consumption }\end{array}$ & 573.96 & $\mathrm{~g} / \mathrm{kW} * \mathrm{~h}$ \\
\hline $\begin{array}{l}\text { Average Gross Indicated Mean Effective } \\
\text { Pressure }\end{array}$ & 142.1 & $\mathrm{kPa}$ \\
\hline $\begin{array}{l}\text { Average Gross Fuel Conversion } \\
\text { Efficiency }\end{array}$ & 14.4 & $\%$ \\
\hline
\end{tabular}

In an effort to determine if these calculated values were reasonable, research was conducted to find typical values for the parameters. From Heywood [2], it was discovered that typical exhaust gas temperatures for spark ignition engines are approximately $650{ }^{\circ} \mathrm{C}$. The experimentally determined value of $806.7^{\circ} \mathrm{C}$ seems to be reasonably close to the expected value but is a bit high. The exact reason for this deviation is uncertain. The readings were reproduced multiple times using a multitude of different hardware. As discussed in Taylor [27], the accurate measurement of exhaust gas temperature is nearly impossible; normally the temperatures obtained have only comparative significance. Since the work here is only concerned with comparing the temperatures in an effort to judge the performance of an ignition system, and not with using the temperatures to calculate engine parameters, the inaccuracy is inconsequential. In addition to typical exhaust temperatures, Heywood [2] also supplies typical best values 
for brake specific fuel consumption and brake mean effective pressure. They are 350 $\mathrm{g} / \mathrm{kW}^{*} \mathrm{~h}$ and $900 \mathrm{kPa}$, respectively. These parameters are determined using brake power and are representative of the most efficient engine performance. However, the work here is concerned with indicated parameters and not brake parameters, and due to the low loads on the engine during testing, the engine was not operating near peak efficiency. Therefore, the only comparison that can be made is to check that the experimental results are on the same order of magnitude as values taken from Heywood [2], which they are.

As previously stated, due to low loads during testing, the engine was not operating near peak efficiency, which is evident in the calculated value for average gross fuel conversion efficiency of $14.4 \%$. According to Heywood [2], this value can reach up to $96 \%$ in lean burning spark ignition engines.

\subsection{Test Results for Champion Model RC12YC with a 0.008 " Gap}

The next sparkplug to be tested was the Champion Model RC12YC with the gap set to 0.008 ". This is substantially less than the gap of 0.03 ", which is recommended by the manufacturer. The gap was reduced in an attempt to impair the performance of the plug and thus create poor combustion. The pressure versus volume curve shown in Figure 28 shows signs of this poor combustion. The shape formed by the compression and expansion strokes is no longer that of a smooth club. Instead, it shows signs of delayed combustion. Delayed combustion occurs when the flame front does not propagate quickly after ignition, and hence the piston has already begun to move down the bore when combustion occurs. This is characterized by the dramatic pressure increase late in the expansion stroke resulting in the shape displayed in Figure 28. 


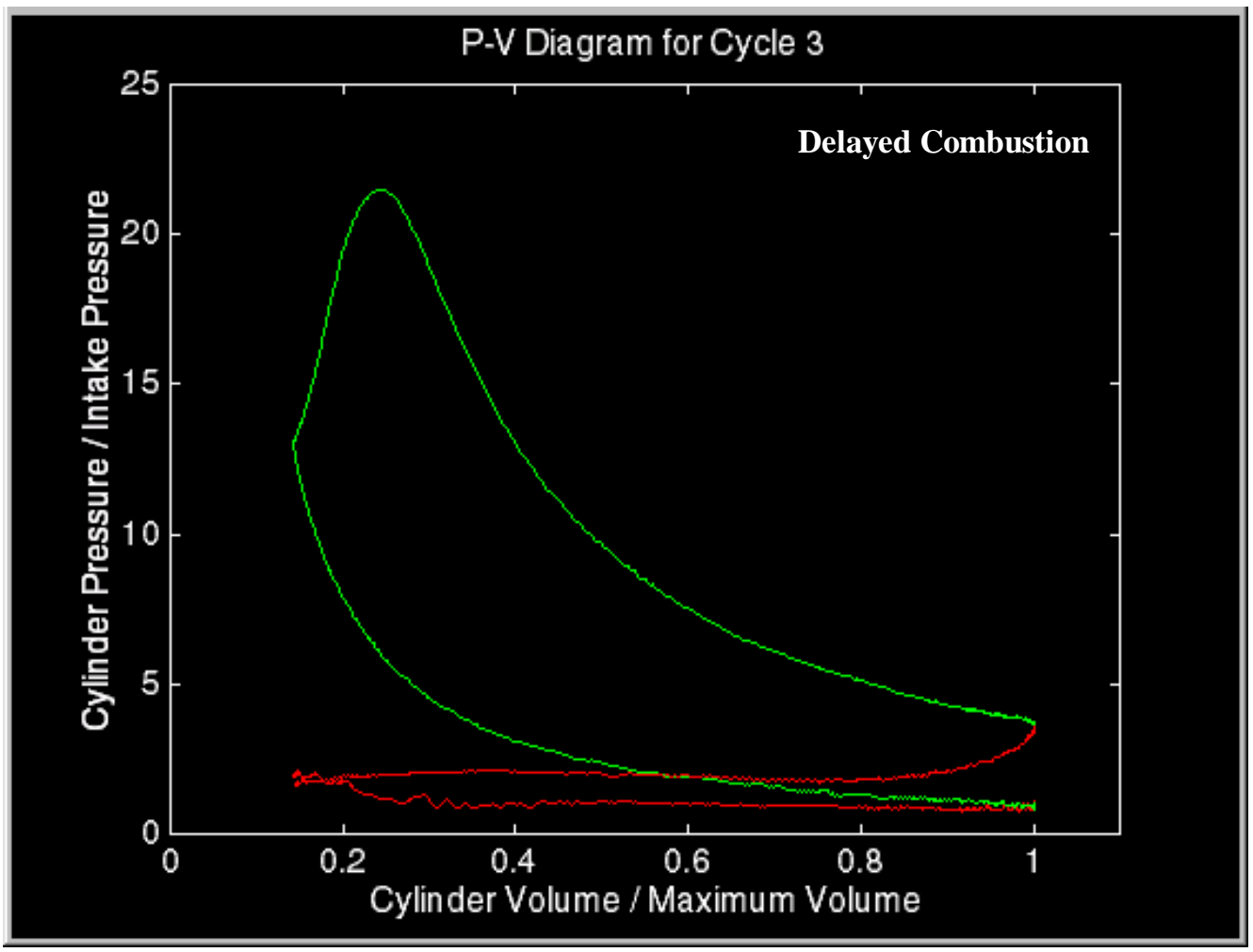

Figure 28 - A P.V diagram for the cylinder using the Champion model RC12YC with a gap of 0.008 " displaying delayed combustion.

In addition to the poor combustion discussed above, the second test plug produced an even greater ignition problem known as misfire. Misfire occurs when a fresh charge is drawn into the engine and compressed but fails to ignite and is discharged from the cylinder during the exhaust stroke. This results in loss of power and wasted fuel. The characteristic P-V diagram of a misfire caused by the second test plug can be seen in Figure 29. 


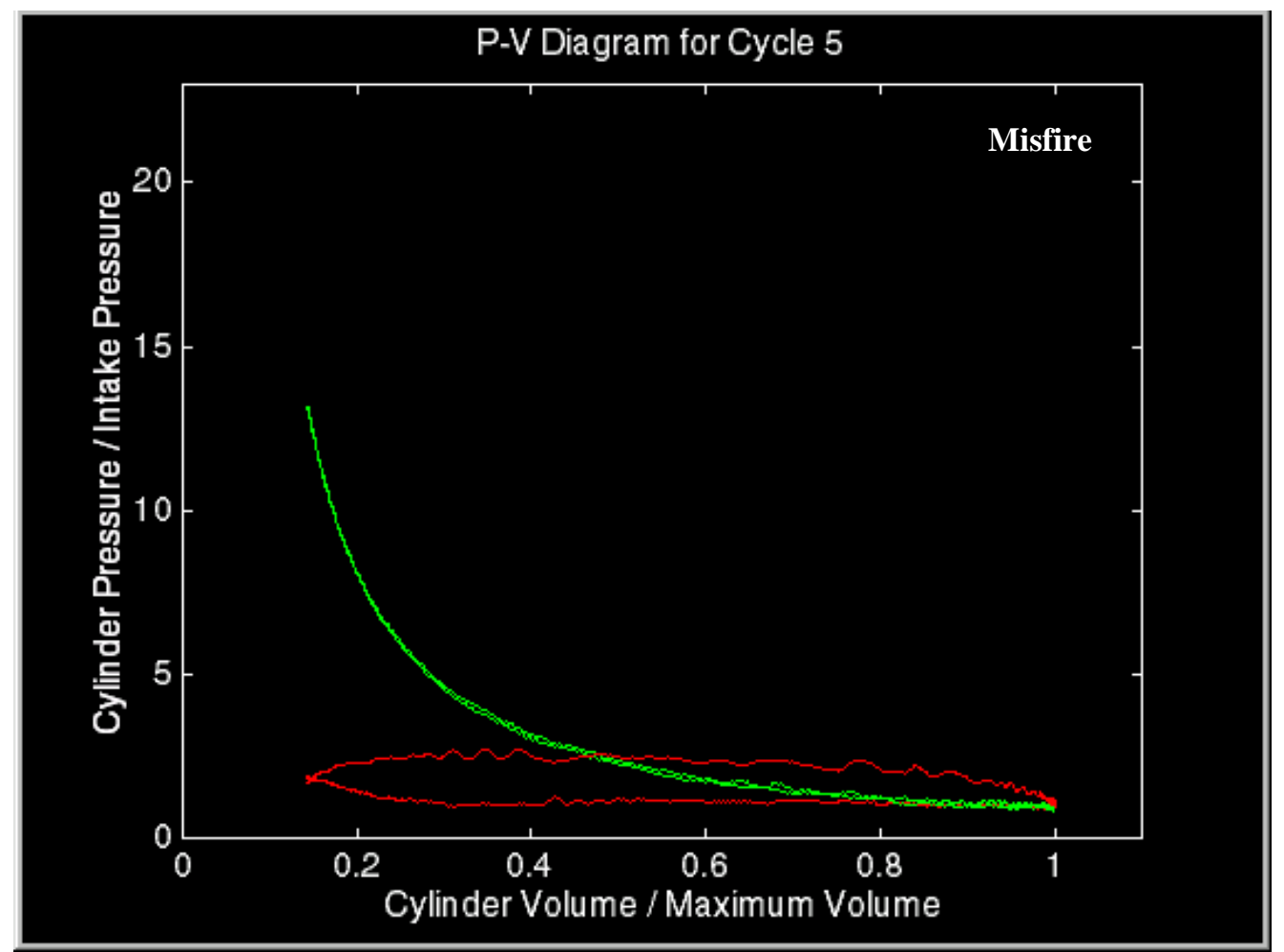

Figure 29 - A P-V diagram for the cylinder using the Champion model RC12YC with a gap of 0.008 " displaying a misfire.

When the performance parameters for the engine were calculated using the data collected from the test engine while the second test plug was used, the results supported the theories formulated from the P-V diagram analysis. These performance parameters are displayed in Table 2. 
Table 2 - Engine performance parameters for the Champion Model RC12YC with a gap of 0.008".

\begin{tabular}{|l|l|l|}
\hline PARAMETER & VALUE & UNIT \\
\hline Average Engine Speed & 2607 & $\mathrm{RPM}$ \\
\hline Fuel Consumption & 19.6 & $\mathrm{~g} / \mathrm{min}$ \\
\hline Average Exhaust Temperature & 680.6 & $\mathrm{Celsius}$ \\
\hline Average Gross Indicated Power & 0.66 & $\mathrm{~kW}$ \\
\hline $\begin{array}{l}\text { Average Gross Indicated Specific Fuel } \\
\text { Consumption }\end{array}$ & 885.99 & $\mathrm{~g} / \mathrm{kW} * \mathrm{~h}$ \\
\hline $\begin{array}{l}\text { Average Gross Indicated Mean Effective } \\
\text { Pressure }\end{array}$ & 127.25 & $\mathrm{kPa}$ \\
\hline $\begin{array}{l}\text { Average Gross Fuel Conversion } \\
\text { Efficiency }\end{array}$ & 9.2 & $\%$ \\
\hline
\end{tabular}

These values show that for approximately the same engine speed and load, the fuel consumption increased while the power produced decreased. This is a result of the misfire cycles together with poor combustion. The presence of misfire is also evident in the average exhaust temperature, which dropped significantly from the value shown in the previous test. This drop was due to the discharge of cool unburned mixture after each misfire cycle.

\subsection{Test Results for Champion Model J19LM with a 0.03 " Gap}

The final test plug was the Champion model J19LM with a gap setting of 0.03". This plug has the same thread size as the model RC12YC, but it is not long enough to extend into the combustion chamber. This increased the clearance volume of the cylinder slightly. However, the difference was insignificant when compared to the total clearance volume and the effects due to this change were deemed negligible. When the data 
collected while the engine was run using this ignition source was compiled, it was clear that this design also resulted in poor combustion. The plot of pressure versus volume for this data set, shown in Figure 30, displays signs of both delayed and incomplete combustion. This is characterized by the gradual pressure increase late in the expansion cycle. The pressure waves that can be seen on the expansion stroke in Figure 30 are most likely due to resonation in the cavity that is created by the plug not extending fully into the combustion chamber.

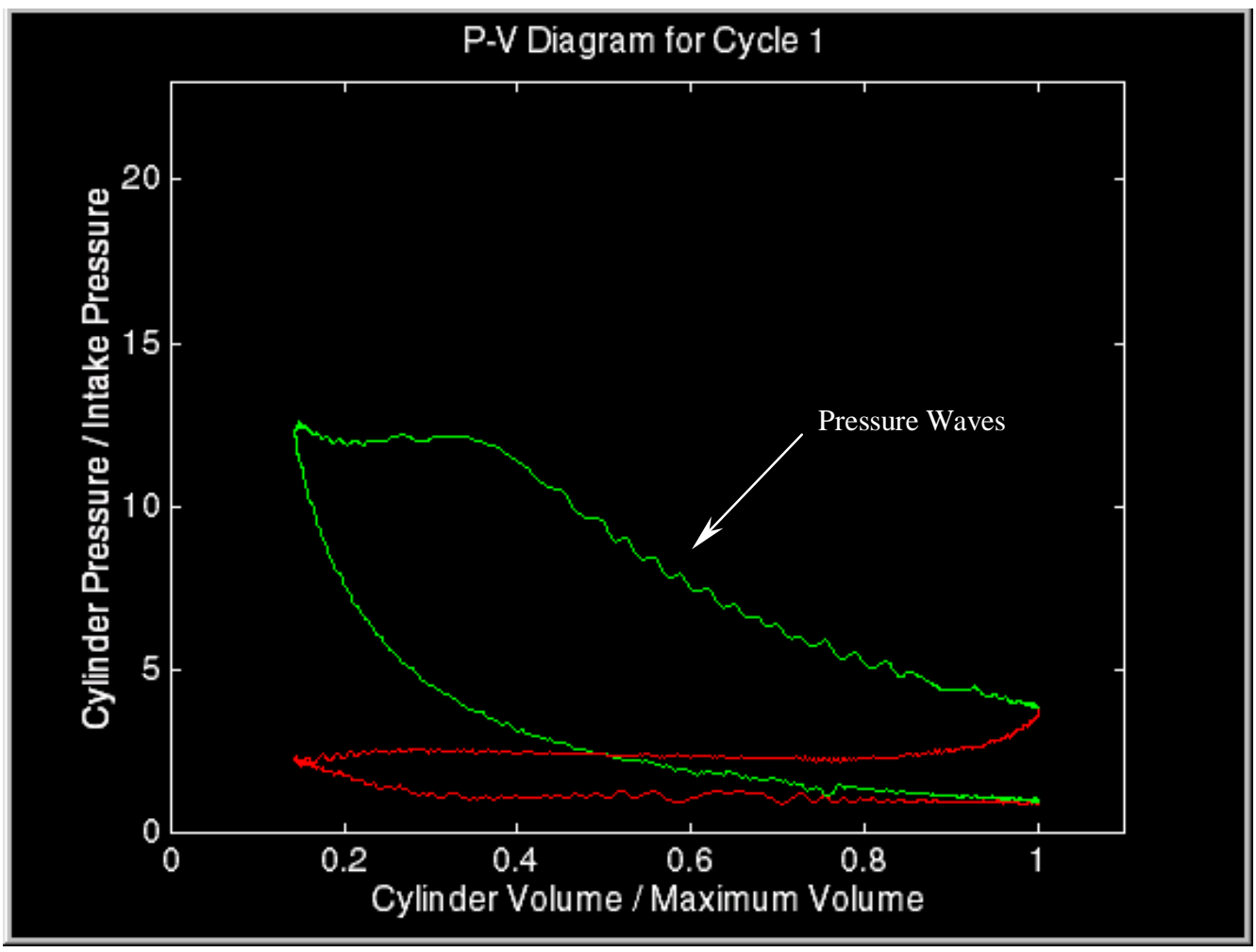

Figure 30 - A P-V diagram for the cylinder using the Champion model J19LM with a gap of $0.03 "$ displaying delayed and incomplete combustion.

The engine operation parameters that were calculated by Engine.m for this ignition source, displayed in Table 3, support the theories stated above. The values show that for approximately the same engine speed and loading, the power output shows a significant decrease from the values calculated for the first two plugs. And this decrease 
occurs with out any evidence of misfire. This shows that the overall combustion resulting from an ignition source of this design is very poor. In addition, the fuel consumption remains approximately equal to that of the first test, which results in the very poor value for fuel conversion efficiency.

Table 3 - Engine performance parameters for the Champion Model J19LM with a gap of 0.03 '.

\begin{tabular}{|l|l|l|}
\hline PARAMETER & VALUE & UNIT \\
\hline Average Engine Speed & 2663 & $\mathrm{RPM}$ \\
\hline Fuel Consumption & 15.4 & $\mathrm{~g} / \mathrm{min}$ \\
\hline Average Exhaust Temperature & 851.1 & Celsius \\
\hline Average Gross Indicated Power & 0.48 & $\mathrm{~kW}$ \\
\hline $\begin{array}{l}\text { Average Gross Indicated Specific Fuel } \\
\text { Consumption }\end{array}$ & 1109 & $\mathrm{~g} / \mathrm{kW} * \mathrm{~h}$ \\
\hline $\begin{array}{l}\text { Average Gross Indicated Mean Effective } \\
\text { Pressure }\end{array}$ & 91 & $\mathrm{kPa}$ \\
\hline $\begin{array}{l}\text { Average Gross Fuel Conversion } \\
\text { Efficiency }\end{array}$ & 8.6 & $\%$ \\
\hline
\end{tabular}

The test results discussed in this chapter show that the test engine is capable of quantifying the performance of an ignition system. The Champion model RC12YC with a gap setting of 0.03 " clearly outperforms the Champion model J19LM with the same gap setting and the Champion model RC12YC with a gap setting of 0.008 ". 


\section{Chapter 8 - Conclusions and Recommendations}

The goal of this work was to develop a test engine onto which an ignition system could be installed and subsequently tested. This system was to allow the analysis of the combustion process, as well as support the determination of values that could be used to quantify the engine performance under the given operating conditions.

This test engine has been developed, and its abilities and accuracy tested. The hardware portion of this system utilizes a 16 horsepower Briggs \& Stratton Vanguard engine along with multiple pressure, position, and temperature transducers. The signals from these transducers are collected and compiled using a variety of software packages including Labview, Excel, and Matlab. It is felt that this engine is capable of accurately meeting the requirements set forth by the goals of this research.

The location of a dynamometer that is suitable for loading the test engine is encouraged. It is felt that cycle-to-cycle variations will decrease dramatically with increased engine load, and this will undoubtedly increase the reliability of the information supplied by the test system. 


\section{List of References}

1. Cummins, Lyle C. Internal Fire, Warrendale, PA, Society of Automotive Engineers, Inc., 1989.

2. Heywood, John B. Internal Combustion Engine Fundamentals, New York, NY, McGraw-Hill Book Company, 1988.

3. Smith, James E. (Morgantown, WV); Craven, Robert M. (Morgantown, WV); VanVoorhies, Kurt L. (Morgantown, WV); Bonazza, Thomas J. (Fairmont, WV); U.S. patent number 5,361,737, November 8, 1994.

4. Stiles, Richard; Thompson, Gregory J. Smith, James E. "Investigation of a Radio Frequency Plasma Igniter for Possible Internal Combustion Engine Use," Society of Automotive Engineers Technical Paper No. 970071, International Congress and Exposition, Detroit, MI, February 24 - 27, 1997.

5. Amann, Charles A. "Classical Combustion Diagnostics for Engine Research," Society of Automotive Engineers Technical Paper No. 850395, International Congress and Exposition, Detroit, MI, February 25 - March 1, 1985.

6. Amann, Charles A. "Cylinder-Pressure Measurement and Its Use in Engine Research," Society of Automotive Engineers Technical Paper No. 852067, International Fuels and Lubricants Meeting and Exposition, Tulsa, OK, October $21-24,1985$.

7. The American Society of Mechanical Engineers, Measurement of Indicated Power, New York, NY, The American Society of Mechanical Engineers, 1970.

8. Alyea, John W. "The Development and Evaluation of an Electronic Indicated Horsepower Meter," Society of Automotive Engineers Technical Paper No. 690181, International Automotive Engineering Congress, Detroit, MI, January $13-17,1969$.

9. Brown, William L. "The Caterpillar imep Meter and Engine Friction," Society of Automotive Engineers Technical Paper No. 730150, International Automotive Engineering Congress, Detroit, MI, January 8 - 12, 1973.

10. Schafer, H.J. Krull, O. and Maege, B. "Thermal Stress on a Piezoelectric Pressure Transducer in the Combustion Chamber of an SI-Engine," Society of Automotive Engineers Technical Paper No. 850375, International Congress and Exposition, Detroit, MI, February 25 - March 1, 1985. 
11. Randolph, Andrew L. "Methods of Processing Cylinder-Pressure Transducer Signals to Maximize Data Accuracy," Society of Automotive Engineers Technical Paper No. 900170, International Congress and Exposition, Detroit, MI, February 26 - March 2, 1990.

12. Omega Engineering, Inc. The Temperature Handbook, Stamford, CT, 1995.

13. Department of Mechanical and Aerospace Engineering, West Virginia University, Morgantown, WV, http://www.cemr.wvu.edu/ englab/, December 1, 1998.

14. Superflow Corporation, Colorado Springs, CO, http://www.superflow.com, December 1, 1998.

15. Briggs \& Stratton Corporation, Milwaukee, WI, http://www.briggsracing.com, December 1, 1998.

16. Briggs \& Stratton Corporation. Operator/Owner Manual Model Series 290400, 294400, 303400 \& 350400, Milwaukee, WI, 1997.

17. PCB Piezotronics, Inc., Depew, NY, http://www.pcb.com, December 1, 1998.

18. PCB Piezotronics, Inc. Pressure Transducer Model 112B11 Operator's Manual, Depew, NY, 1994.

19. Omega Engineering, Inc. The Pressure Strain and Force Handbook, Stamford, CT, 1990.

20. Encoder Products Company, Sandpoint, Idaho, http://www.encoderprod.com, December 1, 1998.

21. National Instruments, Instrumentation Catalogue, Austin, TX, 1998.

22. Labview, Vers. 5.0 (Windows 95), National Instruments, 1998.

23. Excel 97, Vers. 97 (Windows 95), Microsoft, 1996.

24. Matlab, Vers. 4.2c. (Windows 95), The Math Works Inc., 1994.

25. Traver, Michael L. "An Analysis of In-Cylinder Pressure Histories in a Bi-Fuel Engine," Masters Thesis, West Virginia University, Morgantown, WV, 1994.

26. Doebelin, Ernest O. Measurement Systems Application and Design, New York, NY, McGraw-Hill Publishing Company, 1990. 
27. Taylor, Charles F. The Internal Combustion Engine in Theory and Practice, Cambridge, MA, The MIT Press, 1985. 


\section{Appendix A - Intra-Cylinder Engine Data Excel Macro}

Sub engine()

' engine Macro

'Macro recorded 9/3/98 by chambers

'Keyboard Shortcut: Ctrl+e

Application.Run "ATPVBAEN.XLA!Moveavg", ActiveSheet.Range("\$A \$1:\$A $12000 ")$

, ActiveSheet.Range("\$B:\$B"), 5, False, False, False

Range("B1001:B9000").Select

Selection.Cut

Range("D1").Select

ActiveSheet.Paste

Range("B9001:B12000").Select

Selection.Cut

Range("E1").Select

ActiveSheet.Paste

ChDir "C:\MATLAB42\bin"

ActiveWorkbook.SaveAs FileName:="C:IMATLAB42lbinleng.wk1", FileFormat:=xlWK1

, Password:="", CreateBackup:=False

End Sub 


\section{Appendix B - Extra-Cylinder Engine Data Excel Macro}

Sub engine2()

' engine2 Macro

'Macro recorded 9/9/98 by chambers

'Keyboard Shortcut: Ctrl+s

Range("B62002").Select

ActiveCell.FormulaR1C1 = "=AVERAGE(R[-62001]C:R[-2]C)"

Range("C62002").Select

ActiveCell.FormulaR1C1 = "=AVERAGE(R[-62001]C:R[-2]C)"

Range("D62002").Select

ActiveCell.FormulaR1C1 = "=AVERAGE(R[-62001]C:R[-2]C)"

Range("B62002").Select

Selection.Copy

Range("A62002").Select

Selection.PasteSpecial Paste:=xlValues, Operation:=xlNone, SkipBlanks:=

False, Transpose:=False

Range("C62002").Select

Application.CutCopyMode $=$ False

Selection.Copy

Range("A62003").Select

Selection.PasteSpecial Paste:=xlValues, Operation:=xlNone, SkipBlanks:=

False, Transpose:=False

Range("D62002").Select

Application.CutCopyMode $=$ False

Selection.Copy

Range("A62004").Select

Selection.PasteSpecial Paste:=xlValues, Operation:=xlNone, SkipBlanks:=

False, Transpose:=False

Columns("B:B").Select

Application.CutCopyMode $=$ False

Selection.ClearContents

Columns("C:C").Select

Selection.ClearContents

Columns("D:D").Select

Selection.ClearContents

Range("A8001:A15997").Select

Selection.Cut

Range("B1").Select 
ActiveSheet.Paste

Range("A62002:A62004").Select

Selection.Copy

Range("B7998").Select

Selection.PasteSpecial Paste:=xlValues, Operation:=xlNone, SkipBlanks:=

False, Transpose:=False

Application. CutCopyMode $=$ False

ChDir "C:IMATLAB42\BIN"

ActiveWorkbook.SaveAs FileName:="C:IMATLAB42LBINleng2.wk1", FileFormat:=

xlWK1, Password:="", CreateBackup:=False

End Sub 


\section{Appendix C - Engine.m}

To be run on a Matlab platform.

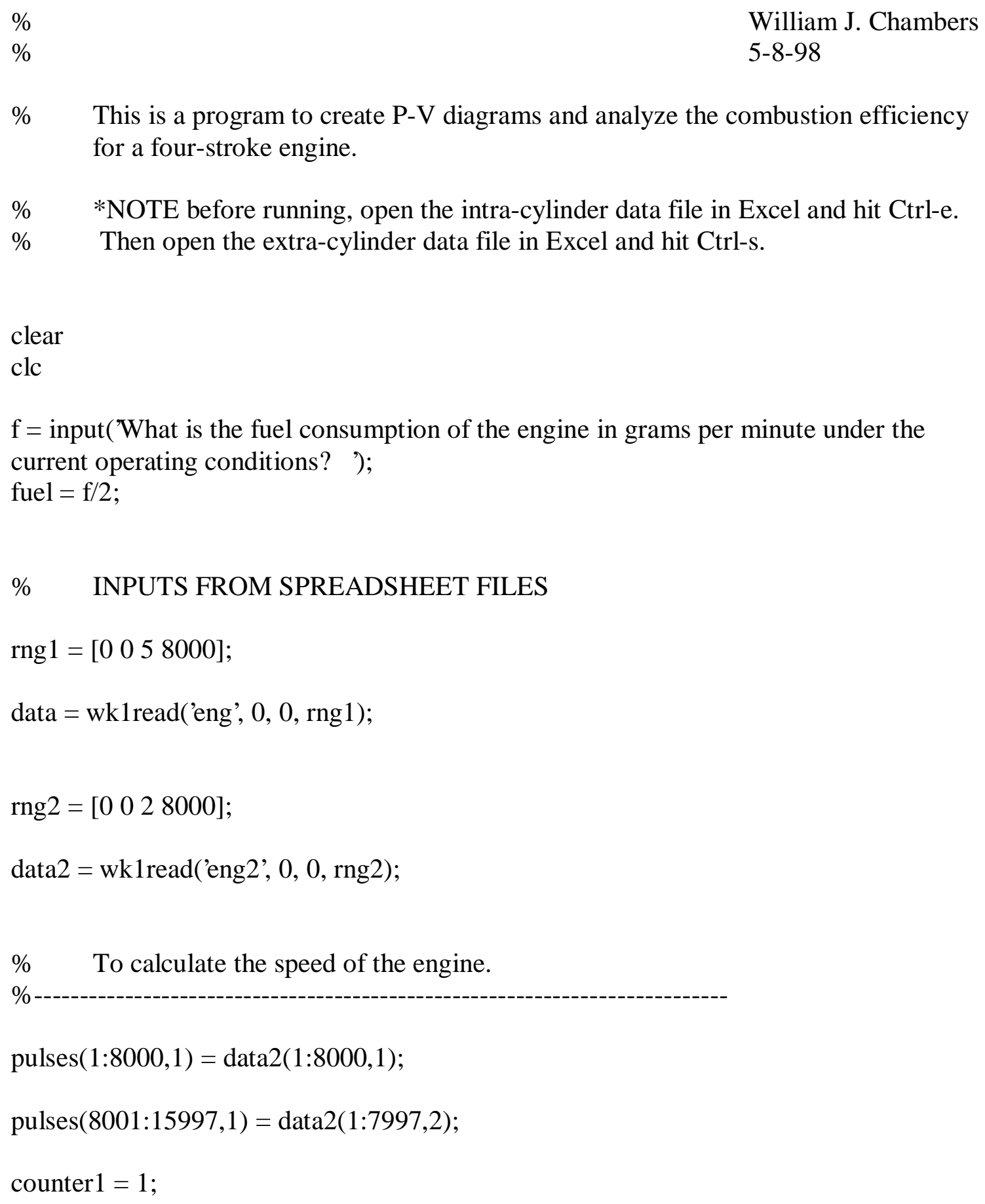




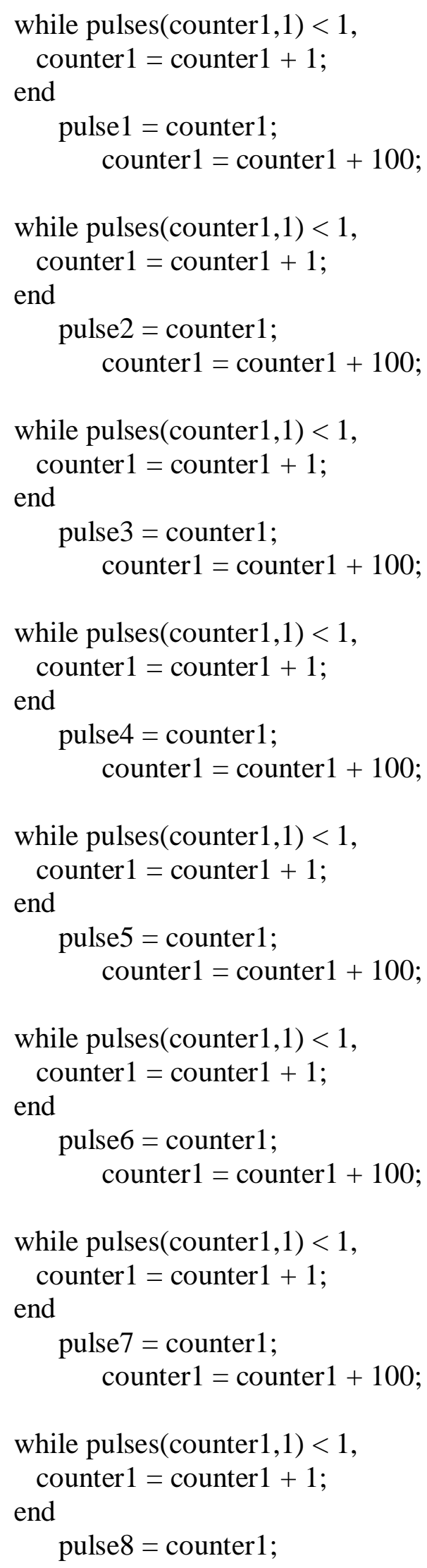




$$
\text { counter } 1=\text { counter } 1+100 \text {; }
$$

while pulses(counter 1,1$)<1$,

$$
\text { counter } 1=\text { counter } 1+1 \text {; }
$$

end

$$
\begin{aligned}
& \text { pulse } 9=\text { counter } 1 \\
& \quad \text { counter } 1=\text { counter } 1+100
\end{aligned}
$$

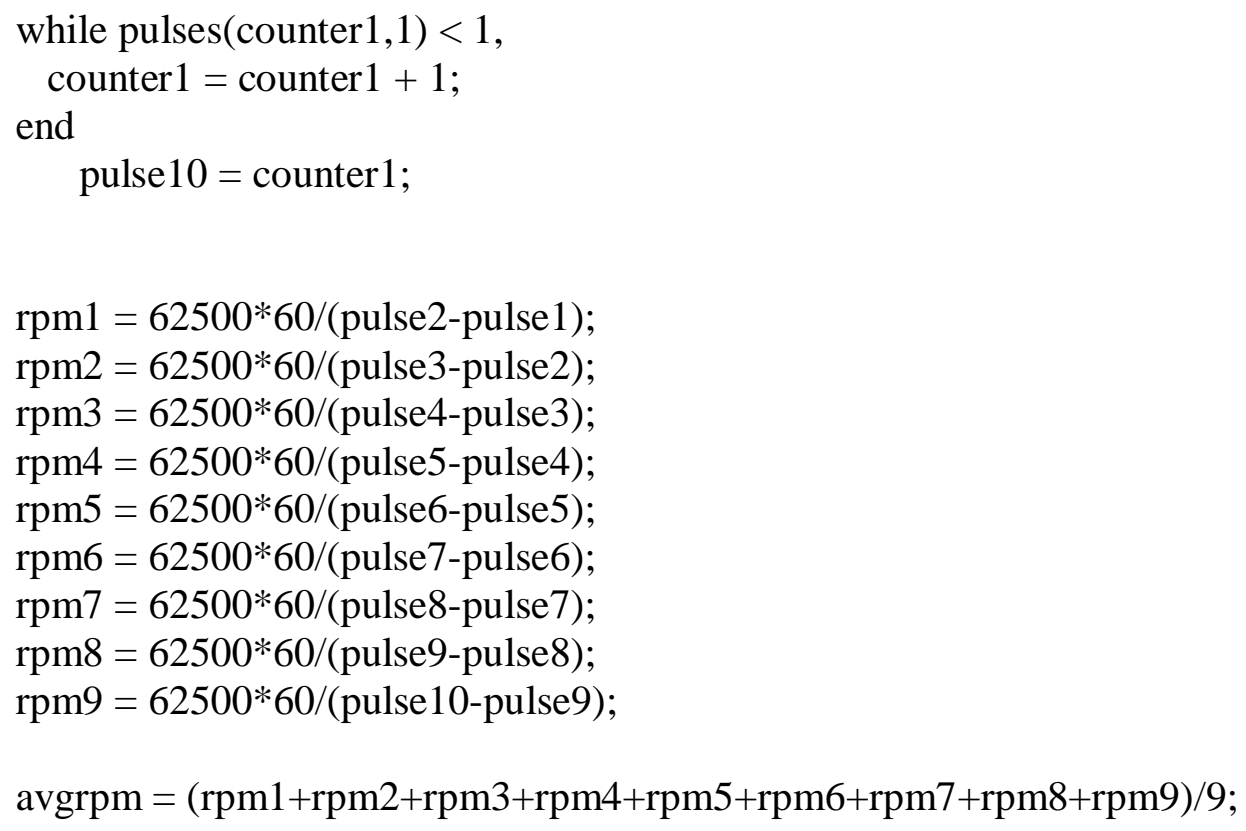

$\%$ The program will now determine the inlet pressure, inlet temperature, and exhaust temperature.

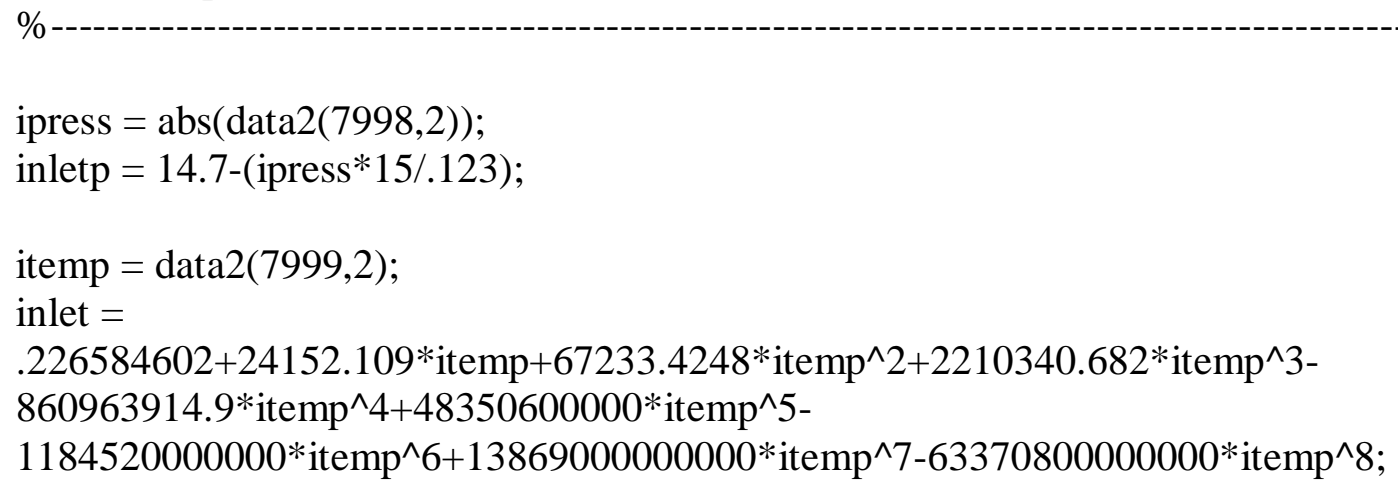




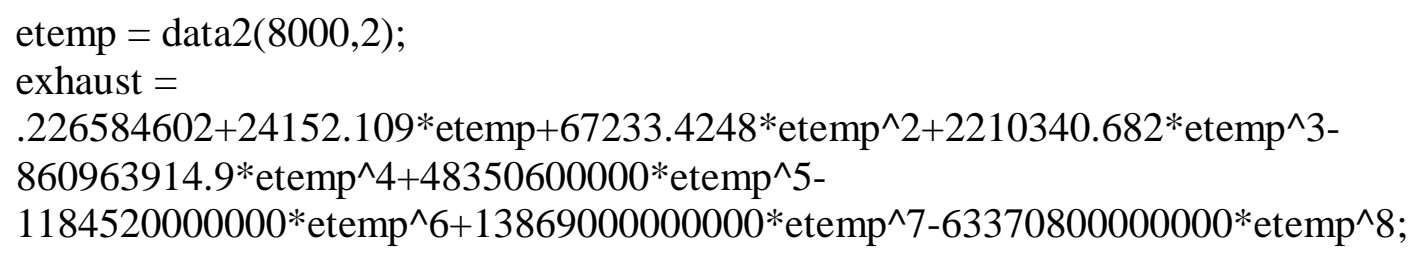

else

$$
\text { TDC1 = 1000; }
$$

end

TDC2 = TDC $1+1000$;

TDC3 = TDC2 + 1000;

TDC4 = TDC $3+1000$

TDC5 $=$ TDC $4+1000$;

TDC6 = TDC5 + 1000;

TDC7 = TDC6 + 1000;

TDC $8=$ TDC7 + 1000;

TDC9 = TDC8 + 1000;

TDC10 = TDC9 + 1000;

TDC11 = TDC10 + 999; 
$\% \quad$ Now, the program will form the P-V diagrams to be plotted.

$\%$ -

$\% \quad$ To convert the pressure data to pressure units

\%--

constantp $1=\mathrm{TDC} 1+250$

constantp $2=$ constantp $1+1$

constantp $3=$ constantp $2+1$

constantp $4=$ constantp $3+1$

constantp5 $=$ constantp $4+1$

zeroingp $1=(\mathrm{p}($ constantp 1$)+\mathrm{p}($ constantp 2$)+\mathrm{p}($ constantp 3$)+\mathrm{p}($ constantp 4$)+$ $\mathrm{p}($ constantp5))/5;

pressure $1=((((\mathrm{p}(\mathrm{TDC} 1: \mathrm{TDC} 3,1))-$ zeroingp1 $) * 1000) / 1.08216)+$ inletp;

constantp6 $=\mathrm{TDC} 3+250$;

constantp7 $=$ constantp $6+1$

constantp8 $=$ constantp $7+1$

constantp9 $=$ constantp $8+1$

constantp $10=$ constantp $9+1$;

zeroingp $2=(\mathrm{p}($ constantp 6$)+\mathrm{p}($ constantp 7$)+\mathrm{p}($ constantp 8$)+\mathrm{p}($ constantp 9$)+$ $\mathrm{p}($ constantp10))/5;

pressure $2=(((\mathrm{p}(\mathrm{TDC} 3: \mathrm{TDC} 5,1))-$ zeroingp2 $) * 1000) / 1.08216)+$ inletp;

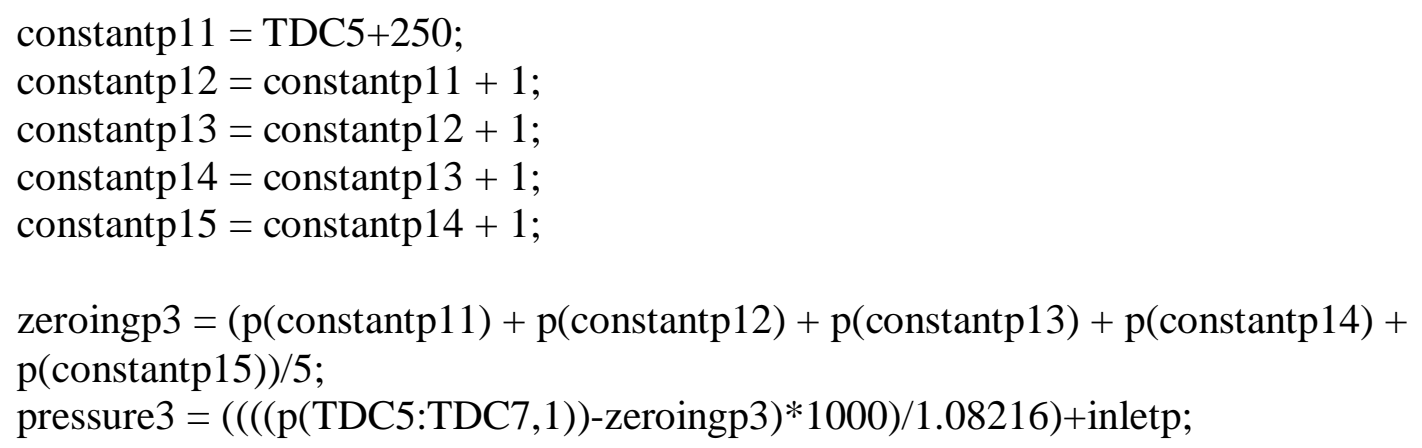




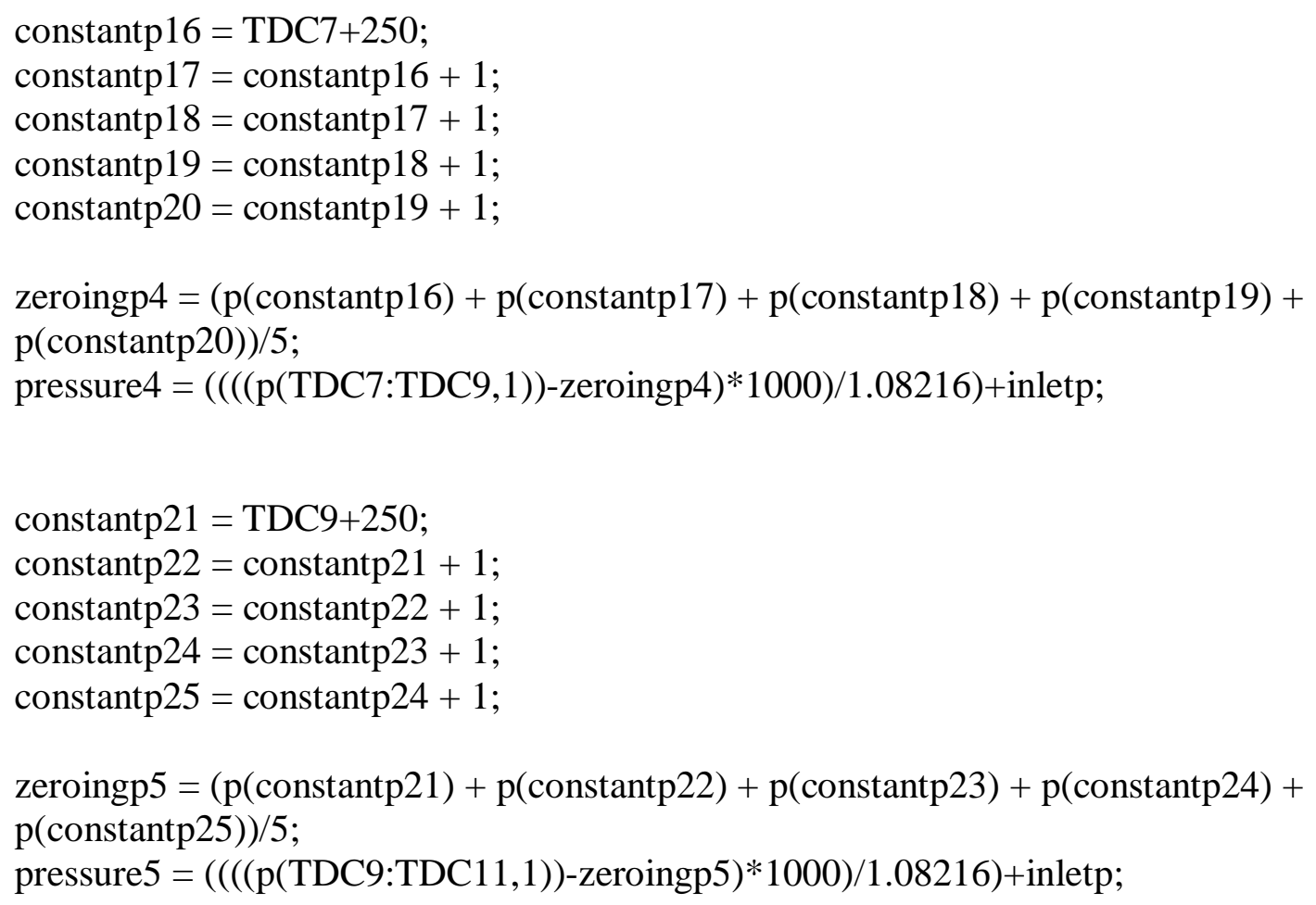

$\% \quad$ To convert the position data to volume units

$\%$

$\% \quad$ First we must form theta arrays from 0 to 4 pi radians in increments of $2 \mathrm{pi} / 1000$.

$\% \quad$ To form the theta array for the first cycle.

array $=[1: 2000] ;$
Theta1 = array $* 2 *$ pi/1000;
$\% \quad$ To form the theta array for the second cycle.

Theta $2=$ array $* 2 *$ pi $/ 1000$; 
$\% \quad$ To form the theta array for the third cycle.

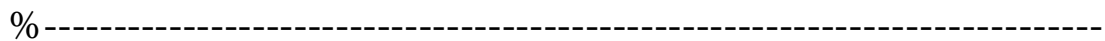

Theta $3=\operatorname{array} * 2 *$ pi $/ 1000$

$\% \quad$ To form the theta array for the fourth cycle.

\%---

Theta $4=$ array $* 2 * \mathrm{pi} / 1000 ;$

$\% \quad$ To form the theta array for the fifth cycle.

\%---

Theta $5=\operatorname{array} * 2 *$ pi $/ 1000$

$\% \quad$ The theta values must now be converted to volume units.

\%-- The

$\% \quad$ Specifying the physical parameters of the test engine:

$\mathrm{r}=1.3$

$1=4.13$

$\mathrm{b}=2.68$;

clearanceV $=2.45$;

$\% \quad$ For the first cycle

$\%$------

$\%$ From Heywood:

$\mathrm{s}=\sin ($ Theta1);

s2 = s.^2; 


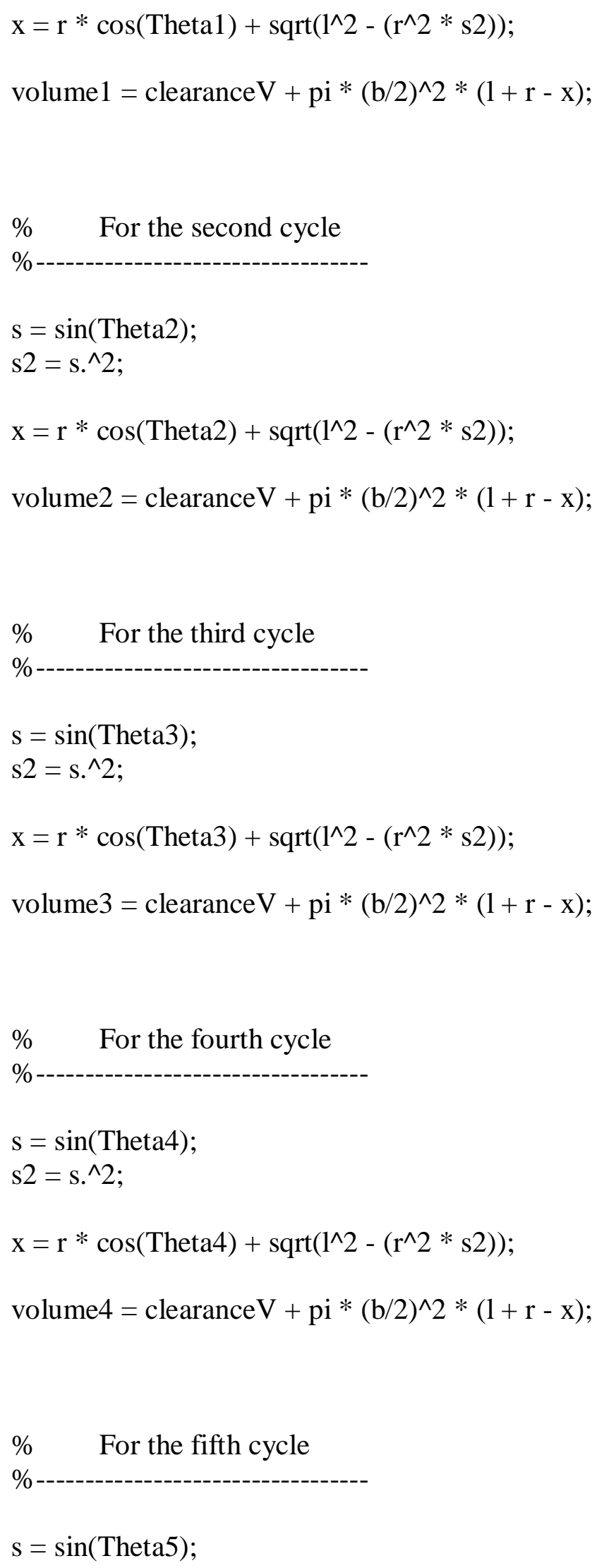


$\mathrm{s} 2=\mathrm{s} .{ }^{\wedge} 2$

$\mathrm{x}=\mathrm{r} * \cos ($ Theta5 $)+\operatorname{sqrt}\left(1^{\wedge} 2-\left(\mathrm{r}^{\wedge} 2 * \mathrm{~s} 2\right)\right)$

volume $5=$ clearanceV + pi $*(\mathrm{~b} / 2)^{\wedge} 2 *(1+\mathrm{r}-\mathrm{x})$

$\% \quad$ To create the arrays for the first cycle's $\mathrm{P}-\mathrm{V}$ diagram

$\%$----------------------------------------------------------------------------------

PRESSURE1a = pressure $1(1: 500,1)$;

PRESSURE1b = pressure1 $(500: 1000,1)$;

PRESSURE1c $=$ pressure $1(1000: 1500,1)$;

PRESSURE1d = pressure1(1500:2000,1);

VOLUME1a = volume1 $(1: 500,1)$

VOLUME1b = volume1 $(500: 1000,1)$;

VOLUME1c = volume1(1000:1500,1);

VOLUME1d = volume1(1500:2000,1);

$\% \quad$ To create the arrays for the second cycle's P-V diagram

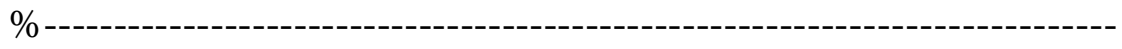

PRESSURE2a = pressure 2(1:500,1);

PRESSURE2b = pressure $2(500: 1000,1)$;

PRESSURE2c $=$ pressure 2(1000:1500,1);

PRESSURE2d = pressure2(1500:2000,1);

VOLUME2a = volume2(1:500,1);

VOLUME2b = volume2(500:1000,1);

VOLUME2c = volume2(1000:1500,1);

VOLUME2d = volume2(1500:2000,1);

$\% \quad$ To create the arrays for the third cycle's P-V diagram

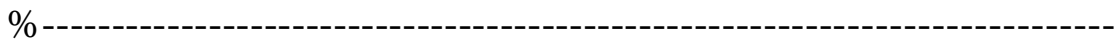


PRESSURE3a $=$ pressure $3(1: 500,1)$;

PRESSURE3b $=$ pressure $3(500: 1000,1)$;

PRESSURE3c $=$ pressure $3(1000: 1500,1)$;

PRESSURE3d $=$ pressure3(1500:2000,1);

VOLUME3a $=$ volume $3(1: 500,1)$

VOLUME3b = volume $3(500: 1000,1)$;

VOLUME3c $=$ volume $3(1000: 1500,1)$

VOLUME3d = volume3(1500:2000,1);

$\% \quad$ To create the arrays for the fourth cycle's P-V diagram

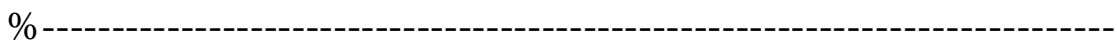

PRESSURE4a $=$ pressure $4(1: 500,1) ;$

PRESSURE4b $=$ pressure $4(500: 1000,1)$;

PRESSURE4c $=$ pressure $4(1000: 1500,1)$;

PRESSURE4d $=$ pressure $4(1500: 2000,1)$;

VOLUME4a $=$ volume $4(1: 500,1)$

VOLUME4b $=$ volume $4(500: 1000,1)$;

VOLUME4c $=$ volume $4(1000: 1500,1)$

VOLUME4d = volume4(1500:2000,1);

$\% \quad$ To create the arrays for the fifth cycle's P-V diagram

$\%$--

PRESSURE5 $\mathrm{a}=\operatorname{pressure} 5(1: 500,1)$

PRESSURE5b $=$ pressure 5(500:1000,1);

PRESSURE5c $=$ pressure $5(1000: 1500,1)$;

PRESSURE5d $=$ pressure5 (1500:2000,1);

VOLUME5a $=$ volume $5(1: 500,1)$

VOLUME5b = volume5 $(500: 1000,1)$;

VOLUME5c $=$ volume5 $(1000: 1500,1)$

VOLUME5d = volume5(1500:2000,1);

$\% \quad$ The program will now calculate the gross and net indicated work, and gross power per cycle.

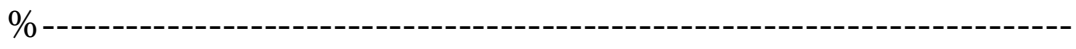




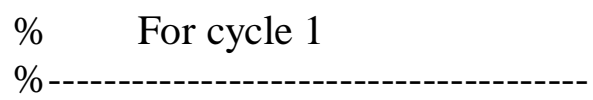

A1a $=$ abs(TRAPZ(PRESSURE1a, VOLUME1a) $)$; $\mathrm{A} 1 \mathrm{~b}=\mathrm{abs}($ TRAPZ(PRESSURE1 $b$, VOLUME1 $)$ ); A1 $\mathrm{c}=\operatorname{abs}($ TRAPZ $($ PRESSURE1 $\mathrm{c}$, VOLUME1c $))$; A1d $=\operatorname{abs}($ TRAPZ (PRESSURE1d,VOLUME1d $)$;

$\mathrm{C} 1$ giw $=(\mathrm{A} 1 \mathrm{c}-\mathrm{A} 1 \mathrm{~b})$

$\mathrm{C} 1 \mathrm{niw}=(\mathrm{A} 1 \mathrm{c}-\mathrm{A} 1 \mathrm{~b})-(\mathrm{A} 1 \mathrm{~d}-\mathrm{A} 1 \mathrm{a}) ;$

hp1 = avgrpm*C1giw/60/12/2/550;

p1metric $=$ hp $1 * .7457$;

$\% \quad$ For cycle 2

\%-----------------------------

A2a $=$ abs(TRAPZ(PRESSURE2a,VOLUME2a)); $\mathrm{A} 2 \mathrm{~b}=\mathrm{abs}($ TRAPZ(PRESSURE2 $\mathrm{b}$, VOLUME2 $\mathrm{b})$ ); $\mathrm{A} 2 \mathrm{c}=\mathrm{abs}($ TRAPZ $($ PRESSURE2 $\mathrm{c}$, VOLUME2c $)) ;$ $\mathrm{A} 2 \mathrm{~d}=\operatorname{abs}($ TRAPZ(PRESSURE2d,VOLUME2d));

$\mathrm{C} 2 \mathrm{giw}=(\mathrm{A} 2 \mathrm{c}-\mathrm{A} 2 \mathrm{~b})$

$\mathrm{C} 2$ niw $=(\mathrm{A} 2 \mathrm{c}-\mathrm{A} 2 \mathrm{~b})-(\mathrm{A} 2 \mathrm{~d}-\mathrm{A} 2 \mathrm{a})$

hp2 $=$ avgrpm $*$ C2giw/60/12/2/550;

p2metric $=$ hp $2 * .7457$;

$\% \quad$ For cycle 3

$\%$---

$\mathrm{A} 3 \mathrm{a}=\mathrm{abs}($ TRAPZ(PRESSURE3a, VOLUME3a $)$ ); $\mathrm{A} 3 \mathrm{~b}=\mathrm{abs}($ TRAPZ(PRESSURE3b,VOLUME3b)); $\mathrm{A} 3 \mathrm{c}=\operatorname{abs}($ TRAPZ $($ PRESSURE3c, VOLUME3c $))$; $\mathrm{A} 3 \mathrm{~d}=\operatorname{abs}($ TRAPZ $($ PRESSURE3d,VOLUME3d $)$;

$\mathrm{C} 3$ giw $=(\mathrm{A} 3 \mathrm{c}-\mathrm{A} 3 \mathrm{~b})$

$\mathrm{C} 3 \mathrm{niw}=(\mathrm{A} 3 \mathrm{c}-\mathrm{A} 3 \mathrm{~b})-(\mathrm{A} 3 \mathrm{~d}-\mathrm{A} 3 \mathrm{a})$ 


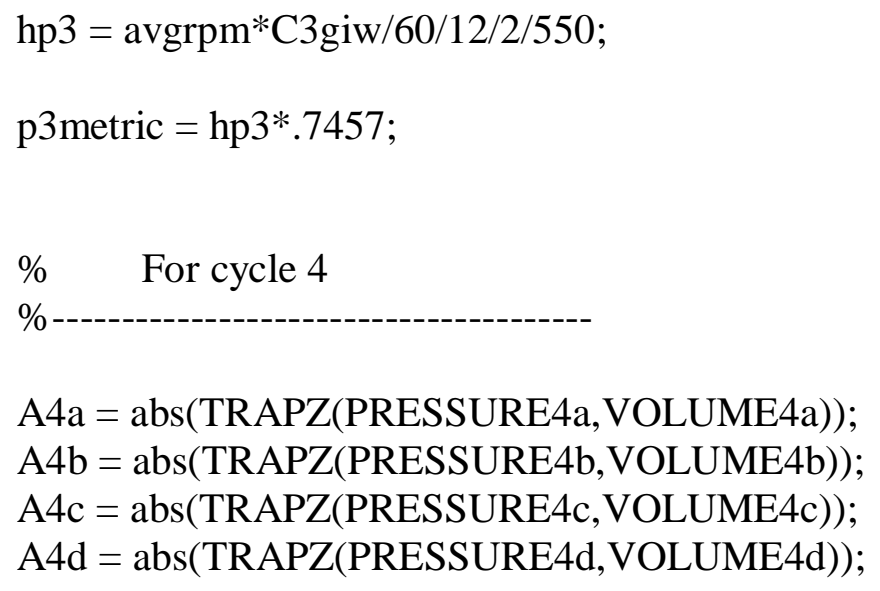

A5a $=$ abs (TRAPZ $($ PRESSURE5a,VOLUME5a $)$; $\mathrm{A} 5 \mathrm{~b}=\mathrm{abs}($ TRAPZ(PRESSURE5b,VOLUME5b) ; A5 $\mathrm{c}=\operatorname{abs}($ TRAPZ $($ PRESSURE5 $\mathrm{c}$, VOLUME5c $)$; $\mathrm{A} 5 \mathrm{~d}=\mathrm{abs}($ TRAPZ(PRESSURE5d,VOLUME5d $)$;

$\mathrm{C} 5$ giw $=(\mathrm{A} 5 \mathrm{c}-\mathrm{A} 5 \mathrm{~b})$

$\mathrm{C} 5 \mathrm{niw}=(\mathrm{A} 5 \mathrm{c}-\mathrm{A} 5 \mathrm{~b})-(\mathrm{A} 5 \mathrm{~d}-\mathrm{A} 5 \mathrm{a})$

hp5 $=$ avgrpm $*$ C5giw/60/12/2/550;

$\mathrm{p} 5$ metric $=\mathrm{hp} 5^{*} .7457$;

avghp $=($ hp1 1 hp2 $2+$ hp $3+h p 4+h p 5) / 5 ;$

$\operatorname{avgpmetric}=\operatorname{avghp} * .7457$; 
$\% \quad$ The program will now calculate the gross isfc.

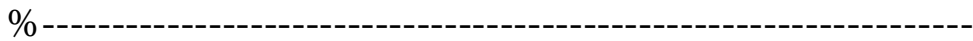

C1isfc $=$ fuel $* 60 / \mathrm{p} 1$ metric;

$\mathrm{C} 2$ isfc $=$ fuel $* 60 /$ p2metric;

$\mathrm{C} 3$ isfc $=$ fuel $* 60 /$ p3metric;

C4isfc $=$ fuel $* 60 /$ p4metric;

C5isfc $=$ fuel $* 60 /$ p 5 metric;

avgisfc $=$ fuel $^{*} 60 /$ avgpmetric;

$\% \quad$ The program will now calculate the gross imep.

\%-------------------------------------------------

Climep $=$ hp $1 * 2 * 396000 / 14.65 /$ avgrpm $* 6.895 ;$

C2imep $=$ hp2 $2 * 396000 / 14.65 /$ avgrpm $* 6.895$;

C3imep $=$ hp $3 * 2 * 396000 / 14.65 /$ avgrpm $* 6.895$;

C4imep $=$ hp4 $* 2 * 396000 / 14.65 /$ avgrpm $* 6.895$;

C5imep $=$ hp5 $2 * 396000 / 14.65 /$ avgrpm*6.895;

avgimep $=(\mathrm{C} 1 \mathrm{imep}+\mathrm{C} 2 \mathrm{imep}+\mathrm{C} 3 \mathrm{ime}+\mathrm{C} 4 \mathrm{ime}+\mathrm{C} 5 \mathrm{imep}) / 5$

$\%$ The program will now calculate the average fuel conversion efficiency.

flow $=$ fuel $^{*} 60$;

C1fce $=3600 /($ flow $* 44 /$ p1 metric $) * 100 ;$

$\mathrm{C} 2 \mathrm{fce}=3600 /($ flow $* 44 / \mathrm{p} 2$ metric $) * 100$;

$\mathrm{C} 3 \mathrm{fce}=3600 /($ flow $* 44 / \mathrm{p} 3$ metric $) * 100$;

$\mathrm{C} 4$ fce $=3600 /$ (flow $* 44 /$ p4metric $) * 100$;

C5fce $=3600 /($ flow $* 44 /$ p5 metric $) * 100$;

avgfce $=3600 /($ flow $* 44 /$ avgpmetric $) * 100$

$\% \quad$ The program will now display the calculated values.

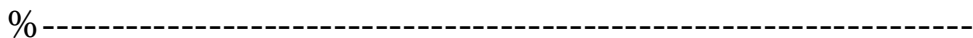

space $=$ ' $;$ 


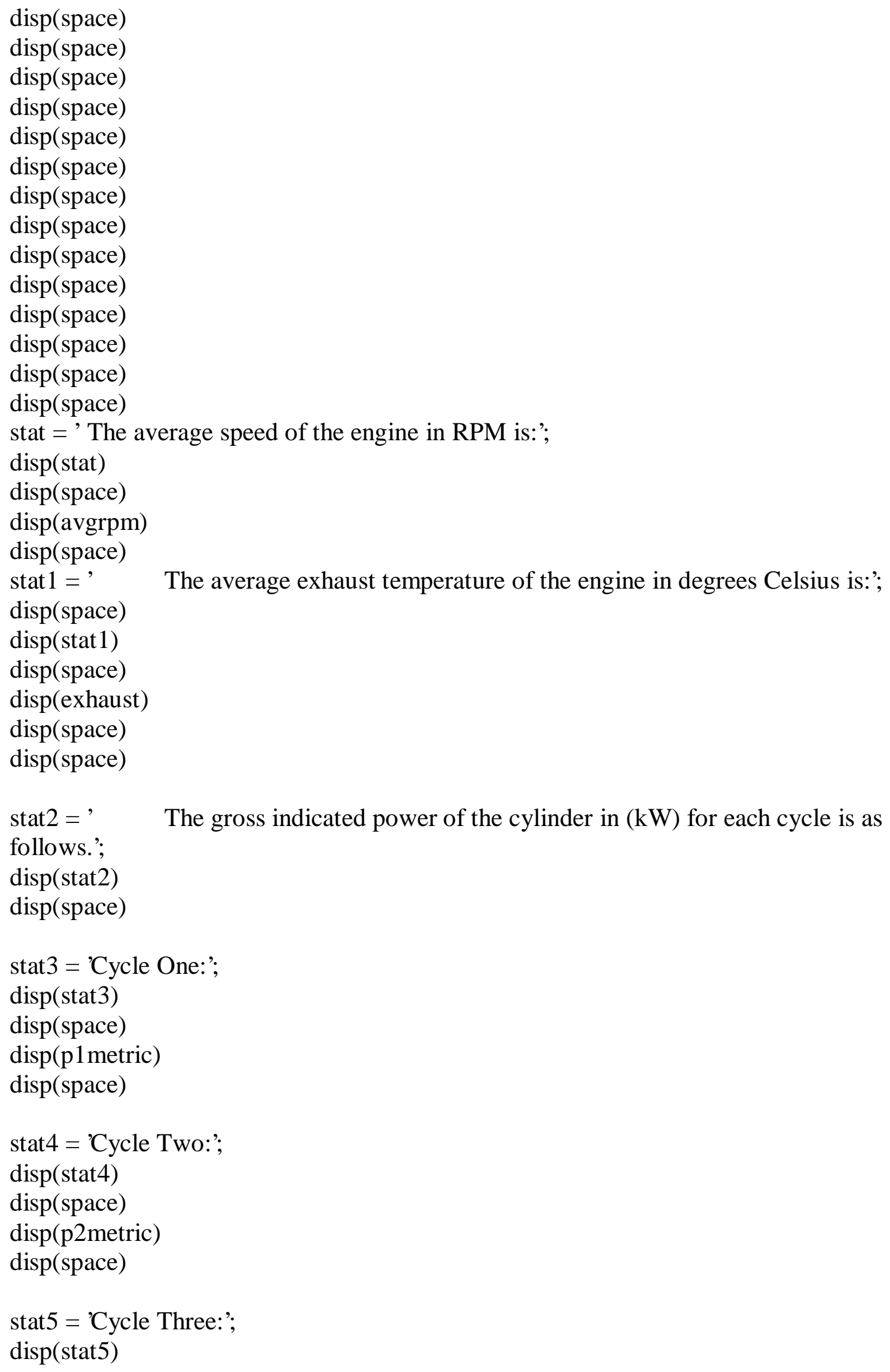




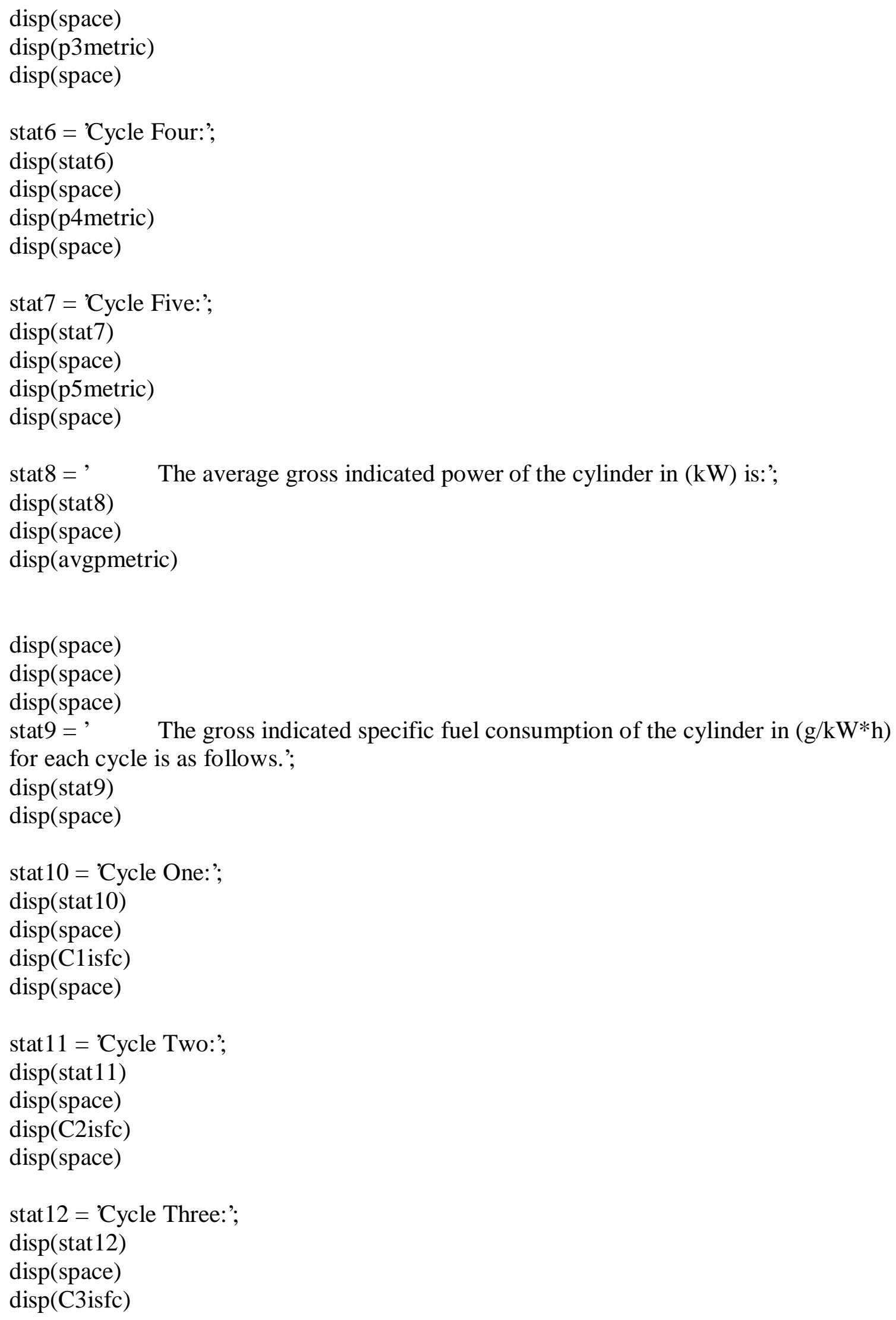




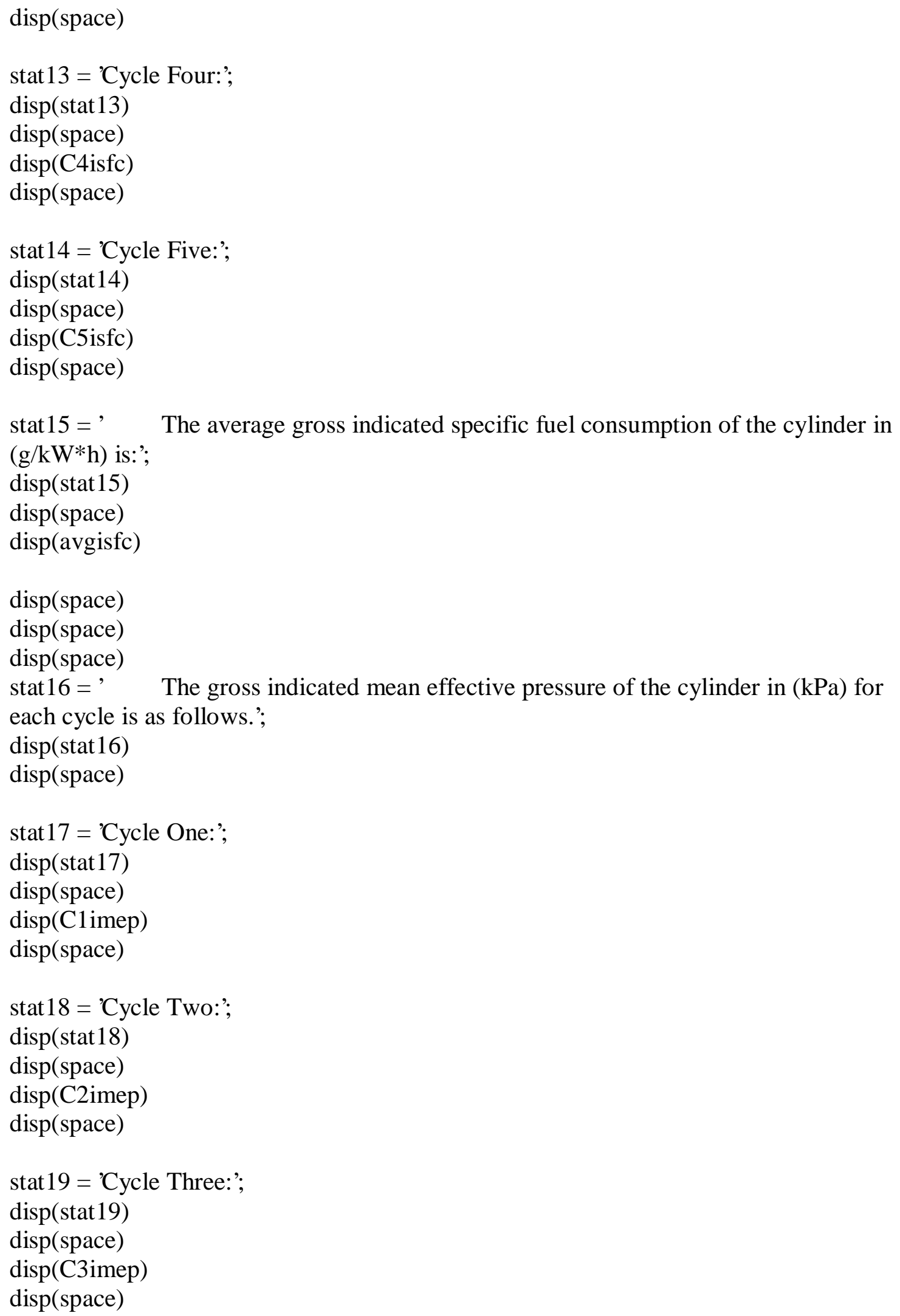




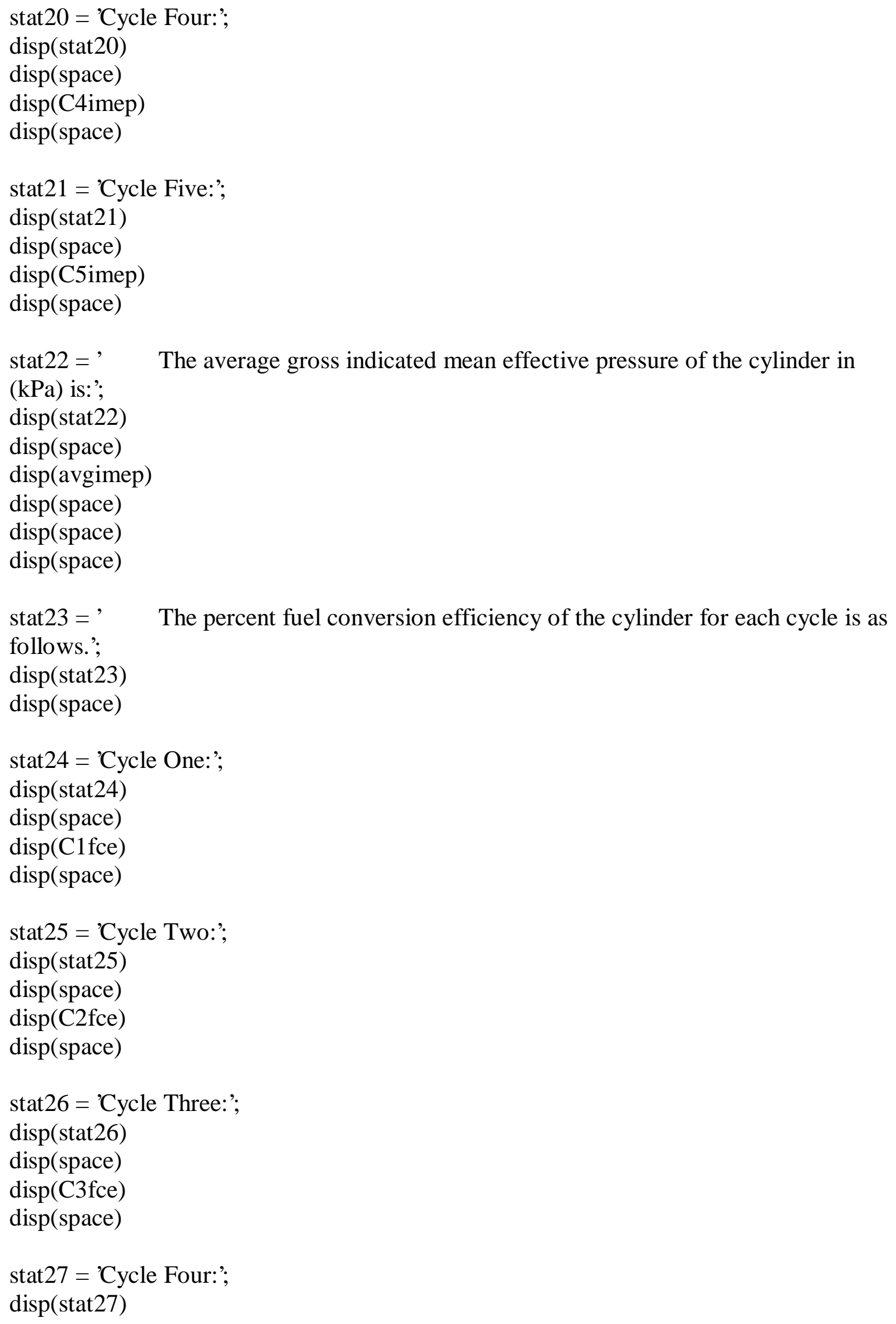




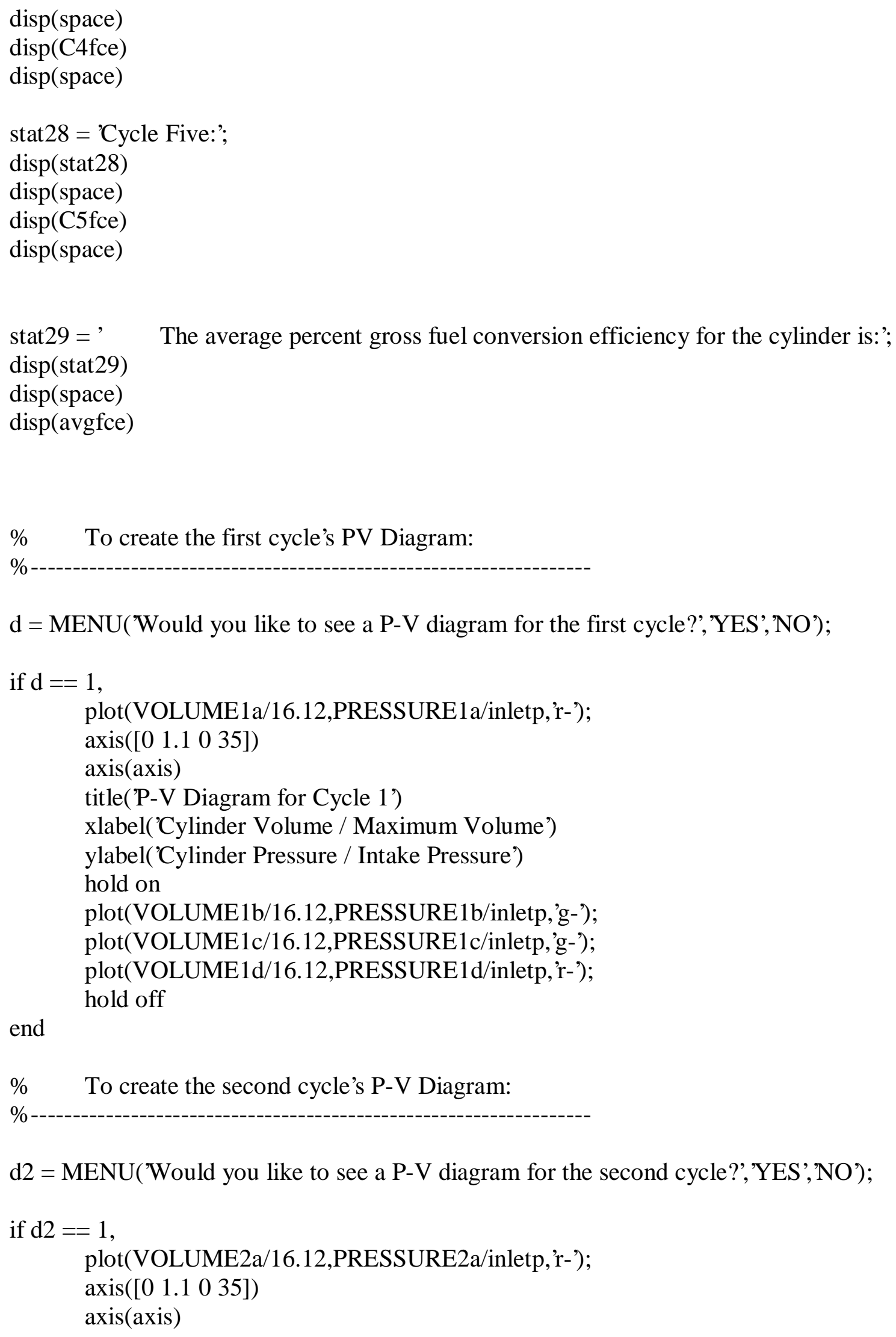


title('P-V Diagram for Cycle 2')

xlabel('Cylinder Volume / Maximum Volume')

ylabel('Cylinder Pressure / Intake Pressure')

hold on

plot(VOLUME2b/16.12,PRESSURE2b/inletp,'g-');

plot(VOLUME2c/16.12,PRESSURE2c/inletp,'g-');

plot(VOLUME2d/16.12,PRESSURE2d/inletp,'r-');

hold off

end

$\%$ To create the third cycle's P-V Diagram:

$\%$

d3 = MENU('Would you like to see a P-V diagram for the third cycle?','YES','NO');

if $\mathrm{d} 3==1$, plot(VOLUME3a/16.12,PRESSURE3a/inletp,'r-');

$\operatorname{axis}\left(\left[\begin{array}{llll}0 & 1.1 & 0 & 35\end{array}\right]\right)$

axis(axis)

title('P-V Diagram for Cycle 3')

xlabel('Cylinder Volume / Maximum Volume')

ylabel('Cylinder Pressure / Intake Pressure')

hold on

plot(VOLUME3b/16.12,PRESSURE3b/inletp,'g-'); plot(VOLUME3c/16.12,PRESSURE3c/inletp,'g-'); plot(VOLUME3d/16.12,PRESSURE3d/inletp,'r-');

hold off

end

$\% \quad$ To create the fourth cycle's P-V Diagram:

\%--------------------------------------------------------------------

d4 = MENU('Would you like to see a P-V diagram for the fourth cycle?','YES','NO');

if $\mathrm{d} 4==1$, plot(VOLUME4a/16.12,PRESSURE4a/inletp,'r-');

axis( $\left.\left(\begin{array}{llll}0 & 1.1 & 0 & 35\end{array}\right]\right)$

axis(axis)

title('P-V Diagram for Cycle 4')

xlabel('Cylinder Volume / Maximum Volume)')

ylabel('Cylinder Pressure / Intake Pressure')

hold on 
$\operatorname{plot}($ VOLUME4b/16.12,PRESSURE4b/inletp,'g-'); plot(VOLUME4c/16.12,PRESSURE4c/inletp,'g-'); $\operatorname{plot}($ VOLUME4d/16.12,PRESSURE4d/inletp,'r-'); hold off

end

$\% \quad$ To create the fifth cycle's P-V Diagram:

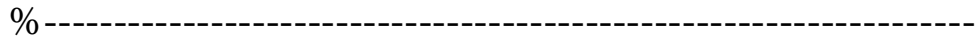

d5 = MENU('Would you like to see a P-V diagram for the fifth cycle?','YES',NO');

if $\mathrm{d} 5==1$, plot(VOLUME5a/16.12,PRESSURE5a/inletp,'r-'); $\operatorname{axis}\left(\left[\begin{array}{llll}0 & 1.1 & 0 & 35\end{array}\right]\right)$ axis(axis) title('P-V Diagram for Cycle 5') xlabel('Cylinder Volume / Maximum Volume') ylabel('Cylinder Pressure / Intake Pressure')

hold on plot(VOLUME5b/16.12,PRESSURE5b/inletp,'g-'); plot(VOLUME5c/16.12,PRESSURE5c/inletp,'g-'); plot(VOLUME5d/16.12,PRESSURE5d/inletp,'r-'); hold off

end 


\section{Appendix D - Output of Engine.m for the Champion Model RC12YC Sparkplug with the Recommended Gap of .03"}

What is the fuel consumption of the engine in grams per minute under the current operating conditions? 15.05

The average speed of the engine in RPM is:

$2.7904 e+003$

The average exhaust temperature of the engine in degrees Celsius is:

806.7166

The gross indicated power of the cylinder in $(\mathrm{kW})$ for each cycle is as follows.

Cycle One:

0.7234

Cycle Two:

0.8198

Cycle Three: 
0.7287

Cycle Four:

0.7681

Cycle Five:

0.9261

The average gross indicated power of the cylinder in $(\mathrm{kW})$ is:

0.7932

The gross indicated specific fuel consumption of the cylinder in $(\mathrm{g} / \mathrm{kW}$ *h) for each cycle is as follows.

Cycle One:

624.1563

Cycle Two:

550.7438

Cycle Three:

619.6110

Cycle Four:

587.7845

Cycle Five: 
The average gross indicated specific fuel consumption of the cylinder in $(\mathrm{g} / \mathrm{kW} * \mathrm{~h})$ is: 573.9638

The gross indicated mean effective pressure of the cylinder in $(\mathrm{kPa})$ for each cycle is as follows.

Cycle One:

129.5848

Cycle Two:

146.8581

Cycle Three:

130.5354

Cycle Four:

137.6034

Cycle Five:

165.9022

The average gross indicated mean effective pressure of the cylinder in $(\mathrm{kPa})$ is: 
The percent gross fuel conversion efficiency of the cylinder for each cycle is as follows.

Cycle One:

13.1086

Cycle Two:

14.8559

Cycle Three:

13.2048

Cycle Four:

13.9198

Cycle Five:

16.7824

The average percent gross fuel conversion efficiency for the cylinder is:

14.3743 


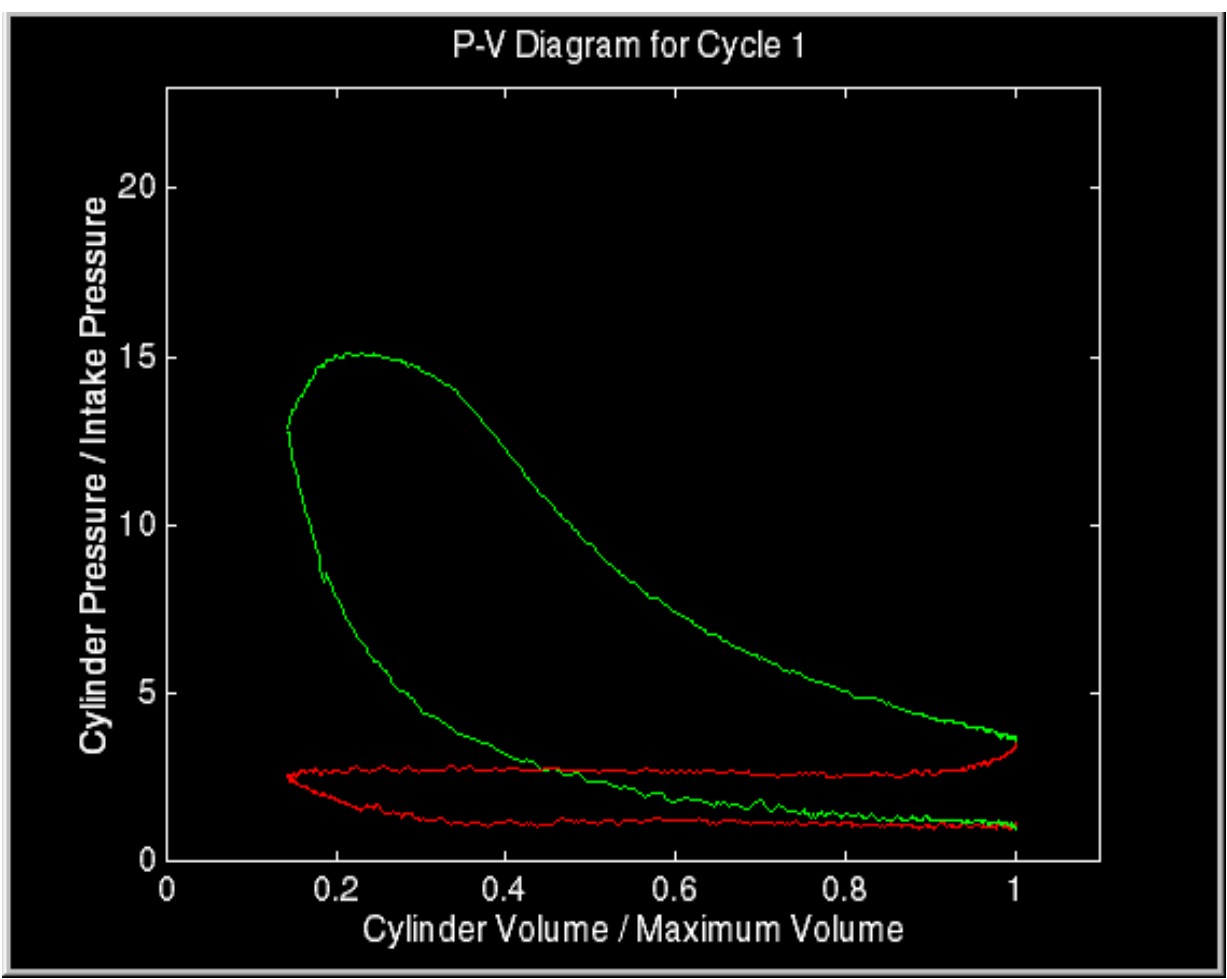

Figure D 1 - Pressure versus volume diagram for cycle one using the Champion model RC12YC sparkplug with the recommended gap of 0.03 "

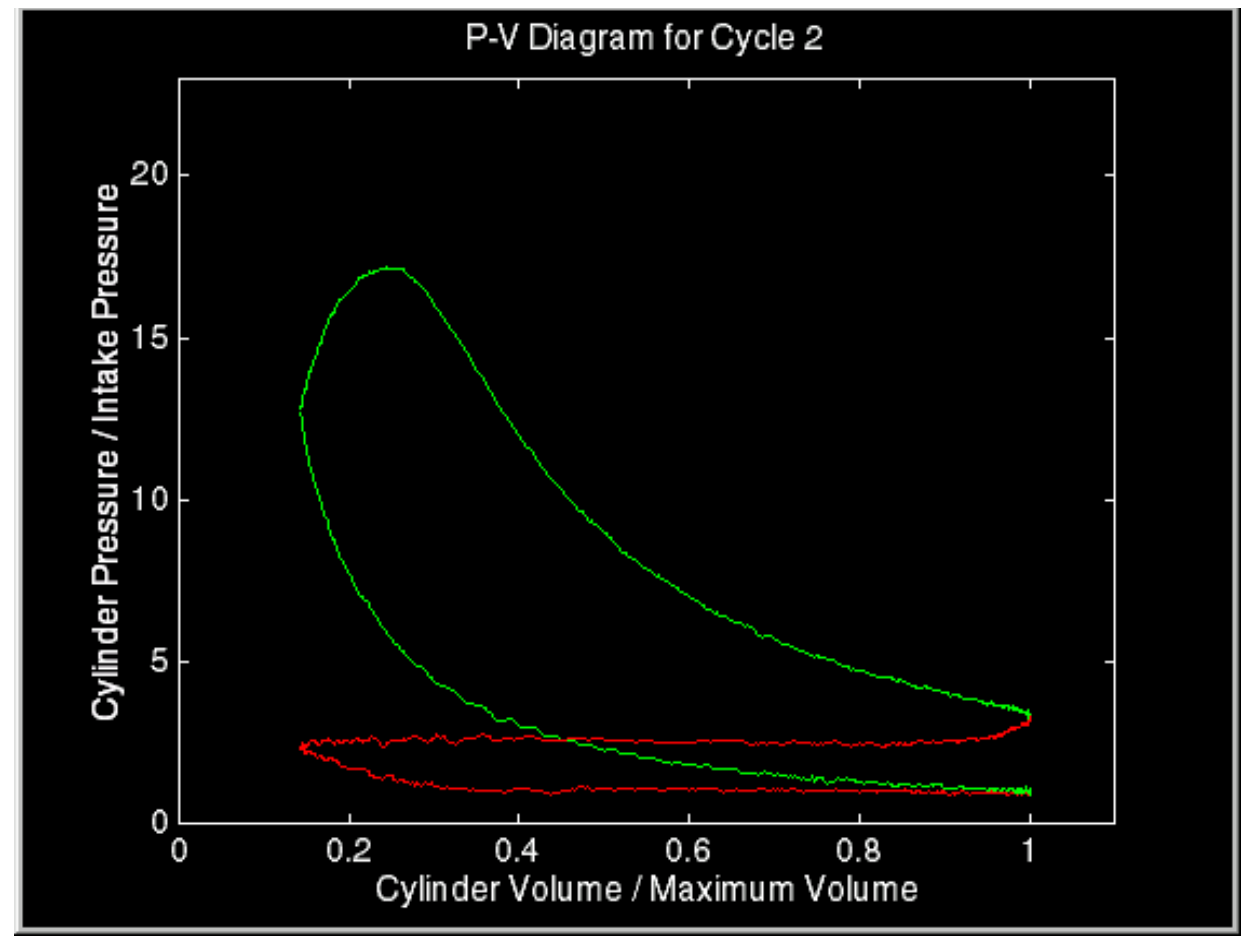

Figure D 2 - Pressure versus volume diagram for cycle two using the Champion model RC12YC sparkplug with the recommended gap of 0.03 "' 


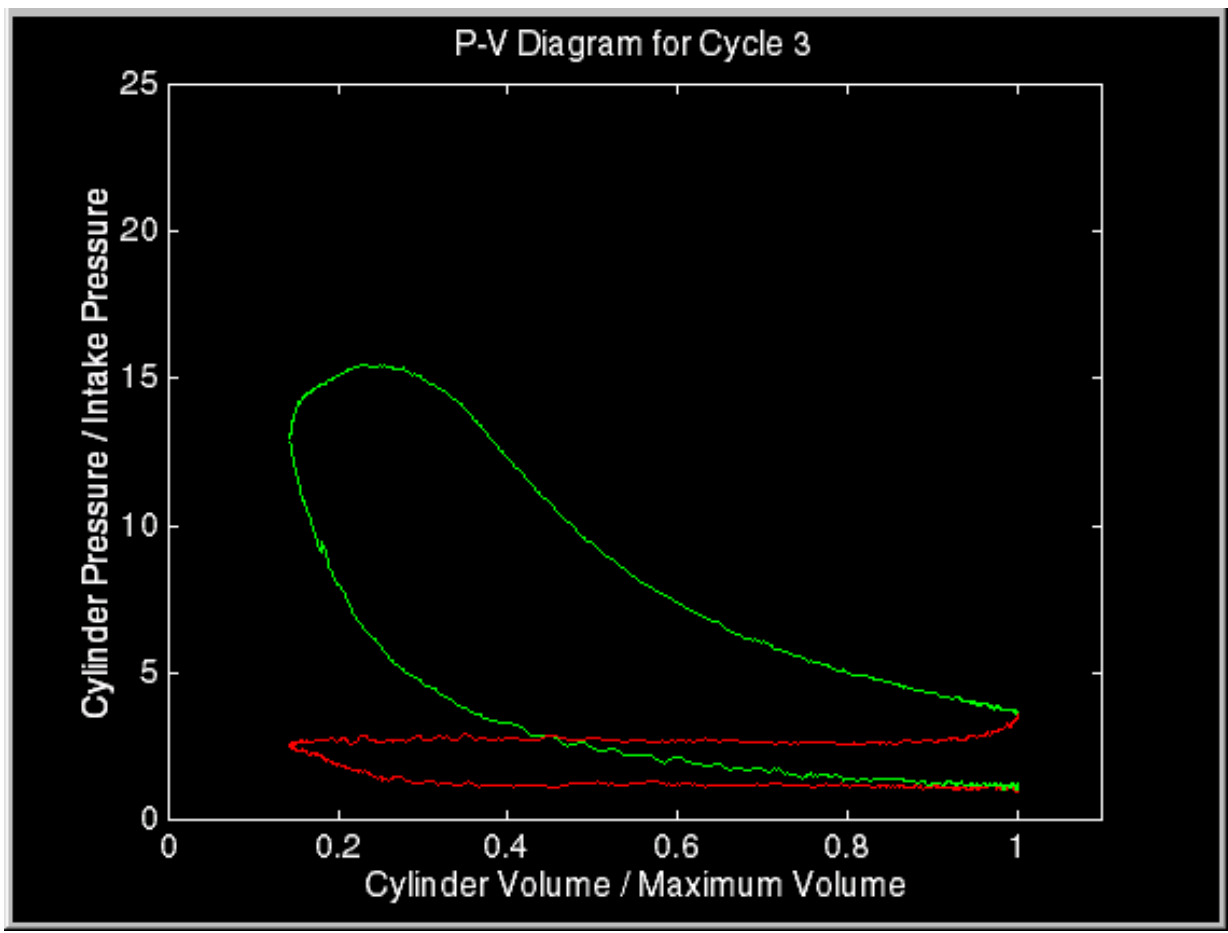

Figure D 3 - Pressure versus volume diagram for cycle three using the Champion model RC12YC sparkplug with the recommended gap of 0.03 "'

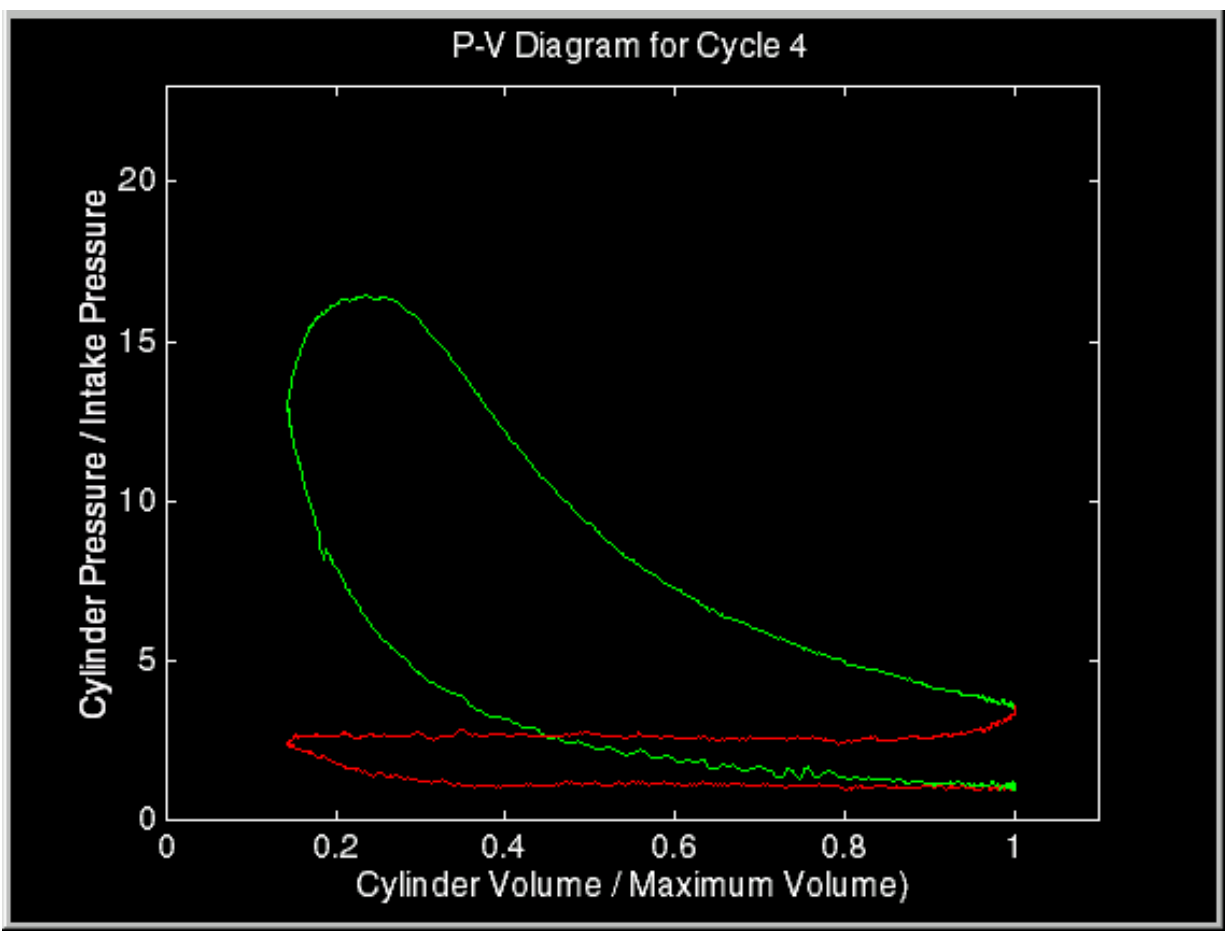

Figure D 4 - Pressure versus volume diagram for cycle four using the Champion model RC12YC sparkplug with the recommended gap of 0.03 "' 


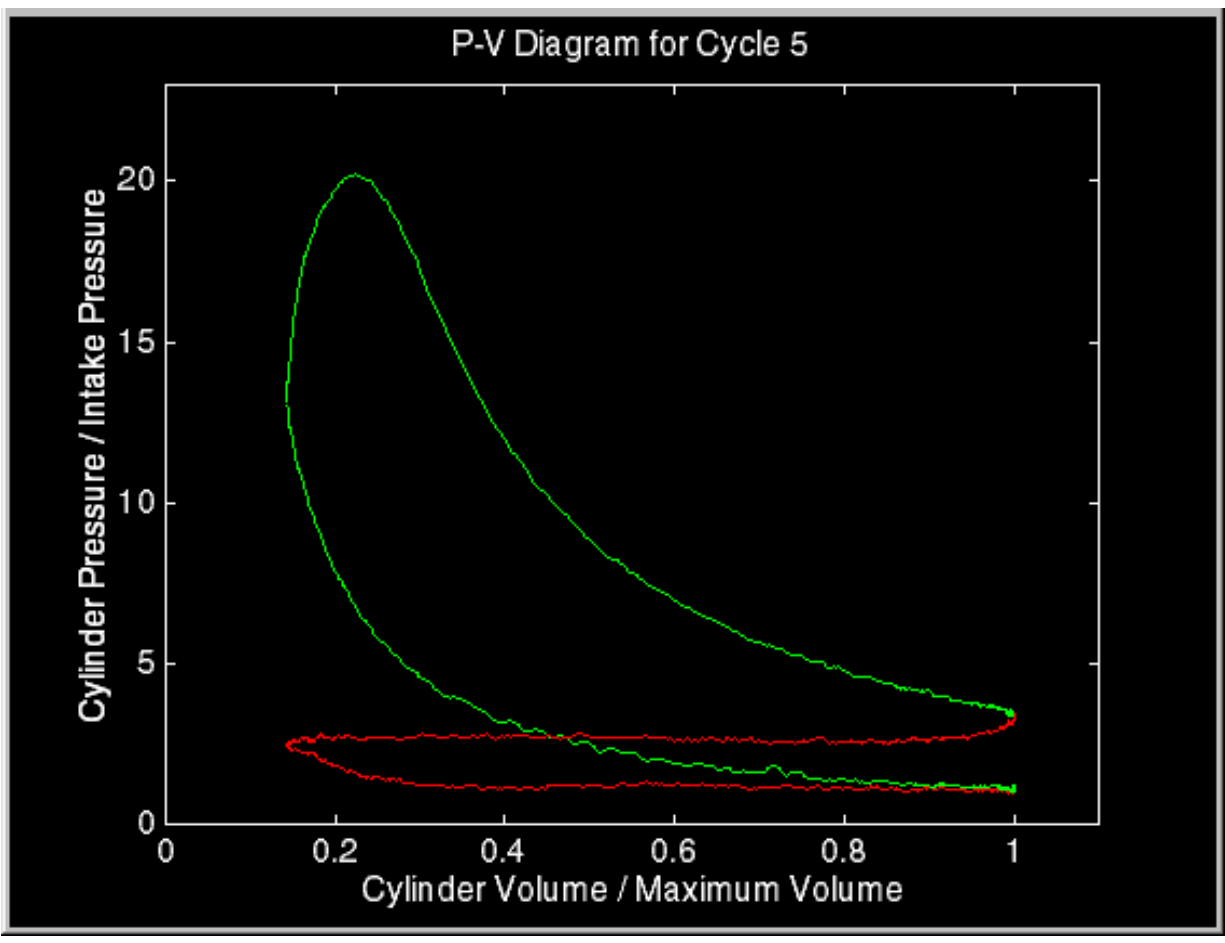

Figure D 5 - Pressure versus volume diagram for cycle five using the Champion model RC12YC sparkplug with the recommended gap of 0.03 ' 


\section{Appendix E - Output of Engine.m for the Champion Model RC12YC Sparkplug with a Gap of .008”}

What is the fuel consumption of the engine in grams per minute under the current operating conditions? 19.6

The average speed of the engine in RPM is:

$2.6070 \mathrm{e}+003$

The average exhaust temperature of the engine in degrees Celsius is:

680.5703

The gross indicated power of the cylinder in $(\mathrm{kW})$ for each cycle is as follows.

Cycle One:

1.1011

Cycle Two:

1.2186

Cycle Three: 
1.1338

Cycle Four:

$-0.0974$

Cycle Five:

$-0.0378$

The average gross indicated power of the cylinder in $(\mathrm{kW})$ is:

0.6637

The gross indicated specific fuel consumption of the cylinder in $(\mathrm{g} / \mathrm{kW} * \mathrm{~h})$ for each cycle is as follows.

Cycle One:

534.0048

Cycle Two:

482.5266

Cycle Three:

518.6245

Cycle Four:

$-6.0369 e+003$

Cycle Five: 
The average gross indicated specific fuel consumption of the cylinder in $\left(\mathrm{g} / \mathrm{kW}^{*} \mathrm{~h}\right)$ is: 885.9916

The gross indicated mean effective pressure of the cylinder in $(\mathrm{kPa})$ for each cycle is as follows.

Cycle One:

211.1287

Cycle Two:

233.6528

Cycle Three:

217.3899

Cycle Four:

$-18.6757$

Cycle Five:

$-7.2384$

The average gross indicated mean effective pressure of the cylinder in $(\mathrm{kPa})$ is: 
The percent fuel conversion efficiency of the cylinder for each cycle is as follows.

Cycle One:

15.3216

Cycle Two:

16.9562

Cycle Three:

15.7760

Cycle Four:

$-1.3553$

Cycle Five:

$-0.5253$

The average percent gross fuel conversion efficiency for the cylinder is:

9.2346 


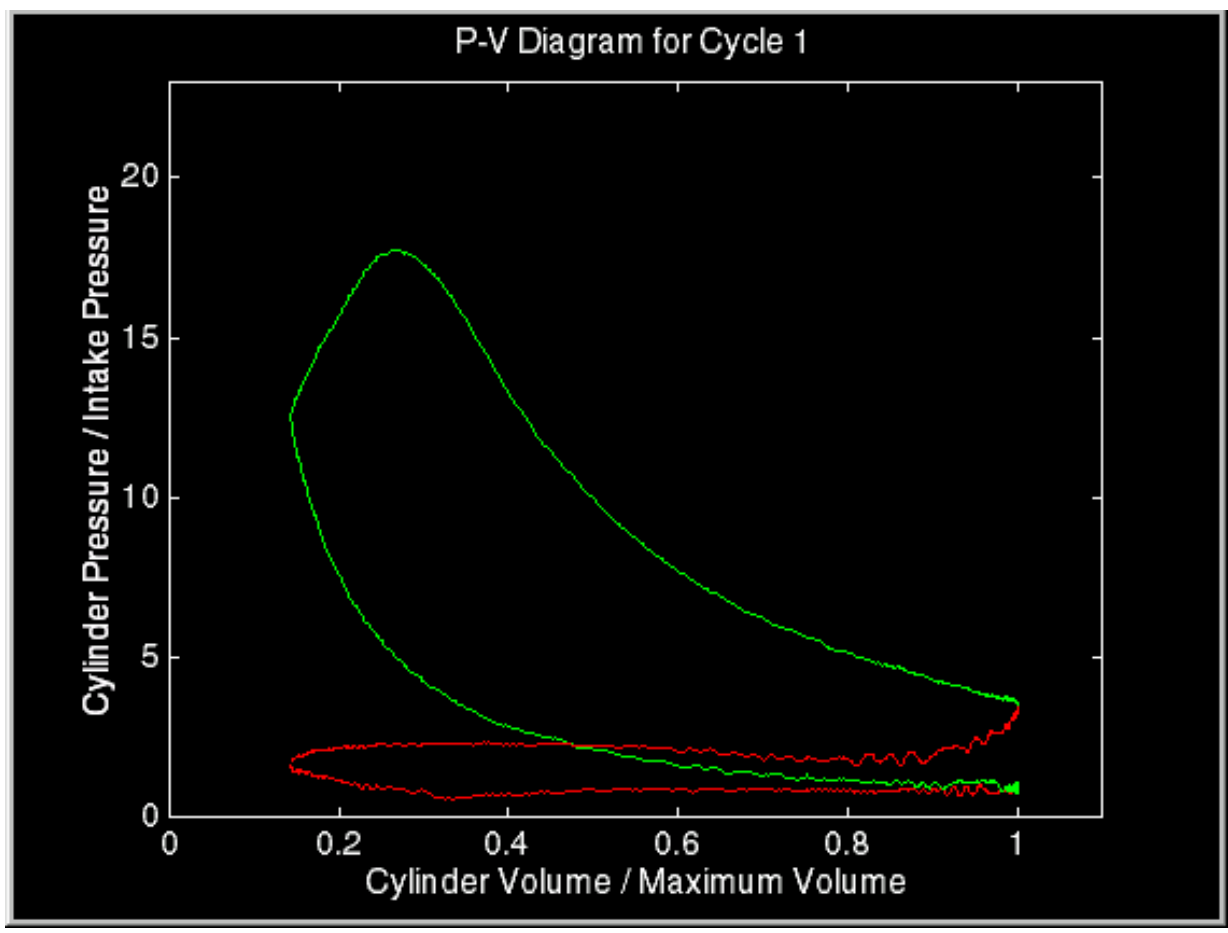

Figure E 1 - Pressure versus volume diagram for cycle one using the Champion model RC12YC sparkplug with a gap of 0.008 "

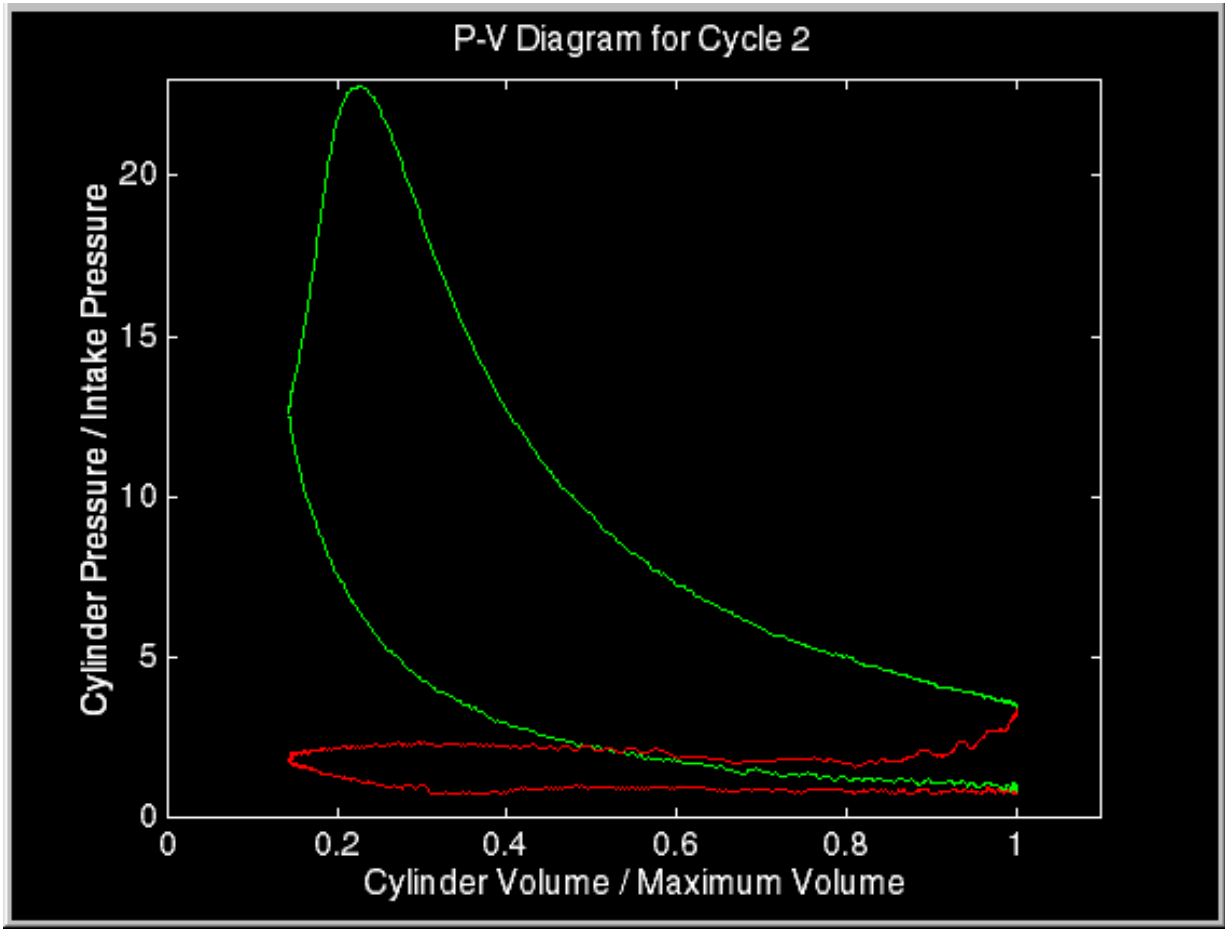

Figure E 2 - Pressure versus volume diagram for cycle two using the Champion model RC12YC sparkplug with a gap of 0.008 " 


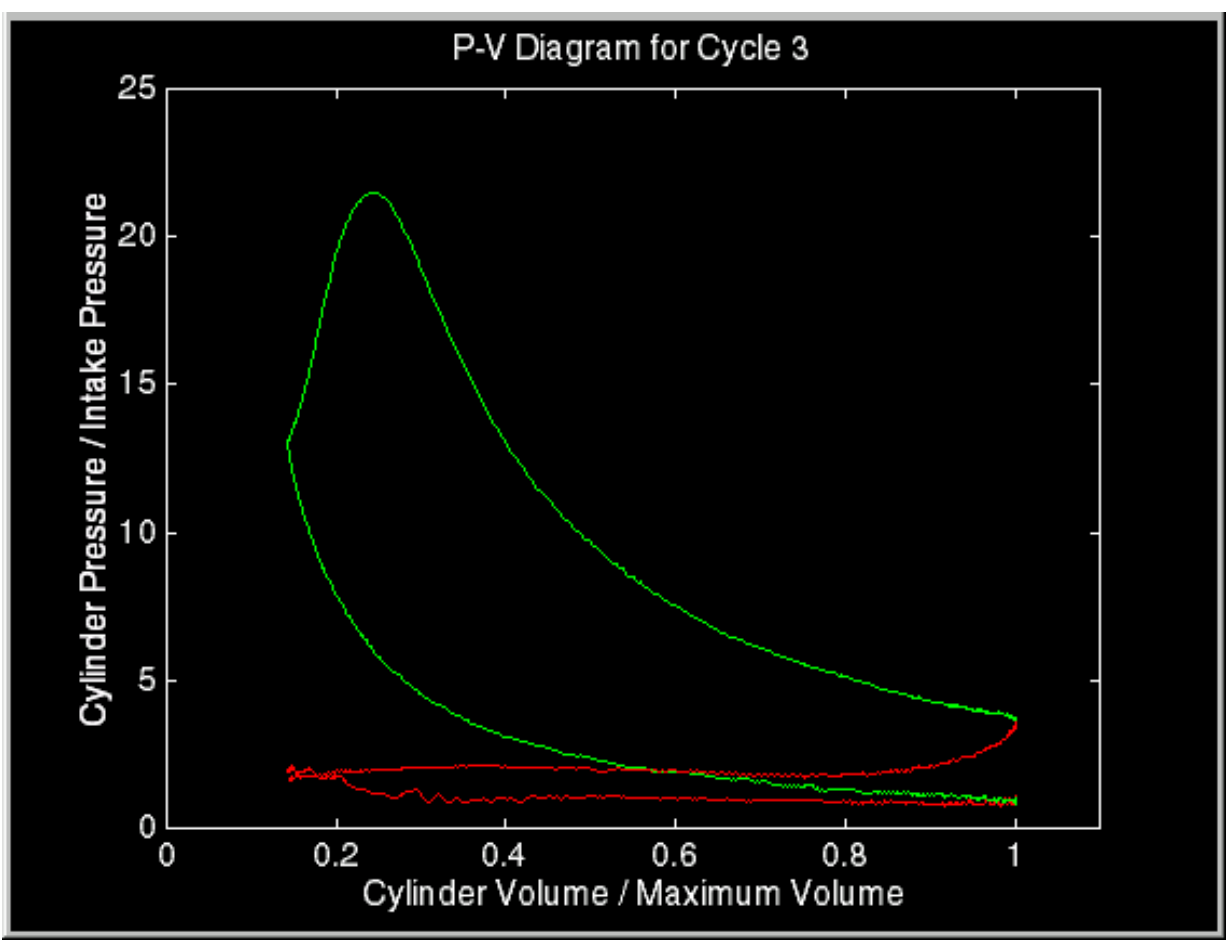

Figure E 3 - Pressure versus volume diagram for cycle three using the Champion model RC12YC sparkplug with a gap of 0.008 "

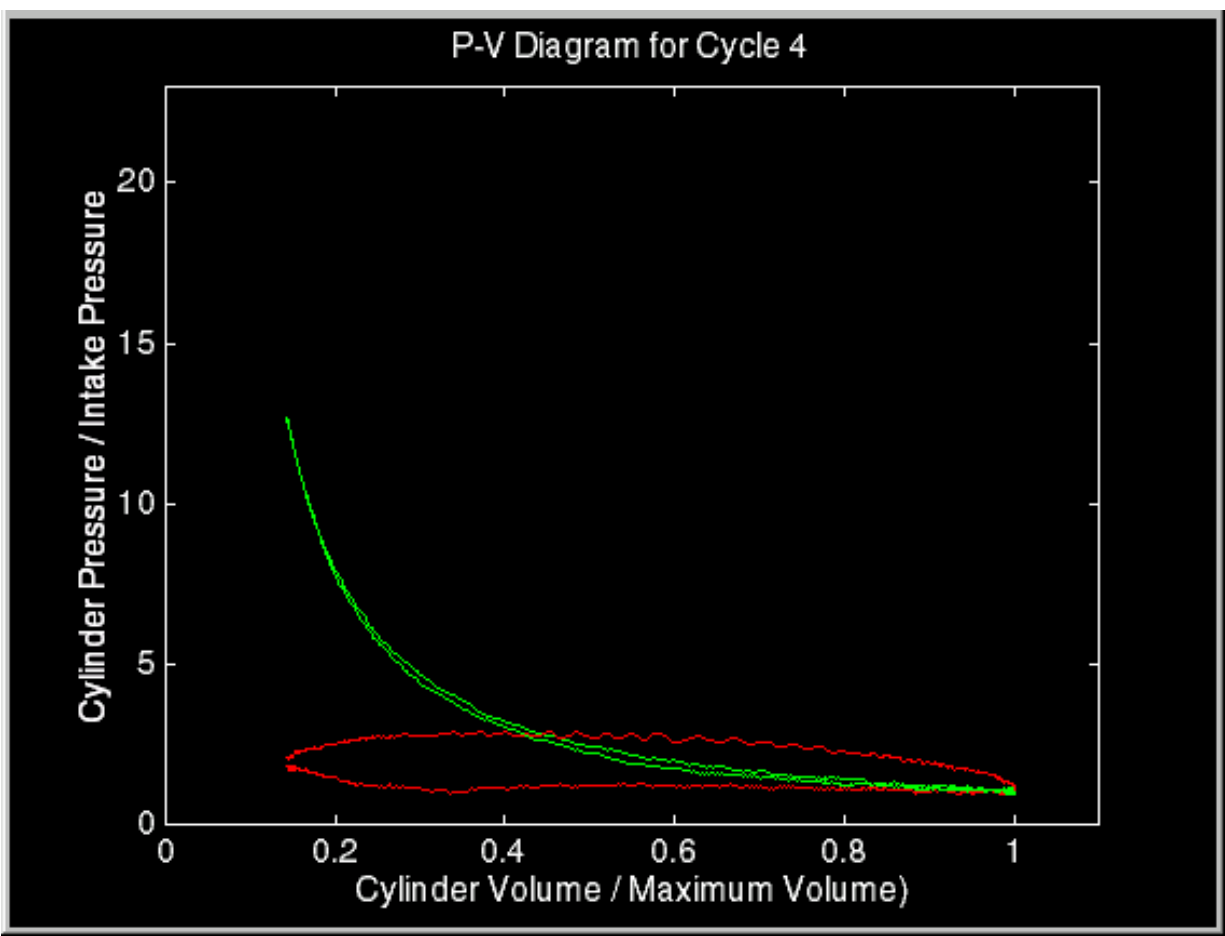

Figure E 4 - Pressure versus volume diagram for cycle four using the Champion model RC12YC sparkplug with a gap of 0.008 " 


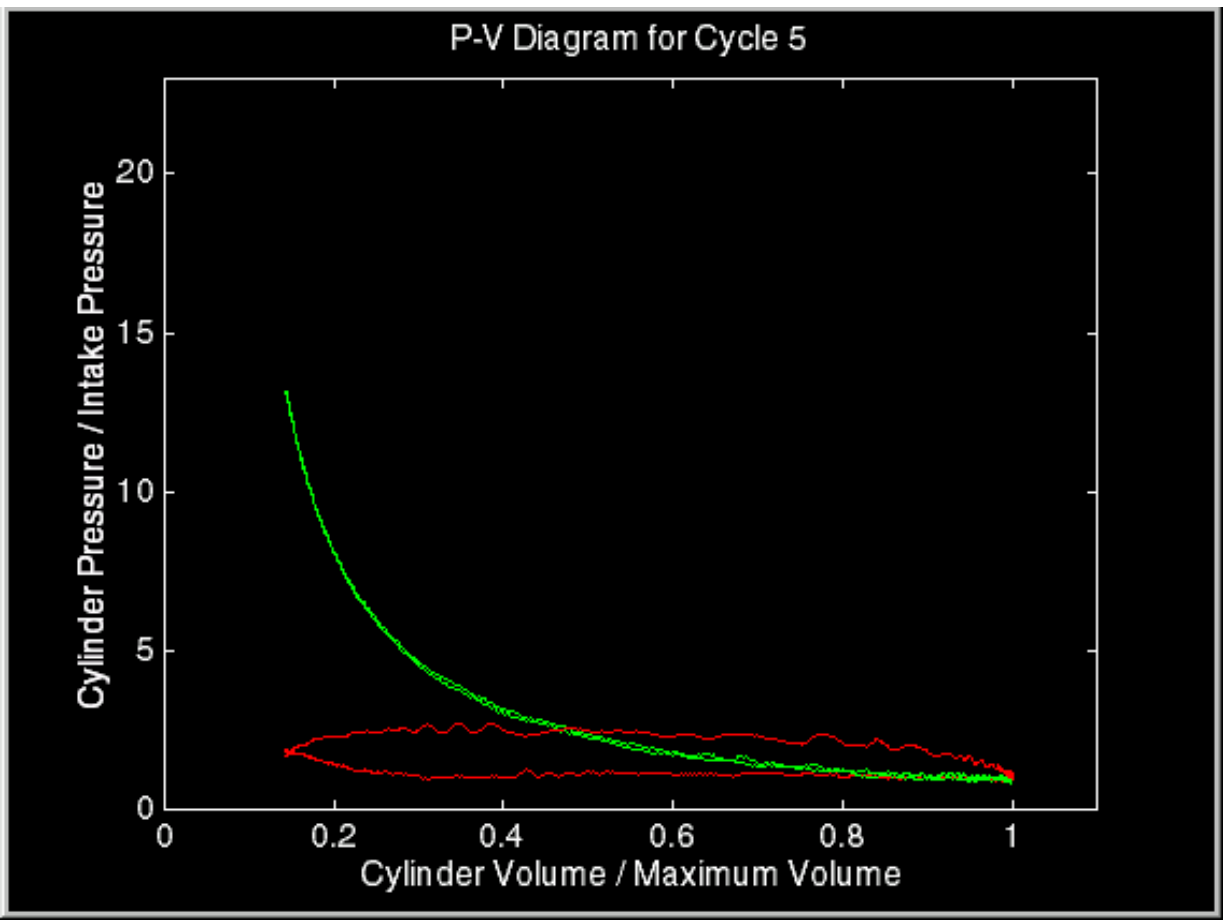

Figure E 5 - Pressure versus volume diagram for cycle five using the Champion model RC12YC sparkplug with a gap of 0.008 "' 


\section{Appendix F - Output of Engine.m for the Champion Model J19LM Sparkplug with a .03" Gap.}

What is the fuel consumption of the engine in grams per minute under the current operating conditions? 15.4

The average speed of the engine in RPM is:

$2.6627 e+003$

The average exhaust temperature of the engine in degrees Celsius is:

851.1185

The gross indicated power of the cylinder in $(\mathrm{kW})$ for each cycle is as follows.

Cycle One:

0.5258

Cycle Two:

0.6227

Cycle Three: 
0.5756

Cycle Four:

0.2127

Cycle Five:

0.4872

The average gross indicated power of the cylinder in $(\mathrm{kW})$ is:

0.4848

The gross indicated specific fuel consumption of the cylinder in $(\mathrm{g} / \mathrm{kW} * \mathrm{~h})$ for each cycle is as follows.

Cycle One:

878.7269

Cycle Two:

741.9529

Cycle Three:

802.5948

Cycle Four:

$2.1720 \mathrm{e}+003$

Cycle Five: 
The average gross indicated specific fuel consumption of the cylinder in $\left(\mathrm{g} / \mathrm{kW}^{*} \mathrm{~h}\right)$ is: $1.1087 \mathrm{e}+003$

The gross indicated mean effective pressure of the cylinder in $(\mathrm{kPa})$ for each cycle is as follows.

Cycle One:

98.7006

Cycle Two:

116.8954

Cycle Three:

108.0631

Cycle Four:

39.9314

Cycle Five:

91.4562

The average gross indicated mean effective pressure of the cylinder in $(\mathrm{kPa})$ is: 
91.0094

The percent fuel conversion efficiency of the cylinder for each cycle is as follows.

Cycle One:

9.3110

Cycle Two:

11.0274

Cycle Three:

10.1942

Cycle Four:

3.7670

Cycle Five:

8.6276

The average percent gross fuel conversion efficiency for the cylinder is:

8.5854 


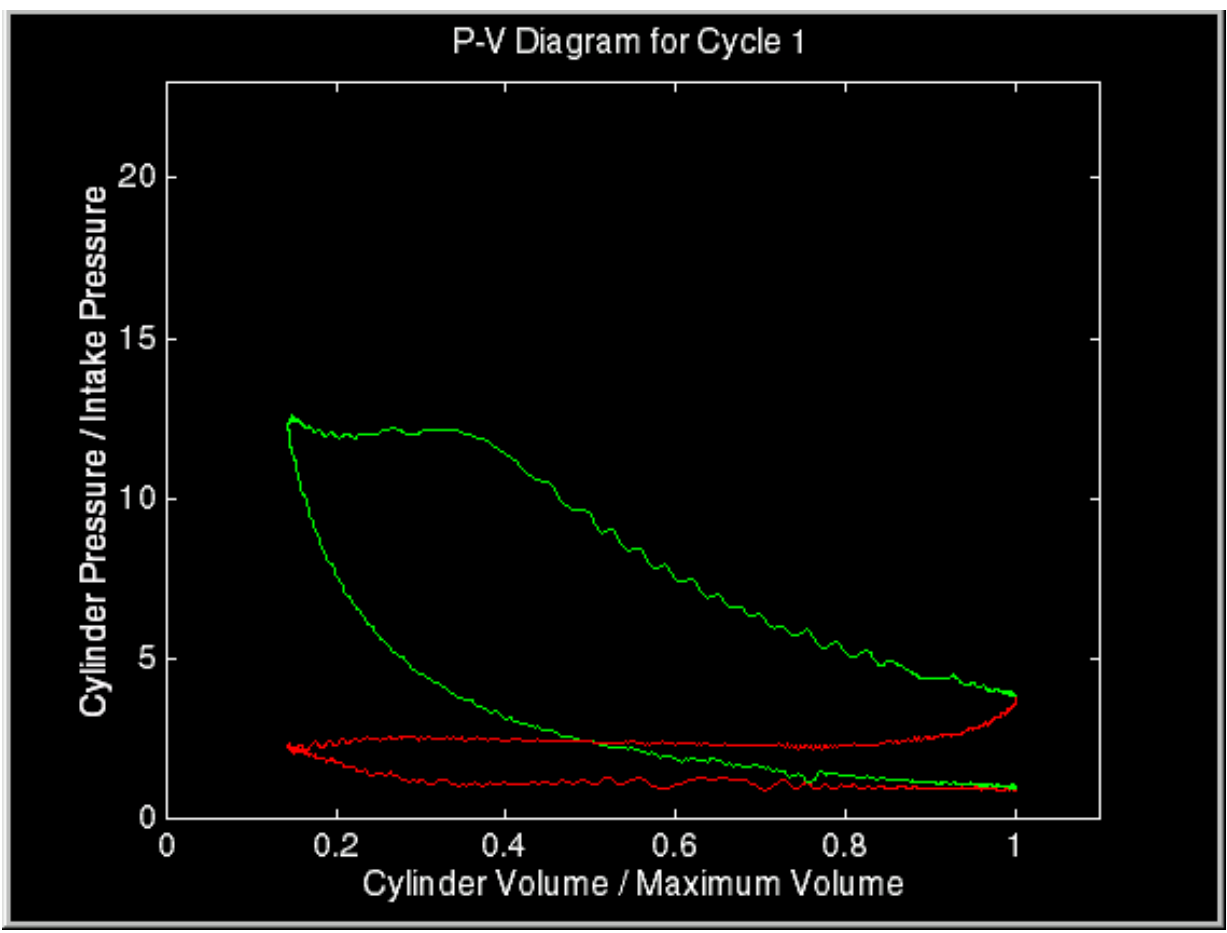

Figure F 1 - Pressure versus volume diagram for cycle one using the Champion model J19LM sparkplug with a 0.03" gap.

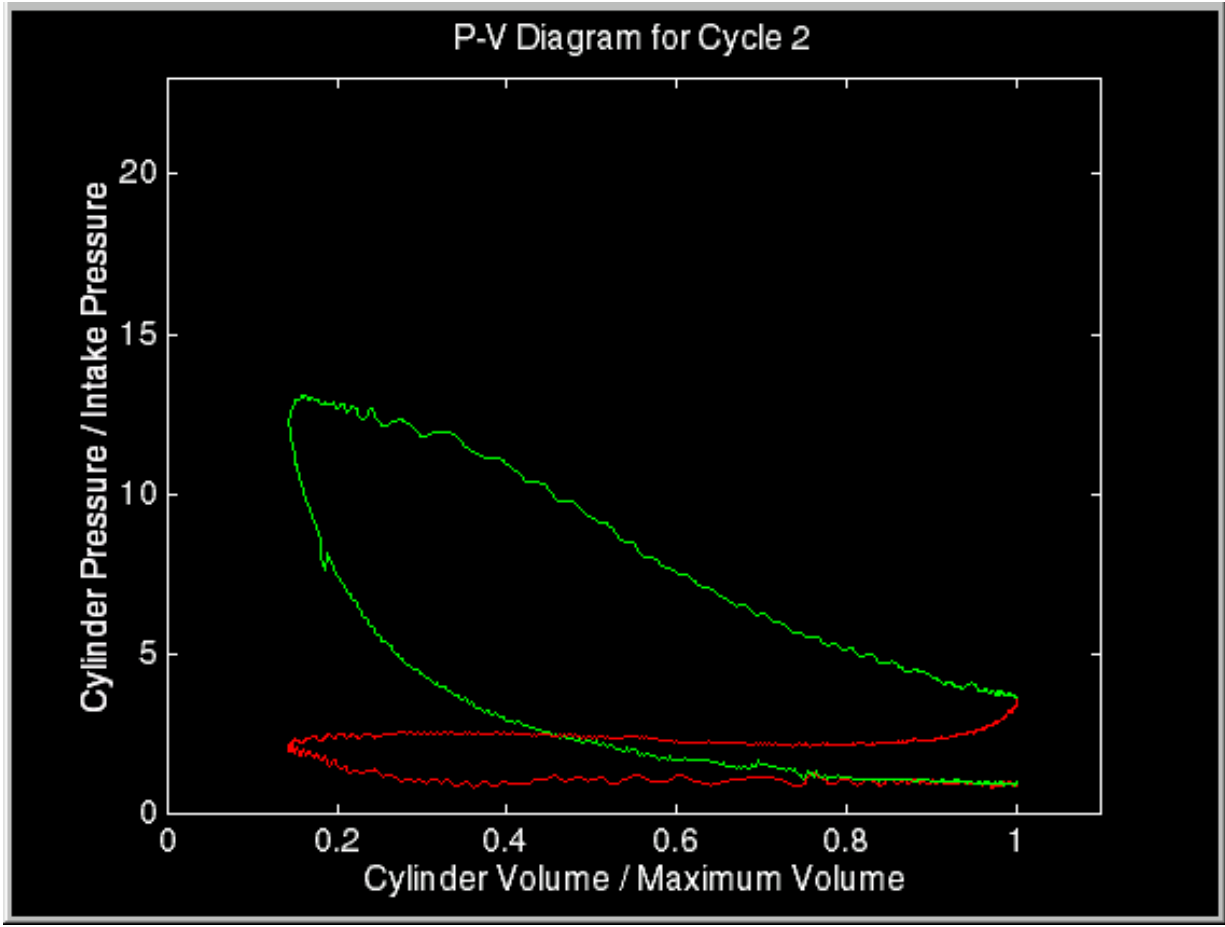

Figure F 2 - Pressure versus volume diagram for cycle two using the Champion model J19LM sparkplug with a 0.03" gap. 


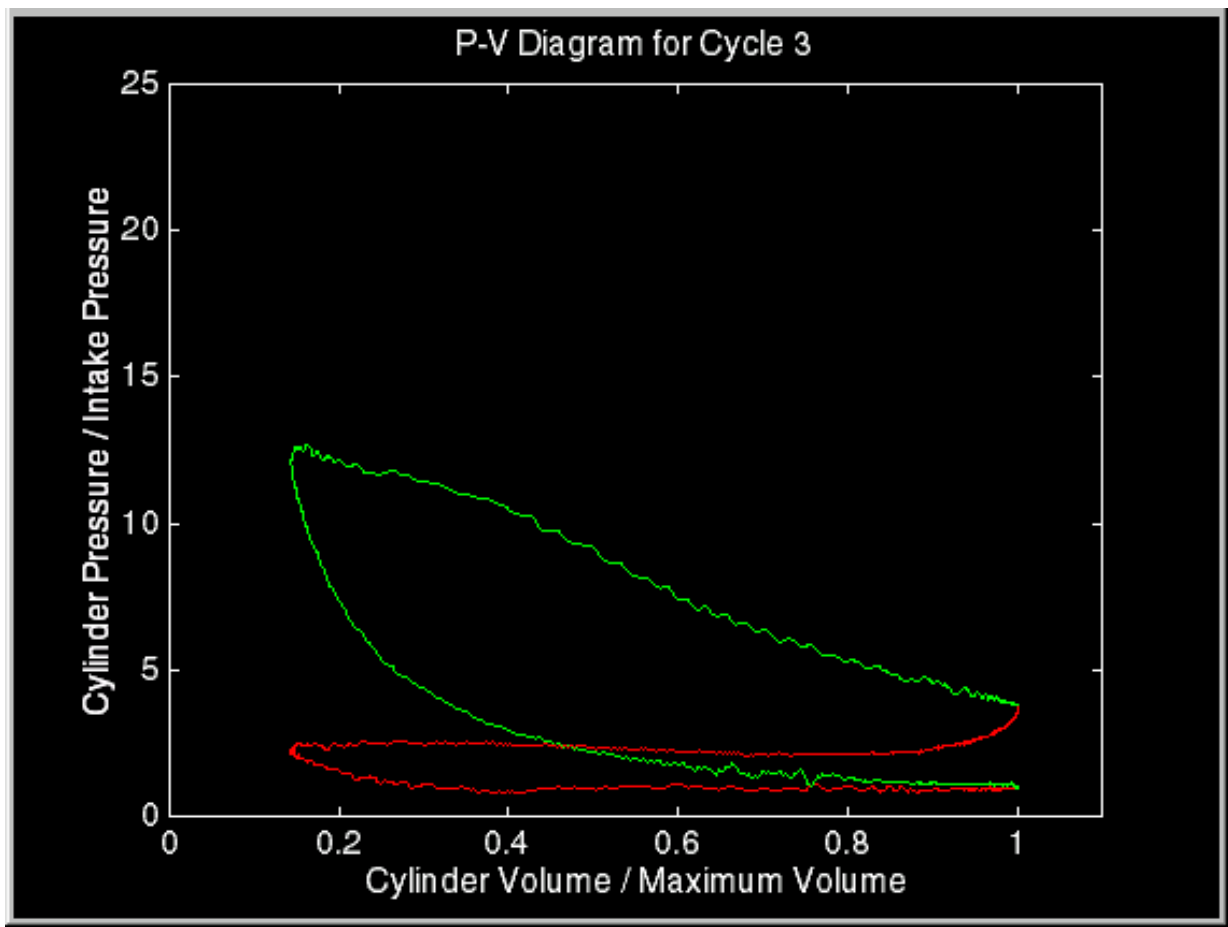

Figure F 3 - Pressure versus volume diagram for cycle three using the Champion model J19LM sparkplug with a 0.03" gap.

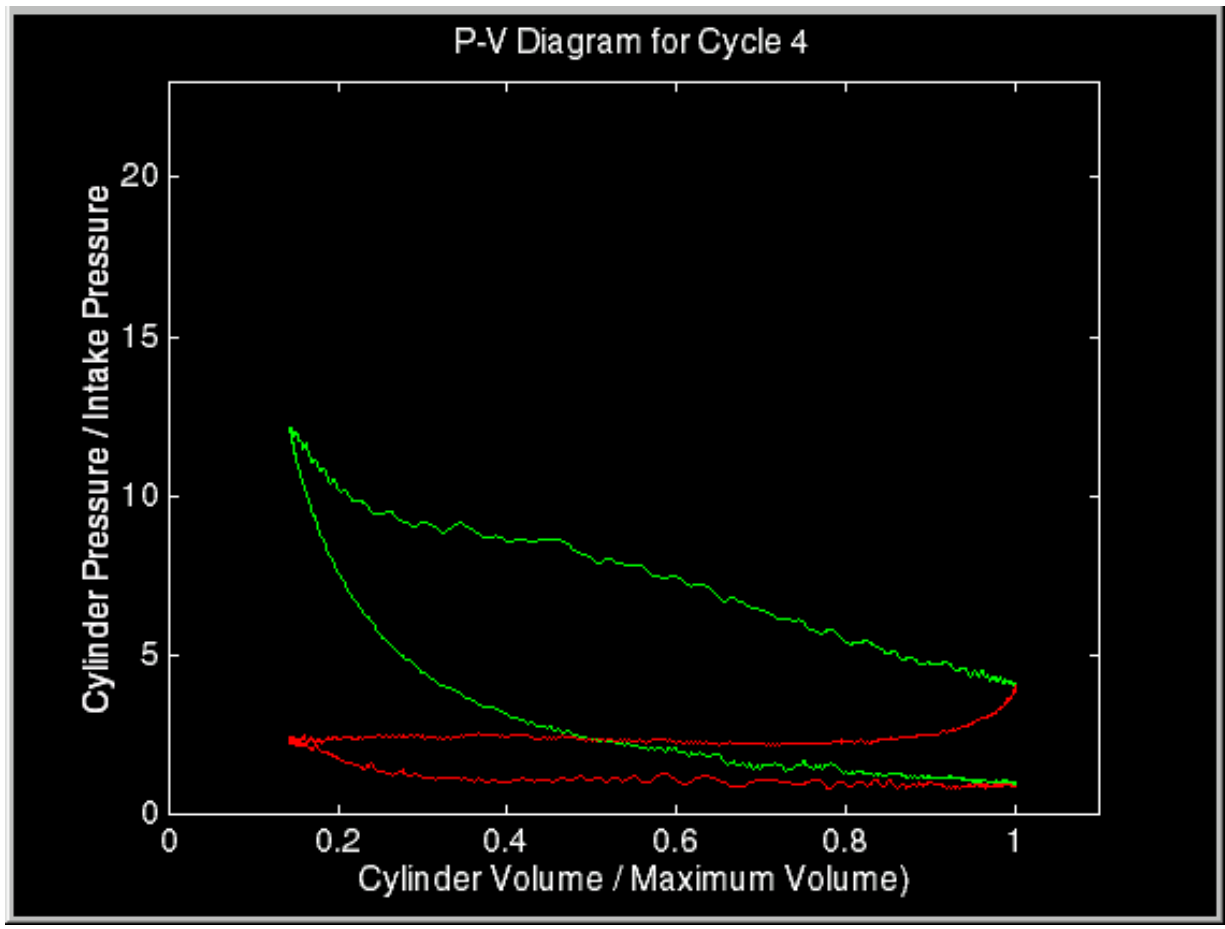

Figure F 4 - Pressure versus volume diagram for cycle four using the Champion model J19LM sparkplug with a 0.03 " gap. 


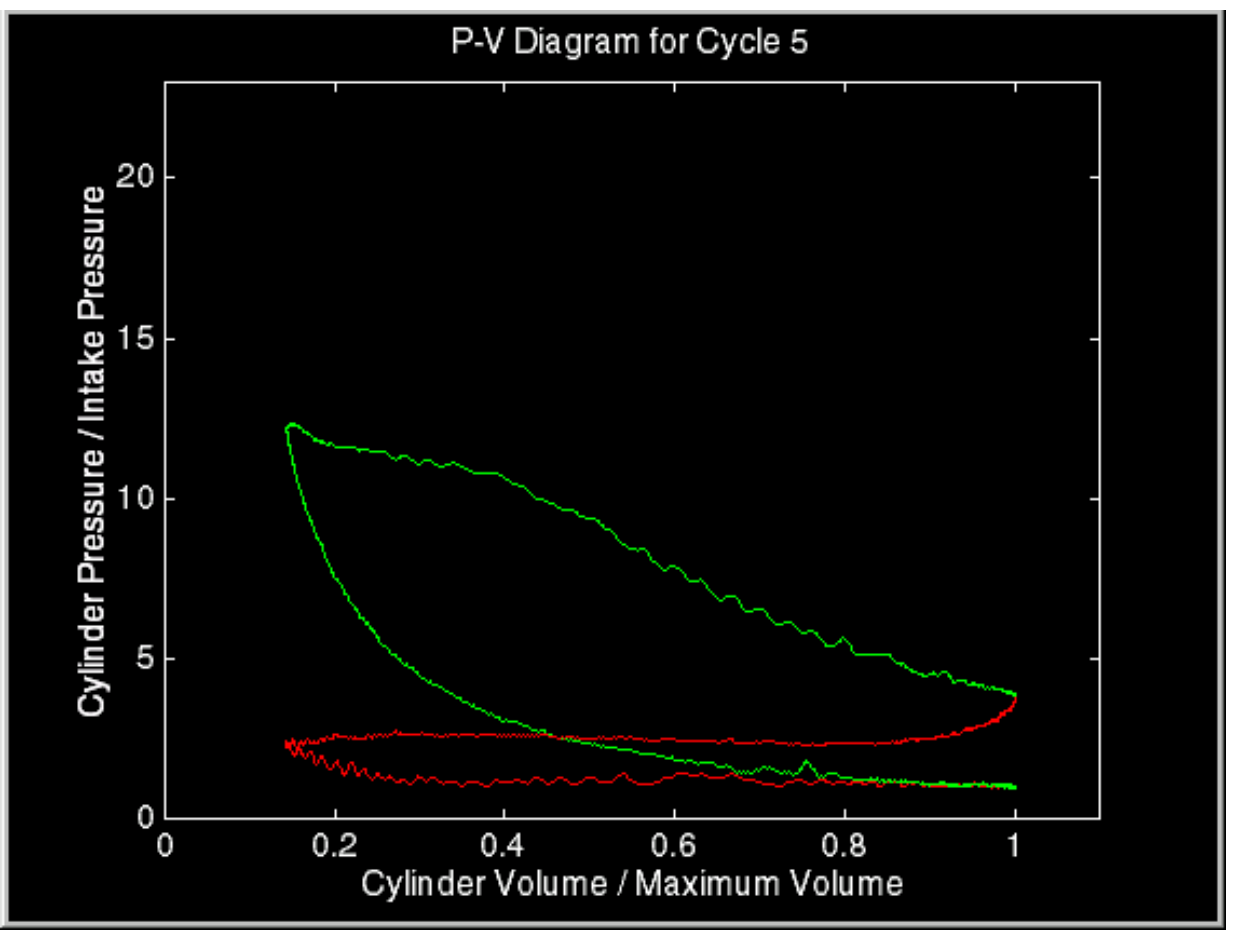

Figure F 5 - Pressure versus volume diagram for cycle five using the Champion model J19LM sparkplug with a 0.03" gap. 


\section{Approval of Examining Committee}

Nigel N. Clark, Ph.D.

James E. Smith, Ph.D.

Date

Gregory J. Thompson, Ph.D., Chairman 